\title{
DENSITOMETRIA DE TRANSPARËNCIAS INFRAVERMELHAS COLORIDAS (FALSA-COR) NO INVENTÁRIO DE FLORESTAS DE EUCALIPTOS NO ESTADO DE SÃO PAULO
}

\author{
MARI A HELOISA BORGES \\ Engenheiro Florestal
}

Orientador: PROF. DR. GERALDO VICTORINO DE FRANGA

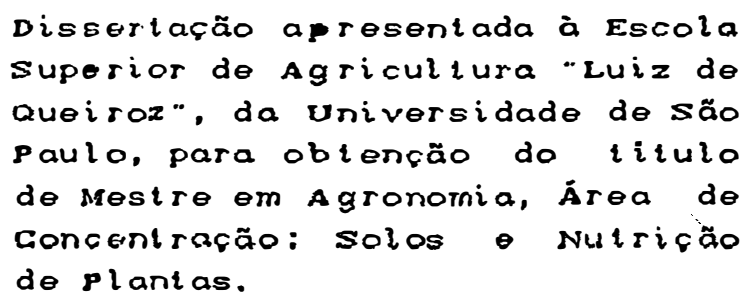

$P I R A C I C A B A$

Estado de São Paulo - Brasil

Janeiro - 1991 
Ficha catalográfica preparada pela Seção de Livros da Divisão de Biblioteca e Documentação - PCAP/USP

Borges, Maria Heloisa

B732d Densitometria de transparências infravermelhas colori das (Falsa-Cor) no inventário de florestas de eucaliptos no Estado de São Paulo. Piracicaba, 1991. $101 \mathrm{p}$.

Diss.(Mestre) - ESALQ

Bibliografia.

1. Eucalipto - Fotointer pretação 2. Floresta - Inventá rio 3. Fotografia aérea - Interpretação 4. Sensoriamento remoto em floresta I. Escola Superior de Agricultura Luiz de Queiroz, Piracicaba

CDD $\quad 634.9734$ 


\section{DENSITOMETRIA DE TRANSPARENCIAS INFRAVERMELHAS COLORIDAS (FALSA-COR) NO INVENTÁRIO DE FLORESTAS DE EUCALIPTOS NO ESTADO DE SĂO PAULO}

MARIA HELOISA BORGES

Aprovada em: 27.03.1982

Comissão Julgadora:

Prof. Dr. Hilton Thadeu Zarate do Couto ESALQ USP

Prof. D. Geraldo Victoriso de França ESALQ USP

Prof. Dr. Carlos Alberto Vettorazzi ESALQ USP

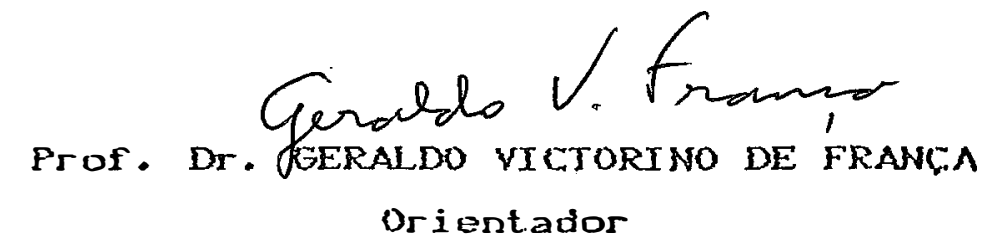


ii.

A memória de meus pais,

HOMENAGEM 


\section{AGRADECI MENTOS}

As Instituicỗes ESALQ USP e FCINUNES por tornarem viável a realização dește trabalho.

Ao Prof. Dr. Geraldo Victorino de Franca, pela orientacão e dedicacão.

A Champion Papel e Celulose S. A. nas pessoas dos Engenheiros Florestais Sérgio Diniz e Benedito Vastano Júnior, que gentilmente nos forneceram os dados, sem os quais o trabalio se tornaria inviável.

A Rosana Cristina Pereira Parente e à Estatística Vilma M. Tachibana pela orientacão e colaboracão na análise estatistica.

A Bibliotecária Chefe da FCTrUNESP, Elilia Ap. Sauro, pela disposição em conseguir o material bibliográfico.

Aos demais colegas da FCI MUNESP e a todos que. direta ou indiretamente, contribuiram para que este trabalho se tornasse realidade. 


\section{SUMARRIO}

Página

LISTA DE FIGURAS ..................

LISTA DE TABELAS ..................... ix

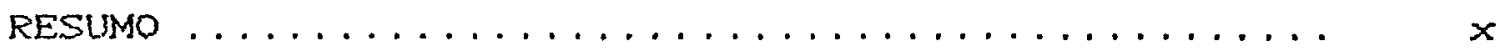

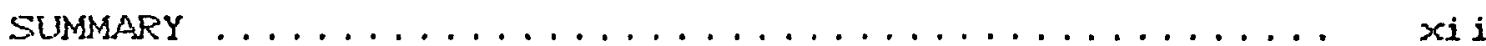

1. INTRODUCAO ........................ 1

2. REVISÄO DE LITERATURA ................ 3

2. 1. Sensoriamento Remoto ............... 3

2. 2. Densitometria .................... 13

2. 3. Densidade optica ................. 21

2. 4. Refilectância .................. 26

3. MATERI AL E MÉTODOS .................... 40

3.1. Caracterizacão da Área de Estudo .......... 40

3.2. Espécies Estudadas ................ 43

3. 3. Cálculo do Vol ume de Madeira ............ 44

3. 4. Fotografias Aéreas ................ 46

3. 5. Densitometro ..................... 47

3. 6. Análise Densitométrica ............... 49

3.7. Arálise Estatistica ................ 50

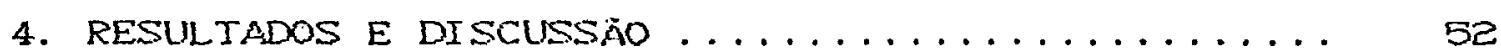

4.1. Eucalyptus Erandis ................ \$4

4. 2. Eucalyptus soligna ............... ss

4.3. Eucalyptus urophylla .............. 57

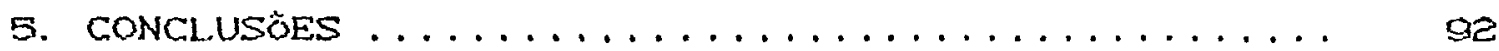

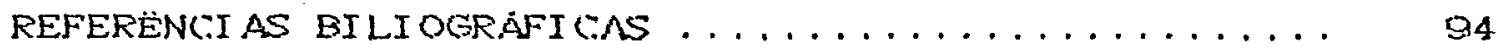




\section{LISTA DE FIGURAS}

Figura

Págína

1 Representação esquemática das camadas de um filme colorido. Fonte: Novo (1989). ........

Curvas de transmitância versus comprimento de onda para os filtros 82,93 a 94 . Fonte:

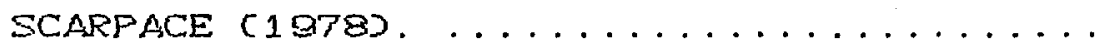

3 Mapa de localizacão da área de estudo. .....

4 Levantamento pedológico semi detal hado do Estado de São Paulo - Quadricula de Araras Horto Santa Terezisha - Champion Papel e Ceivlose S. A. FONTE: OLIVEIRA et alii (1981).

5 Distribuição dos tal hões de Eucalyptus erandis, Eucalyptus saligna, Eucalyptus urophylla. FONTE: CHAMPION PAPEL E CELULOSE S. A. .

6 Densitômetro de Transmissão TD 504. FONTE: MACEETH COLOR \& PHOTOMETRY DIVISION (1973).

7 Caracteristicas dos filtros TD 504. FONTE: MACBETH COLOR \& PHOTOMETRY DIVISION (1973).

8 Representacão esquemática de um densitómetro de transmissão, tipo puntual. FONTE: GARCIA

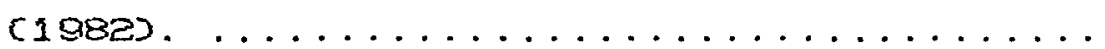

9 Desempenho do volumerna leituras para filtro azul em relação a densidade óptica para $\boldsymbol{E u}^{-}$

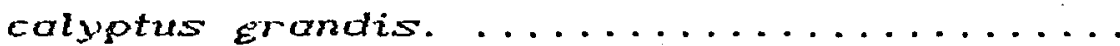

10 Desempentio do volune/n leituras para filtro verde em relação a densidade óptica para Eucalyptus srandis. ................ 
vi .

Figura

Página

11 Desempenho do volume/ne leituras para filtro vermelho em relacão a densidade óptica para Eucalyptus grandis. ................ 68

12 Desempenho do volume/ne leituras para filtro visual em relacão a densidade óptica para Eucalytus grandis. ................

13 Desempenho do inverso do volume $/ n^{2}$ leituras para filtro azul em relarão ao inverso da densidade óptica para Eucalyptus Erandis. . .

14 Desempenho do inverso do volumerre leituras para filtro verde em relacão ao isverso da densidade óptica para Eucalyptus grandis. .

15 Desempenho do inverso do volumérne leituras para filtro vermelho, conjunto 1, em relacão ao inverso da densidade óptica para Eucalyp-

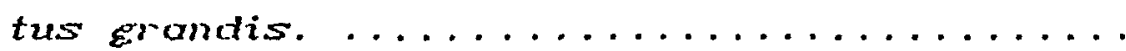

16 Desempenho do inverso do voluméñ leituras para filtro vermelbo, conjunto 2 , em relacăo ao inverso da densidade óptica para Eucalyp-

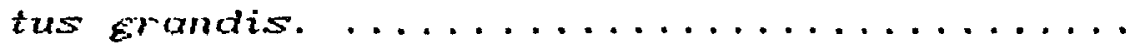

17 Desempentro do inverso do volumerne leituras para filtro visual em relação ao inverso da densidade optica para Eucalyptus erandis. .

18 Desempentio do volume $n^{\text {s }}$ leituras para filtro azul em relacão a densidade óptica para Eucalyptus satigna. ................

19 Desempmho do volume/ne leituras para filtro verde wim relacão a densidade óptica para Eucalyptus saligna. ................. 
vii.

Figura

Página

20 Desempenho do volume/ne leituras para filtro vermelho em relação a densidade óptica para Eucalyptus saligna. ...............

21 Desempenho do volume/n leituras para filtro visual em relacão a densidade óptica para Eucalyptus saliena. ...............

e2 Desempenho do inverso do volume/ns 1 eituras para filtro azul em relacão ao inverso da densidade óptica para Eucalyptus saligna. . .

23 Desempenho do inverso do volume/n? leituras para filtro verde en relacão ao inverso da densidade bptica para Eucalyptus saligna. ..

24 Desempenho do inverso do volume/ne leituras para filtro vermelho, conjunto 1, em relacão ao inverso da densidade óptica para Eucalyptus satigna. ....................

25 Desempenho do inverso do volumejne leituras para filtro vermelho, conjunto 2 , em relacão ao inverso da densidade óptica para Eucalyp-

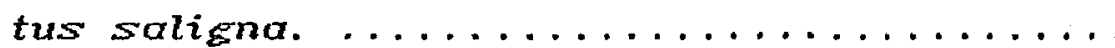

26 Desempenho do inverso do volumerre leituras para filtro visual em relacão ao inverso da densidade óptica para Eucaljptus saliena. ..

Desempenho do volumerno leituras para filtro azul en relacão a densidado óptica para Eucalyptus urophylla. ...............

28 Desempenho do volumerne leituras para filtro verde em relação a densidade óptica para Eucalyptus urophylla. 
viii.

Figura

Página

29 Desempento do vol une/ne leituras para filtro vermeltho em relacão a densidade óptica para Eucalyptus urophylla. . ...................

30 Desempenho do vol umerne leituras para filtro visual em relacão a densidade óptica para Eucalyptus urophylla. ..............

31 Desempento do inverso do vol ume/ne leituras para filtro azul em relacão ao inverso da densidade óptica para Eucalyptus urophylla..

32 Desempenio do inverso do volume/na leituras para filtro verde em relacão ao inverso da densidade óptica para Eucalyptus urophylla..

Desempenho do inverso do volumerne leituras para filtro vermelto em relacão ao inverso da densidade óptica para Eucalyptus uro-

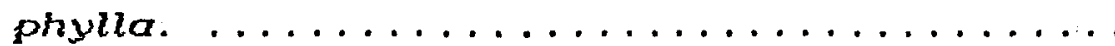

34 Desempenho do inverso do volumerne leituras para filtro visual em relacão ao inverso da densidade óptica para Eucalyptus urophylla.. 


\section{LISTA DE TABELAS}

Tabela

Pági na

1 Características de alguns filmes Kodak para fotografias aéreas. ...............

2 Densitometria dos talhões para Eucalyptus Erandis. ..................... 80

3 Densitometria dos talhóes para Eucalyptus saligna. ......................

4 Densitometria dos talhões para Eucalyotus urophylla. .....................

5 Inverso da densitometria para talhóes de Eucalyptus erandis. ................ Bz

6 Inverso da densitometria para filtro vermeI ho agrupado em 2 conjuntos, para Eucalyptus Erandis. ......................

7 Inverso da densidado para talhóos de Eucalyptus salikna. ................

8 Inverso da densitometria para filtro vermeIho, agrupado em 2 conjuntos, para Eucalyptus soligno. ....................

9 Inverso da densitometria para talhões de Eu-

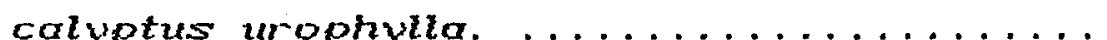




\section{DENSITOMETRIA DE TRANSPARENCIAS INFRAVERMELHAS COLORIDAS (FALSA-COR) NO INVENTÁRIO DE FLORESTAS DE EUCALIPTOS NO ESTADO DE SÃO PAULO}

Autora: MARIA HELOISA BORGES Orientador: PROF, DR. GERALDO VICTORINO DE FRANCA

\section{RESUMO}

o objetivo deste trabalho foi avaliar a utilização de fotografias abreas, na forma do transparoncias infravermelhas coloridas (falsa-cor), no manejo de povoamentos florestais, principalmente no gue se refere à avaliacão do volume de corte, em povoamentos novos e de um ou mais cortes, real cando a utilizacão da densitometria.

Para tanto trabalhou-se con 3 espécies de eucaliptos: Eucalyptus grandis, E. saligna, E. urophylla.

A área de estudo localiza-se no municipio de Mogi-Guacu - SP, mais precisamente no Horto Santa Terezinha, de propriedade da Champion Papel e Celulose S. A. .

o método utilizado foi a densitometria de transparências infravermelhas coloridas, através de densitômetro de transmissão Macbeth TD 504, equipado com filtros Wrattens ge (vermelho), 93 (verde), 94 (azul) o 106 (visual); e a abertura utilizada foi a de $1 \mathrm{~mm}$. 
xi.

De posse dos valores de volume cilindrico em $m^{3}$ e da densidade óptica fez-se análise estatistica, que constituiu na obtenção de equações de regressão para cada filtro e espécie.

Os resultados foram considerados satisfatórios, conseguindo-se valores de $\mathrm{K}^{2}$ superiores a 0,70 .

Com base nos resultados foi possivel chegar às seguintes conclusões: as a análise espectral realizada através da densitometria, utilizando transparencias infravermeIhas coloridas evidenciou a sua utilidade para a estimativa volumétrica em reflorestamento com eucaliptos pelo método semi-automático; b) o grau de detalhamento das fotografias aéreas infravermelhas coloridas as tornam adequadas a este tipo de trabalho, ou seja, a utilizacão da densitometria constitui uma alternativa válida para a realizacão do inventário florestal; e c) tanto para Eucalyptus grandis quanto para Eucalyptus saliena, as equaróes obtidas para os 4 filtros poderão ser de grande utilidade, pois as mesmas foram obtidas através de densidades ópticas de tal hões com diferentes graus de homogeneidade. 
xii.

\section{COLOUR INFRARED TRANSPARENCIES DENSITOMETRY \\ (FALSE-COLOUR) IN THE INVENTORY OF EUCALYPTUS \\ FORESTS IN SAOO PAULO STATE}

Author: MARIA HELOISA BORGES

Adviser: PROF. DR. GERALDO VICTORINO DE FRANCA

SUMARAY

The objective of this work was to evaluate the utilization of aerial photographs in the form of colour infrared transparencies (false-colour) in the handing of homogeneous forest populating, principally regarding the evaluation of cutting volume, in the populations with one or more cuttings, emphasizing the utilization of densitometry.

For this purpose three Eucalyptus specios were employed: Eucalyptus Erandis, E. saligna, E. urophylla. This study area of rosearch is located in the Municipallity of Mogi-Guacú - SP, more precisely in the Horto Sasta Teresirha, which belongs to Champion Papel e Celulose S. A.

The employed method was the colour intrared transparencies densitometry by means of the transmitting densitometer Mucheth TD Sod, equiped with iliters Wrattens 92 (red), 93 (gueen), as (blve) and 100 (visual), aut the openig employed was 1 mili meter. 
xiil.

With the utilization of this figures from cilindric volume in cubic meters and optic density the statistic analysis were performed, which the achievement of the regression equation for each filter and specie.

The results were considered satisfactory as $R^{2}$ values superior to 0.70 were obtained.

Based on the results it was possible to achieve the following conclusions: as the spectral analysis carried out through the densitometry employing colour infrared transparencies made clear its usefullness to the volumetric estimative for reforestments with eucalyptus by the semi-automatic method; b) the degree of detailment of the colour infrared aerial photagraphs makes them adequato for this kind of work, that is, the utilization of the densitometry constitutes an effective alternative for tho performing of a forest inventory, and Cl as much for the $\boldsymbol{E}$. grandis as for the E. saliena the obtained equations for the 4 filters may be of large utility, because they were obtained through out the optical densities of plots with diferent degreas of homogenity. 


\section{INTRODUCĂO}

As áreas destinadas ao reflorestamento tôm crescido continua e vigorosamente nos últimos anos. Até o final da década de 70 este crescimento se deveu, principalmente, aos incentivos fiscais oferecidos pelo governo e, de lá para cá, exclusivamente em funcão das indústrias de transformacão 1 igadas ao reflorestamento, que têm funcionado como polo de atração, fomentando o plantio de essências de interesse, dentro de um raio considerado econômico.

Durante os últimos anos, em funcão da erise de energia, a madeira voltou ao centro das atencónes como alternativa econômica, não só para ser queimada como lenha ou carvão, mas também na producão de metanol.

Por estas razões o reflorestamento entrou numa nova e ativa fase, qual seja, a producão de madeira como fonte alternativa de energia.

Esta atividade exige não só a disponibilidade de terras relativamente baratas, normal mente de baixa fertilidade, como também, após o plantio, o manejo adequado do povoamento florestal até o corte, $B$ a 7 anos depois.

Pela extensão das áreas já reflorestadas o prevendo-se uma expansão do plantio, deverão ser adotadas 
técnicas de manejo e inventário compativeis com as extensas áreas a serem analisadas.

Uma alternativa de grande potencial refere-se às fotografias aéreas em escalas adequadas, já que representam um registro exato da superficie do terreno, no momento da exposi ఢão.

A fotografia aérea apresenta-se como o único instrumento capaz de representar as formas e o arranjo espacial das plantas, individual mente ou em associacôes.

Conforme relata SPURR (1950), a fotointerpretação da vegetacão comerou quando se tornou necessário o levantamento de áreas de dificil acesso, onde o método de reconhecimento baseia-se em parte no estudo da tonalidade e textura fotográficas, padrão de sombra, forma e dimensăo.

A tecnologia do sensoriamento remoto, seja por meio de fotografias aéreas ou imagens de satélite, pode contribuir significativamente para melhorar a gualidade das informacõos, principalmente guanto ao dimensionamento das áreas efetivamente ocupadas pelos reflorestamentos e a determi nacão da sua distribuicão geográfica.

o objetivo deste trabalho foi avaliar a utilização de técnicas densitométricas om fotografias aéreas, na forma de transparências infravermolhas coloridas, no inventário e marejo de povoamentos florestais homogêneos. 
3.

\section{REVISĂO DE LITERATURA}

\subsection{Sensoriamento Remoto}

Segundo Novo (1989), "sensoriamento remoto" в́ a utilização de sistemas sensores para a aquisicão de informaç̃os sobre objet.os ou fenômenos sem que haja contato direto entre eles. "Sensores remotos" são os equi pamentos capazes de captar a energia proveniente dos objetos, gravá-la diretamente ou transformá-la em sinal passivel de ser registrado e apresentá-10 en forma adequada à extracão de informacões. Portanto, a transferéncia de dados do objeto para o sensor é feito por meio do energia.

Alguns autores ineluem como parte integrante do sensoriamento remoto os sensores que operam com energia acústica (sonar), gravitacional (gravímet.ro) ou eletromagnética Cradiometros. A maioria dos autores, porf́n, restringe o termo sensoriamento remoto à utilizacão de equipamentos que operam mediante a deteccão da energia eletromagnética.

Do acordo com a fonte de energia, COLWELL (1966) classifica os sensores remotos em passivos e ativos. Os "sensores passi vos" deperudem de uma fonte de energia externa, como a radiação solar, para que possam operar, como 
- caso dos sistemas fotográficos e do sistema Landsat. Os "sensores ativos" são aqueles que possuem sua própria fonte de energia, como é o caso do sistema radar, gue emite microondas o capta o retorno, após serem refletidas pelos alvos. GARROLL (1973) divide ds sensores remotos em fotográficos $\theta$ rão-fotográficos. Os sensores fotográficos São também denominados "diretos", pris gravam a energia refletida pelos alvos terrestres diretamente em emulsóes ou filmes, através de lentes. Os sensores não-fotográficos são denominados "indiretos", forque convertem a energia detectada pelos sensores em impulsos elétricos, os quais são transformados, via tubo de raios catódicos em luz visivel, que pode ser gravada em filme.

As câmaras fotográficas podem ainda ser classificadas como sensores imageadores, pois os niveis relativos de radiacão de várias superficies i mageadas são gravadas em papel fotográfico, na região espectral selecionada. Estes sistemas são apropriados para isterpretacão visual e, frequentemente, proporcionam boa resolução.

Costa (1979) (citado por DONZELI, 1984), coloca as fotografias aéreas como produto de sensoriamento remoto mais comum e útil, sendo que, quando comparadas a outros sensores, t.êm como importantes atributos a seu favor a resolucão espacial e a fácil identificarão de aspectos da paisagem.

ANSON (1968) comparou fotografias aéreas pancromáticas, coloridas normais $\Leftrightarrow$ infravermelhas coloridas 
para fins de identificacão de tipos de uso da terra, destacando que as fotografias aéreas infravermel has apresentam as seguintes vantagens: as possibilitam um entendimento mais claro e rápido dos padrốes de uso da terra; bl permitem maior diferenciacão entre os diferentes tipos de uso da terra; C) a riqueza de detalhes que registram é excelente para o delineamento dos limites entre os diferentes tipos de vegetacão natural $\theta$ de culturas.

GARCIA (1975) fez um estudo comparativo entre fotografias aéreas paneromáticas, coloridas e infravermel has coloridas, conoluindo que: a) no estudo da vegetacão ratural, os três tipos de fotografias revelaram a mesma eficiencia; b) no estudo das culturas, as fotografias coloridas e as infravermelhas coloridas forneceram resultados semelhantes, porém melhores que os das fotografias pancromáticas; Cs quasto ao total de itens identificados corretamente, a fotografia infravermel ha colorida foi superior à fotografia colorida e esta, superior à fotografia pancromática.

Para SIEPHENS (1976) a vantagem da fotografia infravermelha colorida está so fato de ser mais precisa e rápida na identificacão de culturas gracas à maior gama do matizes, valores e cromas que apresenta quando comparada com a fotografia colorida normal. Uma caracteristica importante da fotografia infravermelha é a deteção da presenca do vegetaøão morta que aparece em cores verde-azuladas ou azul, em contraste com os tons de vermelho ou magenta característicos de vegetação sadia. 
B.

KOFFLER (1982), estudando a identificacão da cultura da cana-de-acúcar através de fotografias aéreas infravermelhas coloridas e dados MSSRandsat, relatou que: a) a cana-de-arúcar possui caracteristicas espectrais próprias, que permitem a sua identificacão diferenciada de outros tipos de uso da terra, tanto em fotografias aéreas infravermeIhas foloridas, como nos dois tipos de dados Landsat, transparências e fitas CC.T; b) os três produtos analisados apresentam caracteristicas que os tornam, rada um deles, mais vantajoso sob determinados aspectos - (1) o maior grau de detalhamento das fotografias aereas infravermelhas coloridas as fazem mais adequadas para a interpretarão visual; (2) a simplicidade de manuseio das transparências Landsat possibilita a sua análise quantitativa por meio de densitometria.

MARCHETII \& GARCIA (1978) relatam pesquisas feitas nos Estados Unidos, segundo os quais o olho humano capaz de distinguir 200 tons de cinza em filmes preto-e-branco e mais de 2.000 combinacö́es de cores em filmes coloridos.

Segundo HELLER (1978a), os desenvol vimentos nas técnicas de sensoriamento remoto desde 1971 incluem: novos filmes infravermelhos coloridos e coloridos normais para fotografias obtidas em grandes altitudes e em nivel orbital; un novo filme infravermelho multiespectral com respostas mais uniformes em todos os comprimentos de onda; "scanners" multiespectrais de uma só abertura para faixas de comprimento de onda discretos variando do ultravioleta ao 
infravermelho; "scanners" para mapear incêndias; radar de visada lateral: e asálise óptica e técricas de processamento assistido por computador. Enfase particular é dada às aplicąónes em recursos naturais e florestais.

ZEL (1985) relata que o projeto de mapeament.o florestal na Africa do Sul comeqou em outubro de 1981 , com o objetivo de preparar um mapa florestal com a ajuda de dados Landsat, apresentando 4 classes distintas: al florestas de essências nativas; b) plantacões comerciais de Pinus; 0 plantações de eucaliptos; e d) plantações de Acácia. o Landsat também tem sido usado num projeto para detectar e classificar espécies nativas invasoras nas plantacóes de Pinus na Nyalazi State Forest em Zululand e para cartografar a vegetação natural no Zimbabwe, Botswana, Malawi e áfrica do Sul. É usado também para avaliar os danos causados à vegetacão por incêndior na Árica do Sul.

Para HELLER (1978b), a avaliacão dos danos na vegetacão por sensoriamento remoto atingiu um nivel razoavelmente sofisticado. Em seu artigo, relata as vantagens, os riscos, as aplicaróos práticas comuns e as possibilidades de uso futuro do sensoriamento remoto para este propósito. As vantagens incluem: C1) uso mais amplo do espectro eletromagnético; $(2)$ a economia de tempo, de dinheiro e de trabaIho humano; (3) a habilidade para cobrir grandes áreas; (4) - uso de levantamentos sucessivos de sensoriamento remoto para acompanhar tendências de danificação. Alguns riscos foram incluidos: (1) venda excessiva de técnicas de senso- 
8.

riamento remoto sem dados quantitativos mostrando estimativas em confianca; (2) uso de sistemas muito caros de sensoriamento remoto num fenômeno trassitório; (3) a inabilidade de alguns usuários do Landsat en reconhecer que valores de reflectância incluem atenuacão atmosférica e sinais ampliados; (4) o projeto incompleto de faixas de comprimento de onda Landsat para avaliarão dos danos da vegetarão Cprecisa-se de uma faixa de ondas amarela-alaranjada, 0,58 a 0,62 $\mathrm{m}$; (5) necessidade de melhores técnicas estatisticas para revisar a exatidão da classificacăo; e (B) uso de filmes coloridos ou infravermelhos coloridos para obter averiguacão pré-visual dos danos em coníferas.

Ainda segundo HELLER (1978b), as aplicacões práticas comuss de sensoriamento remoto para avaliação de danos na vegetacão incluem: (1) técnicas de observacão visual (esbopo de mapeamento e registro de faixa); (2) fotografias coloridas e infravermel has coloridas cem escalas grandes e pequenas) quando apropriadamente ajustadas com indicios de danos e condicóos atmosféricas; (3) amostras de multi-fase; e (4) sistemas de graduacão de risco usando fotografias aéreas para definir fatores tais como: aspecto, declive, elevacão que contribuem para a suscetibilidade da vegetacão aos agentes danificadores. Futuras possibilidades do sensoriamento remoto prenunciadas são: (1) aumento da afericão de fotografias coloridas e infravermelhas coloridas e maior uso destas últimas em pequena escala; (2) utilizacão de balóes, radares mais baratos e altimetros a laser junta- 
mente com as melhores sistemas de posicionamento eletrónico para vôos repetitivos; (3) maior rapidez na aquisicão do dados Landsat que serão geomet.ricamente corrigidos e realcados; (4) aprimoramento de imagens Landsat classificadas automaticamente com exatidâo; (5) melhor resolução disponível no Landsat 4 e 5 (Thematic Mapper) com faixas de comprimentos de onda mais estreitas, melhorando os procedimentos classificatórios e exatidóes; $\theta$ (B) melhorias em outros sensores como radar de visada latoral, CCD Cdotectores acoplados com cargas e imageadores de microondas.

HOLBEN et alii (1980) informaram que radiâncias espectrais vermelhas e infravermelhas tem sido correlacionadas com o indice de área foliar total de soja, indice de área foliar verde, indice da área foliar de rlorofila, biomassa de folha verde, biomassa de folha clorótica e biomassa total. As correlacões mais significantes foram encontradas entre os dados espectrais e indice de área foliar verde efou biomassa de folha verde. Estas descobertas demonstram que dados de sensoriamento remoto com base no solo podem fornecer informacão básica para o crescimento de cobertura, desenvol vimento e estado da soja pela determinacão não-destrutiva de ásea foliar verde ou biomassa de folba verde.

ARVANITES \& NEWBURNE (1984) apresentam os resultados de um estudo prático destinado a determinar a possibilidade de uso do sensoriamento remoto fotográfico, para descrever Melaleuca quinquenervia no sul da flórida. 
Três tipos de filmes e várias escalas de fotos foram avaliadas em duas áreas testes de campo. Os resultados preliminares indicam que árvores individuais e grupos de árvores Melaleuca podem ser identificados nas transparências infravermelhas coloridas com suficientes detal hes para mapeamento subsequente.

THOMPSON \& WEHMANEN (1979) descreVEM uma técnica utilizando dados digitais Landsat transformados para deteccão do seca agrícola, que foi definida empiricamente durante a seca de 1976 em Dakota do Sul. Durante 1977, o procedimento foi expandido para a Grande flanicie para avaliacão de uma técrica para deterrão e monitoramento de estresse de água na vegetacão sobre extensas áreas. A técnica, "Green Index Number", usa dados digitais Landsat em estrutura (segmento) de amostragem de 5 a 5 milhas náuticas, para indicar quando a vegetacão, dentro de um segmento, resistente à seca. Em estágios de crescimento conhecidos para trigo, segmentos foram classificados como áreas secas ou não-secas. A informação baseada em sensoriamento remoto foi comparada com um indice semanal de obtido no campo "Crop Moisture Index" - Indice de Umidade da Cultura fornecido pelo Departamento de Comércio dos Estados unidos. Esta comparação demonstrou um alto grau de concordância entre a técnica de sensoriamento remoto de 18 dias a o indice semanal de base-solo.

AASE et alii (1984) relacionaram medidas de radiância obtidas por um radiometro manual (Exotech $100-A) 0$ 
por um sensor de varjedura multiespectral CDaedalus DEI $1260 s$ a bordo de uma aeronave, para diferentes padróes de densidade (simulação de morte por frio) do trigo do inverno CTriticum aestiuum L.J e para producão de grãos. O campo de experiencia estava localizado a $11 \mathrm{~km}$ à noroeste de Sidney Montana $647^{\circ} 45^{\prime} \mathrm{N} ; 104^{\circ}$ 16' Wo num solo argiloso Williams (Argiborolls tipico, argila fina, mesclado). Três classes B7-27 e $13 \mathrm{Kg} / \mathrm{ha}$, do "Len", um rultivo semi-anão da variedade de trigo vermelho da primavera, foram semeadas para representar grupos de $100 \%, 40 \%$ e $20 \%$. Radiancias foram medidas com um radiômetro manual em mashãs claras por toda a estacão de crescimento. Medidas foram feitas mediante sobrevôos de aeronave, em três estágios de crescimento: germinacão, elongamento da haste e periodo de espigamento. Foi usada na análise a razão infravermelho próximorvermelto. As medidas feitas, tanto via aeronave como no terreno, possibilitaram diferenciar e avaliar densidades de grupos de trigo num estágio precoce, suficiente para tomar decisões de manejo. As medidas abtidas por aeronave também confirmaram as medidas do radiometro manual quando referentes ao prognóstico de produção. Embora havendo alguma dependência do crescimento, a razão infravermel ho próximorvermel ho mostrou correlação com a produção quando medida desde o estágio de germinaç̃o até próximo a maturacão-úmida. Os resultados reforcam o potencial do sensoriamento remoto para estimar produção de grãos e avaliar morte invernal. 
THOMPSON \& WEHMANEN (1980), relatam que como parte de um estudo complementar para deteccão do estresse de umidade, conduzido no Experimento de Cultivo em Grandes Areas Clarge Area Crop Inventory Experiment - LACIES uma técnica utilizando dados digitais Landsat transformados, foi avaliada para detecção do estresse de umidade numa região úmida de crescimento usando segmentos de amostra de Iowa, Illinois e Indiana. Em estágios de crescimento conhecidos, de milho soja, segmentos foram classificados como suportando o estresse de umidade ou não suportando o estresse. Informaçă baseada em sensoriamento remoto foi comparada com um indice semanal medido no terreno (Crop Moisture Index). Esta comparacão demonstrou que a técnica de sensoriamerto remoto pode ser usada para monitorar as condicóces de crescimento, dentro de uma região onde o milho e a soja são as maiores culturas.

Segundo YOU-CHING (1980), a utilização de fotografia aérea em florestas comecou na China em 1953 . Um grande número de projetos de cobertura aerofotográfica e de mapeamento fotográfico na silvicultura foram completados, e isto promoveu inovacão tecnológica em levantamentos florestais. Exemplos incluem um método de determinacão visual modificado, fotointerpretarão de tipos de floresta, amostra estratificada, amostra dupla, tripla, etc. Todos estes métodos ut.ilizam fotografias aéreas. Atwalmente, o inventário de florestas de toda a China foi completado por uma ou mais vezes, e os dados e mapas de inventário de florestas 
tem sido completados por mais de duas mil comarcas. Acrescentando-se que um sistema continuo de inventário de florestas foi estabelecido.

\subsection{Densitometria}

É sabido que as dificuldades na fotointerpretacão aumentam à medida que diminui a escala fotográfica. Pode-se dizer que, pela seguranca gue oferece, a importância da densitometria aumenta a medida que diminui a escala fotográfica CGARCIA \& MARCHETTI, 1977 )

Os aparelhos que medem a densidade de reflexão são usados para medir a quantidade de luz que reflete da superficie de uma cópia fotográfica, enquanto que os densitômetros de transmissão medem a quantidade de 1 uz que atravessa uma transparência (EASTMAN KODAK COMPANY, 1972$).$

SMITH (1970), que realizou estimativas de volume de madeira usando Plotter Kelsh e densitometria concluiu gue perfis obtidos no Plotter Kelsh apenas, não forneceram estimativas satisfatórias enquanto que o uso de um densitômetro, para proporcionar uma variável adicional, ofereceu uma estimativa mel hor do volume de apoio. Quando as duas variáveis for am rombinadas numa equacão de regressão, houve uma melhora significativa em relacão às varláveis usadas isoladamente, para calcular o volume de madeira.

DOVERSPIKE et atii (1965) argumentam que a aquisicão fundamental dos dados de uso da terra, atraviss das 
fotos aéreas coloridas, será facilitada se o processo for automatizado. Contudo, somente a densidade das cores não parece oferecer uma solucão para diferenciar o uso da terra pelas fotos. Embora o tamanbo da abertura afetasse as leituras de densidado, nenhuma melhora na discriminafão do uso da terra podia sør atribuido à área de abertura. Além disso, a forma geométrica da abertura do mierodensitómetro ccircular, alongada ou guadradas era de pequena importancia ou insignificante. As diferencas de densidade na região azul do espectro eletromagnético ofereciam mais possibilidades na separacão de 10 elasses de uso da terra do que ofereciam as regi ôes do vermel ho verde.

SMITH (1971), realizou estudo sobre estimativa de volume de madeira utilizando transparencias positivas de florestas de Pinus, no sul da Goórgia, e fazendo leituras com um microdensi tomet.ro. Embora o estudo tenha mostrado altas variaçós entre varreduras en diferentes direqões e em duas fotos diferentes, o autor sugere que o método seja adotado em novas experiências, por exemplo, com o uso de um microdensitômetro e algumas técnicas de correcăo para sombras em áreas abertas.

EROONER \& SIMONETT (1971) explicam que em densitometria de fotografias abreas infravermelbas coloridas, utilizando-se um filtro vermel ho detecta-se a presenca de I uz vermel ha ou ausência de corante cíano, sendo a quant.idade deste inversamente proporcional a luz infravermelha próxima refletida pela área de interosse. Aralogamente, o 
filtro verde detecta apenas a 1 uz verde modulada pelo corante magenta, o filtro azul detecta somente a luz azul resultante da ausóncia do corante amarelo. Dessa forma, modidas da intensidade do corante em cada camada do filme fornecem uma estimativa da quantidade de radiacăo verde, vermelha o infravermelha refletida pela cultura. Embora as medidas foram de vermelho, verde e azul, estas cores resultam da exposicão à luz infravermelha, vermel ha e verde, respecti vamente.

DRISCOL et alii (1974) utilizaram um microdensitómetro de varredura automática para medir as densidades opticas de várias características do terreno em fotos panorâmicas nas montanhas do Colorado. As diferencas de densidade óptica foram suficientes para discriminar entre as espécies individuais de árvores $\theta$ arbustos em fotos de grande escala (1: 1.100$)$ de floresta de Pinus edulis e funiperus scopulorum; entre as comunidades de plantas incluindo floresta de madeira-de-lei, floresta de Sprucerfir e floresta de arbustos em fotos de pequena escala (1: 139.0003. Seletivamente, amostras de Pinus ponderosa derrubadas e não tratadas tiveram "raios de alcance" de densidade óptica bem semelhantes, mesmo que as diferencas fossem aparentes nas fotos.

JORDAN et alii (1978) realizaram um estudo, o qual indica que o densitometro manual é um instrumento valioso para a classificacão de cobertura de regióos que incluem áreas de superficie minerada. os densitómetros ma- 
nuais foram usados para discriminar tipos de cobertura do solo para 118 estratos a partir de fotografias áreas multi-temporais na escala 1:24.000, infravermel has coloridas - fotografias aéreas multiespectrais. Usando levantamentos de campo (verdade tersestre) classificou-se cada estrato em um dos 8 tipos de cobertura. A análise discriminante linear - a imagem multi-sazonal conduziram a um sistema de elassificacão razoavelmente exato. A distincão entre árvores coníferas e decíduas é boa sob condiróes fré-folheadas. Cortudo, uma combinarão de condicões folheada e pré-folheada é superior a cada uma isoladamente. A floresta sem disturtios e áreas de superficie minerada são adequadamente classificadas na i magem tirada durante condi róes fol headas.

GARCIA \& MINTZER (1981) explicam que, enquanto a razão espectral original se baseia na relacão entre duas bandas espectrais processadas à partir de fitas digitais compativeis com computador, a técnica utilizada por eles foi a relacão entre leituras densitométricas das bandas 5 e do MMShandsat. Os dados obtidos dessa maneira foram comparados com estimativas de tonalidade obtidas por intermédio de escala graduada para tors de cinza. Tendo como elementos de comparacão, o Cerradão, o Cerrado, o Campo Sujo, o Campo Limpo a Mata, obtiveram as seguintes conclusp̃es: $c$ as a técrica da razão espectral a partir de leituras densitométricas revelou-se satisfatoria, consistindo numa alternativa prática e econômica; Cbo a razão espectral efetuada com estimativas de tonalidado apresentou resultados que podem 
ser considerados satisfatorios, doperdendo da finalidade do estudo da precisão requerida.

EVERITT et alii (1981a) utilizaram uma área no sul do Texas como um local de estudo para testar o uso da microdensitometria em fotograrias infravermelhas $70 \mathrm{~mm}$ Cescalas 1: 19.000 1: 42.000s e fotografias pretome-branco Cesala 1: 15.000) para diforenciar 11 tipos de terreno ce locais de "terra de carvão", dominados respectivamente por Prosopis Elandulosa e Quorcus virginiana; 7 lorais de gramíneas e 2 locais áridos. As fotografias foram tiradas em fevereiro, maio e agosto de $1970, e$ dados reais do solo foram roletados ao mesmo tempo. Leituras de densidade óptica foram feitas em filme infravermelho colorido com luzes branca, vermelha, verde azul em filmes preto-e-branco usando luz branca. As melhores separacóos foram obtidas com luz branca e filme infravermel ho colorido, quando a vegetacão estava no auge do deservol vimento da fol hagem.

Ainda EVERIT et alii(1981b) relatam que a $\mathrm{mi}-$ crodensitometria com filme infravermel ho colorido $70 \mathrm{~mm}$ foi testada para distinguir lugares salinos de năo-salinos num terreno en Starr county. Texas. Foram tomadas fotografias aéreas em maio de 1976 cescala 1:19.000), em junho de 1970 Cescalas $1: 19.000$ e 1:42.000 e fm junho de 1979 Cescala 1:80.0005. Foram feitas loituras de densidade óptica com luzes branca, vermelha, vordo azul. Os terrenos salinos foram separados dos não-sal inos pelo uso de luz branca ou azul, nas fotografias de jumbo de 1976, os terrenos salinos 
18.

foram separados dos não-salinos usando-se todas as quatro luzes em fotografias de escala $1: 19.000$ pelo uso de luz branca, verde ou azul nas fotografias de escala 1:42.000. Os terrenos salinos foram, também, separados dos não-salinos com o uso de luz branca, verde ou azul na fotografias de escala 1:80.000, tiradas em junho do 1979. A capacidado de diferenciar terreno salino de não-salino foi devida à menor cobertura de plantas em terrenos salinos. Estes dados mostram que a fotointerpretacão automatizada pode sor uzàda, com Êxito, para identificar terrenos salinos em fotograrias tiradas usando filme infravermel ho colorido.

LEE 8* MoKELVEY (1984) testaram uma nova abordagem, combinando microdensi tometria e análise computarional de fotografias aéreas infravermelhas de pequeno furmato, para averiguar mudancas em vegetação estuarina causada por cisnes trombeteiros. A téconica foi considerada util prorque seria dificil delinear mudancas pelo uso das truncas convencionais de interpretarão da fotografia aérea, o também porque os métodos de levantamento de campo são trabalhojos. Dois niveis de mudancas de vegetacão, que correspomdian à al imentação "pesada" e "leve", dos cisnes, foram detecturjos. Estas mudansas podiam ser usadas para medir a taka de consumo de alimento dos cisnes trambeteiros.

EVERTIT et alii (1985) testaram a micrulunsitometria em fotografias infravermelhas coloridas (cIk) fara escala pequena (1:120.000), para distinguir entre 10 larais de pastagem matural, 2 terrenos de mato, 6 terrans de 
pastagem e 2 terrenos áridos, no sul do Texas. Fotografias aéreas foram tiradas em maio de 1981 , quando a vegqtação estava no auge do desenvol vimento das fol has. As leituras do densidade óptica feitas sobre filme CIR com luz branca ou azul, foram melhores para distinguir as olasses de ordem mais alta dos 3 tipos cterreno de mato, terreno de pastagem e terreno árido), mas as leituras feitas com luz vermelha distinguiram melhor os 10 locais de pastagem. Uma análise discriminante usando as 4 leituras de densidade optica diferenciou os 10 lacais com $100 \%$ de precisão. Estes resultados demonstraram que a fotointerpretacão automatizada podı ser usada para identificar uma variedade de tipos de cobrertura em fotografias infravermelhas coloridas de pequena escala.

EDWARDS \& BLAZQUEZ (1985) explicam que taxas de valores densitométricos espectrais selecionados do imagens de árvores citricas em tramsparéncias aéreas infravormelhas coloridas foram determinados por meio de três instrumentos: Dokumator DL-2-leitor de microfilmis; un monocromator visivel e um auto-fotômetro. Plotagens de densidade do filme para imagens de árvores cítricas lintiam duas faixas de picos máximos, um dos 490 a $500 \mathrm{~nm}$ o vulro dos 600 a $610 \mathrm{~nm}$. As taxas de densidade do filme, mates dois picos máximos, foram mais baixas para árvores sadiaz do que para árvores não sadias. Uma regressão linciar da fotointerpretacão versus os valores da taxa para imajont de to árvores deu um coeficiente de correlação de $0,85$. 
SIRONG et alii (1985) investigaram a microdansitometria de fotos infravermel has coloridas de escala grande como uma técnica para estimar a producão de fitomassa de 3 estepes do artemisia, Artemisia tridentata, os tipos do babitat num terreno em pousio. Relacões inversas entre producão de fitomassa e reflectância variavamentro tipos do habitat. Reflectância no vermelbo explicava 59 a $56 \%$ da variação em producão de fitomassa para dois tipos de habitat. Variáveis espectrais foram altamente correlacionadas, resultando em faixas de taxas gue foram relativamente constantes, com pouca habilidade de previsibilidade. Uma relacão de curva-linear inversa para dados de dois tipos de habitat explicava 76\% da variância na produção de fitomassa com um erro padrão de $15 \%$ da média. Numa avaliaç̃o de modelos de regressão, a producão de fitomassa roi subestimada, devido a representacão incompleta nos modelos, de grandes valores de reflectância do solo exposto. Regressões usando densidade integral e exposicăo tinham variacốes residuais semelhantes àquelas obtidas usando reflectancia como uma variável independente.

MACLEAN \& MARTIN (1985) descrevem um processo para estimar volume de madeira a partir de medidas de alta precisão do perfil da cobertura em fotografias aéreas vorticais de média escala. Dados do volume de madeira foram obtidos em 75 pontos de uma área de estudos em Wisconsin. contendo vários tipos de floresta, e áreas do perfil da cobertura foram medidas com um estereo-restituidor fotoul a- 
métrico nos pontos correspondentes nas fotografias ab́reas. Os valores de densidado do filme foram também medidos ao longo de cada perfil usando um microdensitómetro de varredura. Constatou-se que a área do perfil da cobertura era independente da direcão do perfil relativo à linha de vôo da fotografia. A relacão entro volume de madeira o área do perfil foi altamente significativa, semilogaritmica, $\theta$ variáveis dependentes, valores de $R^{2}$ Cooeficiente de doterminacăos de 0,67-0,79. A área sob uma curva obtida por plotagen de valores de densidado do filme, năo foi suficientemente correlacionada com o volume de madeira para ser uma variável independente significativa, sozinha ou combinada com a área do perfil. Contudo, a informarão de densidarde do filme foi de valor significativo na correcão de arras do perfil para micro-aberturas na cobertura, as guais foram pequenas para serem medidas com estero-restituidor fotcgramético. Com a área de micro-abertura incluída como uma variável independente, os valores de $R^{2}$ foram $0,82-0,88$.

\section{3. Densidade óptica}

Segundo EASTMAN KODAK COMPANY (1972), a absorᄃão de luz na imagem fotográfica é exprossa em tormos de densidade optica. Para imageamento em preto-e-bramo, a densidade óptica é usual mento duefinida como:

$$
D=\log \frac{1}{\mathrm{~T}}=\log \frac{\mathrm{PO}}{\mathrm{P}}
$$


22.

onde:

$$
\begin{aligned}
& D=\text { densidade óptica; } \\
& I=\text { transmitância; } \\
& P O=f l u \times o \text { de luz incidente; } \\
& P \text { = flumo de luz transmitida. }
\end{aligned}
$$

Valores de densidade óptica obtidos pelo densitometro podem ser convertidos para reflectância através da seguinte rel ação:

$$
R=\frac{1}{\operatorname{antilog} D}
$$

ondo:

$$
\begin{aligned}
& R=\text { reflectância; } \\
& D=\text { densidade óptica. }
\end{aligned}
$$

SCARPACE (1978) explica que imagens em filmes coloridos são mais complexas: assim, as definicões de densidade devem ser cuidadosamente examinadas.

O fluxo de luz transmitida através de um pedaso de filme pode ser escrito assim:

$$
P=P O 10^{-D}
$$

Geralmente, o fluxo de luz incidente e a densidade não são independentes do comprimento de onda; assim, a equação [1] é escrita mais corretamente da seguinte maneira:

$$
P(\lambda)=\operatorname{Fo}(\lambda) 10^{-D(\lambda)}
$$

onde $(\lambda)$ indica gue o termo procedente depende do comprimento de onda, isto é, a equacão 11 lé independentemente válida 
para cada comprimento de onda.

Como o filme colorido é composto pelas camadas cíano C.CD, magenta CM o amarelo CA, além da camada baso (B) onde estão assentadas estas outras (Figura 1), a equaçăo do fluxo total transmitido pode ser expressa como segue:

$$
P(\lambda)=\operatorname{Po}(\lambda) 10^{-[D B(\lambda)+D C(\lambda)+D M(\lambda)+D A(\lambda) s)}
$$

Os termos exponentiais da equarão [3] podom

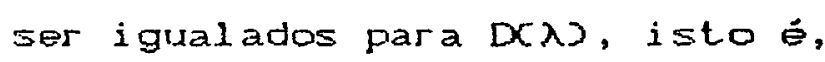

$$
D(\lambda)=D B(\lambda)+D(\lambda)+D M(\lambda)+D A(\lambda)
$$

Onde $D(\lambda) e ́$ a densidade integral da transparência. Os densitômetros medem uma densidade integral. Em um filme multi-camada as densidades das camadas individuais, bem como da base CDB, $D C, D M \in D A$, são densidades analíticas.

Desde que a densidade é funcão do comprimento de onda, a equacão [2] pode ser expressa da seguinte maneira:

$$
D(\lambda a)=\log \frac{P O(\lambda a)}{P(\lambda a)}=\log \frac{1}{T(\lambda a)}
$$

onde $\lambda a$ é um comprimento de onda especifico. A densidado expressa desse modo é denominada densidade integral, que uma medida de densidade para um comprimento de onda especifico.

Porém, quando as densidados são avaliadas através de un filtro, representado por doterminada curva do transmitância espectral, estas são denomi sadas densidades do 
faixas largas espectrais ("broad band densities").

\begin{tabular}{c} 
CAMADA SENSIVEL A RADIAÇĀO AZUL \\
(IMAGEM POSITIVA AMARELA) \\
\hline FILTRO AMARELO(RETENÇĀO DA RADIAÇĀO AZUL) \\
\hline CAMADA SENSÍVEL A RADIAÇĀO VERDE \\
(IMAGEM POSITIVA MAGENTA) \\
CAMADA SENSÍVEL A RADIAÇĀO VERMELHA \\
(IMAGEM POSITIVA CYAN) \\
\hline BASE DO FILME \\
\hline
\end{tabular}

Figura 1 - Representacão esquemática das camadas de um filmo colorido.

Fonte: Novo (1989).

Dovido à natureza da densidade de faixa longa espectral, a expressão matemática é diferente da equacão [5]. A densidade de faixa longa espectral não é somente funcão do fluxo de luz incidente e transmitida, mas também é funcão da transmitância do filtro (Figura es e da sonsibilidade do densitômetro. A equacão [5] pode ser reescrita como:

$$
D f=\log \frac{\int P O(\lambda) \cdot F(\lambda) \cdot S(\lambda) d \lambda}{\int P(\lambda) \cdot F(\lambda) \cdot S(\lambda) d \lambda}
$$


onde,

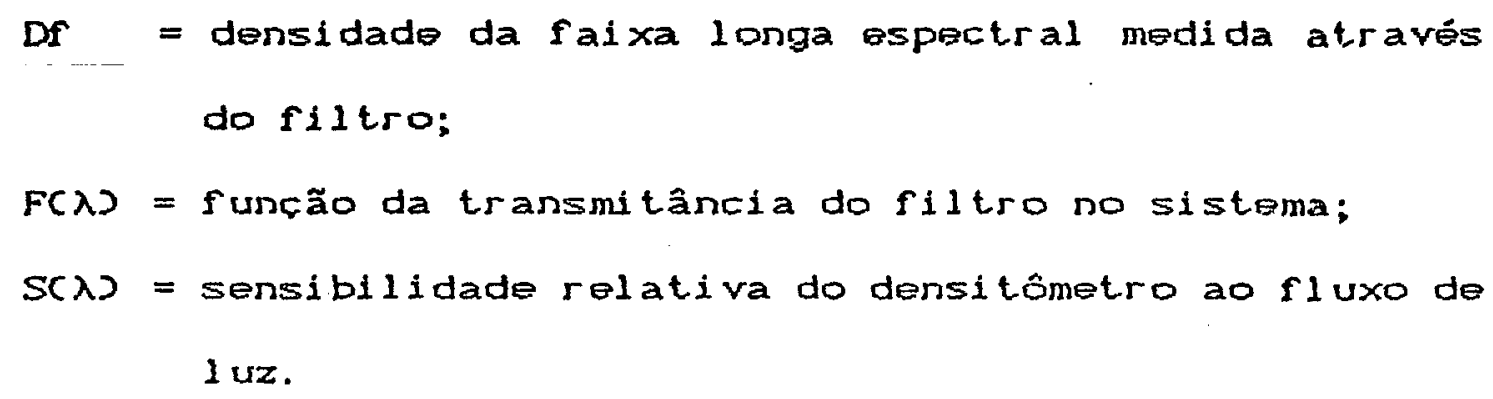

A integral se estende por toda a faixa do comprimento de onda no qual o densitômetro é sensivel.

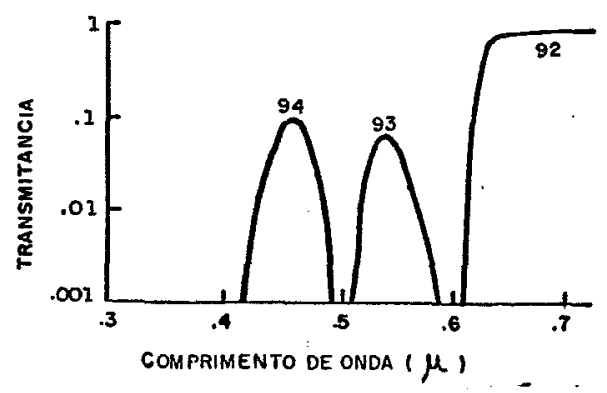

Figura 2 - Curvas de transmitancia versus comprimento de onda para os filtros 92,93 e 94.

Fonte: SCARPACE (1978).

SEgundo MURTHA \& KIPPEN (1970), num filmo falsa-cor a camada formada de corante cíano é sensível a reflectância no infravermelto próximo. Visto que as coniferas fisiologicamente danificadas têm uma menor refloctancia no infravermelto próximo do que têm as árvores mais saudáveis, medicóes de densidade óptica com filtro vermello foram foitas em imagom falsa-cor do Pinus rosinosa ineluindo algu- 
26.

mas árvores contaminadas e outras nas proximidades que não estavam infectadas, para fornecer uma medida da densidade da camada de corante ciano. Em geral, a densidade diminul com o aumento de distância dos focos de infeccão.

MURTHA \& HAMILTON 19702 relataram a deteção de danos simulados em coníferas usando filmes infravermel ho próximo. Resultados das fotos de coniferas jovens tiradas a una altura de 12 pés indicaram que o filme falsa-cor registrou dano animal simulado, não registrado pelo filme colorido normal. A observacão visual indicou que com o filme falsa-cor, as árvores danificadas apresentaram-se com uma cor magenta mais escura do que as árvores não danificadas; galhos de coniferas jovens estavam com uma cor laranjamagenta $\theta$ a folhagem marrom estava verde-amarelada, $\theta$ os galhos secos estavam azulados. A análise das medicóses dos valores de densidade óptica indicaram que a densidade da camada do corante ciano foi maior nas transparênoias do filme falsa-cor, em grandes danos. Nonhuma relacão foi aparente entre o montante do dano e as densidades da camada de corante do filme colorido normal.

\section{4. Rofloctância}

GAUSMAN at alii (190Ba) relatam que plantas de algodão foram produzidas hidroponicamente com cloreto de sódio. As fol has amostradas eram do 39 e 48 nódulos abaixo dos apices da planta de algodäo, slmulando como serian vis- 
tas de cima por um sensor remoto. Un espectrofotómetro fai usado para medir a reflectância e transmitância da luz incidindo na superficie superior das folhas, individualmente. A reflectância total hemisfórica no âmbito espectral de 750-1300 me foi maior para folhas de plantas de algodão cultivadas em substratos salinos com baixa concentracão. Este crescimento na reflectância e uma diminuicão na absortância foi consistente com a observada em folhas mais grossas de plantas em crescimento em substrato salino, as quais tinham maiores paredes palisadas e mesófilos esponjosos folgadamente. Estas mudancas estruturais resultaram em espacos intercelulares maiores, portanto apoiando a premissa de que o espalhamento interno da $1 u z$ é aumentado por interfaces das cavidades de ar das paredes celulares.

Ainda GAUSMAN et alii (19Bgb) relatam gue foIhas de plantas de algodão pul verizadas com $100 \mathrm{~g}$ ha de Cycocel num campo experimental tiveram sua dimensão superficial 40\% mais espessa e 20\% mais 1 arga que as folhas não pulverizadas com cycocel. As folhas tratadas com Gycocel têm um aumento aproximadamente triplicado no número de espacos intercelulares dentro de seus mesófilos. Medidas espectrofotométricas de folhas Individuais num intervalo de comprimento de onda de 500-2500 mi revelou um aumento de 5\% na reflectancia sobre o intervalo de comprimento de onda 500-1350 $\mathrm{m} \mu$ e um decréscimo de 6\% na trassmitância sobre o intervalo de 500-2500 me para folsas tratadas, comparadas com as não tratadas. O aumonto da reflectância o o decrésci- 
mo da transmitância sobre o intervalo de comprimento de onda 750-1350 me foram principalmente associadas com o aumento do número de espacos de ar no mesófllo da folha. A diminuicão da transmitância de folhas tratadas com Gycocel em interva1 os de comprimentos de andas de $500-700 \mathrm{~m} \mu$ e $1390-2300 \mathrm{~m} \mu$ foi devida ao aumento da absortáncia causada pelo aumento da clorofila e conteúdo de água, respectivamente. O tratamento com Gycocel aumentou em $13 \%$ a absortancia para o pico de absorcão da clorofila, $550 \mathrm{m \mu}$; somente $2-3 \%$ sobre o intervalo de comprimento de orda de $750-1350 \mathrm{m \mu}$ e 10-11\% para a banda ou picos de absorção da água, aproximadamente 1450-1950 mu, respectivamente. A reflectancia da luz infravermelha de folluas individuais, medida com um espectrofotômetro, foi isversamente relacionada e a reflectância da $1 \mathrm{uz}$ visivel foi diretamente relacionada com a reflectividade de campos de algodão detectados e regist-rados no filme aéreo infravermelho Kodak Ektachrome tipo 8443 com um Kodak Wratten ne 15(G), com filtro de luz laranja, durante um sobrevôo fotográfico.

Para KNIPLING (1970), o conhecimento da maneira como a radiacão solar interage com a vegetação é necessário para processar o interpretar dados de sensoriamento remoto da agricultura e de alguns rocursos naturais. Uma fol ha típica de planta tem uma reflectância haixa na região espectral do visivel dovido à forte absorcão pela clorofila; uma reflectancia relativamente alta no infravermel ho é devida ao espalhamento interno da fol ha o não à absorcão; o uma re- 
flectância relativamente bai xa no infravermel ho ao redor de $1,3 \mu \mathrm{m}$, devida à forte absorcão pela água. A reflectância de un dossel é similar, mas é modificada pela não uniformidade da incidência da radiação solar, estrutura da planta, área foliar, sombras e refletividade de fundo cbackgrounds. Sensores em avião recebem uma visão integrada de todos estes efeitos, e cada cultura ou tipo de vegetacão tende a ter uma "assinatura" característica, a qual permite a sua discriminacão. Quando a doenca ou estresse fisiológico afetam diretamente as propriedades de reflectância de folbas individuais, as mudarcas iniciais mais pronunciadas, frequentemente, ocorrem mais na região espectral do visivel do que no infravermelho, devido à sensibilidade da clorofila aos disturbios fisiológicos. A base inicial para a detecrão de condicóos de estresse numa cultura ou outra comunidade vegetal por sensores remotos aéreos, porém, não é uma mudança nas características de reflectancia de fol has individuais, mas uma reducão no total da área foliar exposta para o sensor. Esta reducão pode resultar de uma perda direta de folhas, uma mudanca em sua orientacão, ou una supressão do toda planta no terreno. En tais casos a roflectancia infravermelha total tende a ter uma reducão relati vamente menor que a reflectância do visínol por causa de uma reducão no realcamento do infravermel ho devido às camadas múltiplas menores da folha e por causa de um aumento no sundo (background) exposto.

STORY \& YAPP (1972) explicam que plantas verdos, quando dooratess ou quando sob défice hídrico, têm uma 
reflectância infravermel ba mais balxa do que as plantas saudáveis e, consequentemente, quando fotografadas com filme falsa-cor (Kodak Ektachrome Infrared), produzem uma imagem azul. Contudo, em testes do laboratório com amostras do Eucalyptus radiata, a reflectancia infravermelha das folhas que estavam úmidas, quando colhidas avermelhadas igualmente tornaram-se secas e não produziram a cor azul da imagem de falsa-cor em nenhum estágio. Imagens azuis do topo foram registradas em fotografias tiradas no campo, mas isto pode ser atribuido à presenca de muitas flores, que produzem uma reflectáncia mais baixa de comprimentas de onda do infravermelho. As experiências indicam que em Eucalyptus radiata, o stress da umidade antes das árvores serem visivelmente afetadas não será detectado em filme falsa-cor.

GAUSMAN et alii ( 1974 ) relatam gue campos com plantas de sorgo normais e clorb́ticas (Sorehum bicolor (L.) Moenchs, foram aerofotografados a uma altitude de $152 \mathrm{~m}$ com filme Kodak infravermel ho colorido. Medicóes de campo e de laboratório foram efetuadas para determinar as relacõos de tamanbo da planta Cárea foliar total; volume e indice de área foliarl a concentracão do clorofila para reacão do filme. A reflectância da fol ha fol medida no laboratrório com um espectrômetro e a reflectância da cobertura foi medida no campo com um espectrorradiometro. As plantas normais tinham tanto áreas totais de folha, quanto volumes e indices de área foliar maiores do que as plantas cloróticas e de 6 até 10 vezes mais concentragão de clorofila. As folhas cloróti- 
cas tinham estrutura celulas deformada e maior reflectância na região do visível, quando comparadas con folhas normais. A concentracão de clorofila em folhas cloróticas, expressa em miligramas de clorofila por centimetro cúbico de volume de folha, foi positivamente correlacionada com leituras de densidade do filme. Imagens no filme tornam-se mais escuras com o aumento da concentração de clorofila. O tamanho da planta näo foi relacionado à leitura da densidade.

Segundo SIEGAL \& GOETZ (1977), o efeito da ocorrencia natural da vegetação na reflectância espectral de materiais terrestres na região de comprimentos de onda de 0,45 a $2,4 \mathrm{\mu m}$ tem sido determinada por computador, habitualmente a partir de dados espectrais adquiridos localmente. A vegetacăo natural pode mascarar e alterar significativamente a resposta espectral do terreno, como aquelas medidas por "scanners" multiespectrais, em avião ou satélite. Quanto à significância da cobertura vegetal do terreno, materiais de baixo albodo são os mais significativamente afetados e podem ter a identificação alterada com $10 \%$ da cobertura vegetal verde. Vegetação morta ou seca não altera muito a forma da curva de reflectância espectral o muda somente o albedo com - minimo de depondência do comprimento de onda. Com o aumento da quantidade de vegetacão, as razões entre bandas MSS do Landsat, 4/6; 4/7; $5 / 0$ e 5,7 decrescem significativamento, onquanto as razỗs MSS $4 / 5$ e $6 / 7$ permanecem relativamente constantes. 
De acordo com PIECH et alii (1979), algoritmos foram desenvolvidos para possibilitar a classificacão de seis características simples do terreno Cmetal, água, superficio pavimentada, solo e areia, vegetacão clara e escura, principalmente florestas a partir de imagens de filme colorido padrão; tendo os testes sido realizados em cinco áreas no Estado de New York. A técnica que é baseada em medicão de reflectância de objetos em três camadas do filme colorido, incorpora um processo para remover variáveis atmosféricas e de exposicão de forma que novas séries de dados de treinamerto năo são necessários para cada missăo de coleta de dados. A classificacão dos algoritmos mostrou ser 97\% precisa, usando imagens em escalas tão pequenas quanto 1:100.000 (tiradas de 50.000 pés de altitude).

FULLER \& ROUSE (1979) apresentaram dados de um estudo de uma sequência de superfícies queimadas Chá 0,1 , 2, 25 e 80 anos) de floresta "spruce 1ichen" (dominada por Picea marianas em um "drumlin" em Saskatchewan - Canadá. A reflec tância módia aumentou com a ldade da queima e as caracteristicas espectrais alteraram-se sibstancialmente depois da re-vegetação, con dimiruicão de reflectáneia para as faixas do azul o vermelho a aumento para verde $\theta$ infravermelho. Condicôes difusas e obscuras reduziram a reflectância para lodas as superfícies. O efoito de uma cobertura de floresta estacional foi variável e menos prognosticável, uma voz que tornou-so mais complexo. 
33.

TALERICO et alii (1980) explicam que a desfoliação par Lymantria dispar foi medida em uma área de 0,4 hectare de uma amostra dominada por carvalho, principalmente Quereus spp, na Pensilvânia Central, usando: (a) dados de reflectância (R) de fotografias aéreas sequenciais tiradas com filmes colorido infravermelho (CIRS escala 1:33.680 e analisadas pela técrica de padrão de cor de cena, técnica que produz medidas absolutas de $R ; \theta$ Cb estimativas de campo. Dados para $R$ foram também coletados em uma área comparável, não desfoliada. Desfoliacão en (b) foi relacionada com (a) por uma funcão polinomial de terceira ordem do Cindice de desfoliarăo mariposa "gypsy" de fotografia ab́rea - APGMDIJ, por sua vez uma funcão de Rir / Rvermelho / Rverde na maturidade e reflectância média para IR, vermelho e verde; a correlacão foi boa $c r^{2}=0,78$. A técnica é provavelmente econômica e é aplicável a outros insetos e tipos de florestas e para monitoramento de pulverização.

Segundo CURRAN (1982), usualmente hä uma relacão positiva entre a razão de reflectância bidirecional do vermel ho ao infravermel ho próximo e a biomassa da vegetação verde até a assintola da reflectância bidirecional da vegeração. Entretanto, a reflectância bidirecional é conhecida por variar independentemente da biomassa verde devido ao efeito da formacão do solo; à presenca de vegetacão senescente; ângulo do sol e sensor; à geometria da cobertura e mudancas episidicas e fenológicas da cobertura CCURRAN, 1981 J. Uma influência pouco estudada sobre a relacão entre a 
razão de reflectâncla bidirecional $\theta$ a blomassa vordo efeito da produtividade, a qual afetaria teoricamente a reflectancia bidirecional vermel ha independentemente da biomassa verde. Usando dados de reflectância obtidos a partir de um conjunto de 22 fotografias aéreas quase verticais e um conjunto de 56 fotografias obliquas do terreno, foi demonstrado que: (1) o valor da diferenca da razão de reflectância bidirecional calculada pela biomassa verde poderia aumentar ao redor de 6\% com o aumento da produtividado; a (2) num local de pastagem com baixa bi omassa verde poróm alta produtividade, a razão de reflectância bidirecional foi mais alta que para um local de pastagem com alta biomassa verde e com baixa produtividade.

Para CURRAN \& MILTON (1983), a reflectância de um dossel vegetal é determinada principalmente por seu indice de área foliar (IAF); que é a superficie de área foliar por unidade de área do terreno, a qual é usualmente correlacionada à concentracão de clorofila co total de clorofila por unidade de área do terrenol dentro do dossel. Este experimento de laboratório sobre o cresclmento do agrião ondulado Lepedium satiuum CL.J, indica que durante estresse hídrico não há corrolacão entre concentracao de clorofila IAF e, portanto, não há correlacão entre concentracão de clorofila e reflectancia do dossel.

JACKSON et alii (1983) explicam que dados de reflectância foram obtidos para lotes de trigo com estresse hidrico e outros bom supridos de água, com um radiômetro 
35.

manual tendo bandas similares ao MSS do satélite Landsat. Dados para 48 dias claros foram interpolados para permitir obter valores de reflectância para cada dia do período de crescimento, do plantio a colheita. Com um modelo 1 inear de radiância atmosf́rírica e dados de calibraç̃o do Landsat-Z, as reflectâncias foram usadas para simular o resultado digital do Landsat (rão quantizado) para as quatro bandas, para cada um dos dias do período de crescimento, através de uma atmosfera clara $(\cong 100 \mathrm{~km}$ de visibilidade $)$ de uma densa $C \cong$ $10 \mathrm{~km}$ de visibilidades. Várias combinacões 1 ineares e de razões entre bandas foram calculadas usando dados simulados, avaliando entäo sua relativa capacidade para discriminar orescimento vegetativo o estresse da planta através das duas atmosferas. Os resultados mostraram que o estresse hídrico não foi detectado por nenhum dos indices até o crescimento posterior ser retardado; e que a sensibilidade de vários indices de vegetacão depende do estágio de crescimento da planta e da radiância atmośférica.

GERBERMANN et alii (1984), tiveram como objetivo examinar as rolacöos entre porcentagen de reflectância Cpara comprimentos de onda de $1,65 \mu m$ até $2,20 \mu m$ para faixas de comprimentos de onda e $1,55 \mu \mathrm{m}$ até $1,75 \mu \mathrm{m} e \mathrm{e}, 10$ $\mu \mathrm{m}$ até $2,30 \mu \mathrm{m}$ e (1) componentes do cenário (cobertura de planta, sombra solo iluminado pelo solj, (2) populacão de plantas, (3) bi omassa $\theta$ (4) a condicăo de superficie do solo sob a cobertura da planta. As medidas de reflectância foram feitas com um espectrorradiometro de campo CExotech Model 
36.

203 em cinco amostras da populacão de plantas de sorgo alcancando de 50.000 até 3,25 milhôes de plastas ha, todas com a mesma condicão de superficie de solo; e em três populacốs de plantas variando de 370.000 até 1,42 milhões de plantas/ha, cada uma com trés diforentes condicóes de superfício de solo sob a cobertura do plantas. Relaçós para a porcentagem de reflectâscia ccomprimento de onda de 1,65 $\mu m$ até $2,20 \mu m$ e faixas de comprimento de onda de $1,55 \mu m$ até $1,75 \mathrm{~m}$ e de $2,10 \mathrm{\mu m}$ a $2,30 \mu \mathrm{m}$ com porcentagem de solo il uminado pelo sol foram correlacionados significativamente positinos; enguanto as relacöos entre reflectância e porcentagen de cobertura vegetal, porcentagem de sombra, populacão de plantas e biomassa foram correlacionados significativamente negativos. Para todas as populacões de plantas, as porcentagens de reflectância Cpara comprimento de onda 1,65 $\mu m$ e para faixa de comprimento de onda e 1,55 um até 1,75 $\mu m$ para coberturas com superficie de solo-encrostrado seco foram significativamente mais altas, estatisticamente, do que aquelas para coberturas com superfíies de solo seco-encrostrado-quebrado; enquanto a reflestância para cobertura com superficie de solo-encrostrado-quebrado-seco ou encrostrado-quebrado-úmido for am estatisticamente iguais.

Os resultados obtidos por GERBERMANN et alii (1984) indicam que a reflectancia medida nestes comprimentos - faixas espectrais podem ser usadas para determinar a quantidade de cobertura de plantas vivas na superficie do solo num determi nado ponto no tempo; q que a claridade ou a 
escuridão da superficie do solo sob cobertura de plantas tem um efeito significativo sobre as reflectancias do dossel, particularmente nas populacóes de plantas de porte baixo.

KADRO (1984) relata que medicóes de reflectäncia espectral infravermel ha e visual centre 500 nme 1100 nM foram feitas em amostras de florestas e culturas agricolas. Um "scanner" multiespectral operando em alturas de até $3.800 \mathrm{n}$ deu resultados mais confiáveis do que um espectrorradiómetro operando a $17 \mathrm{~m}$ de altura. Curvas de reflectância foram obtidas para Norway spruce Cem vários ângulas de observacãol, carvalho, Corsican pine, Scots pine - amostras de Pinus pinea.

GHIAO \& CHANG (1984) descrevem um estudo com mudas de guatro espécies importantes em Taiwan, Cryptomeria japonica, Taiwania cryptomeriaides, Cunnighamia lanceolata e Calocedrus (Libocedrus) formosana, usando dois radiômetros de quatro bandas com as mesmas amplitudes de faixa que o "scanner" multiespectral do Landsat. A identificação mais exata das espécies foi realizada usando dados de todas as quatro bandas; mas as baixas $B$ e 7 foram melhores quando foi usada uma só faixa; a primavera foi a melhor estacăo para mediç̃es. Houve uma correlacão positiva significativa entre biomassa e assinaturas espectrais de diferentes combinacóes de bandas.

GAUSMAN (1984) comenta que a reflectância em comprimentos de onda $0,45 \mathrm{\mu m} ; 0,55 \mathrm{~mm}$ e $0,05 \mathrm{~mm}$ de laranja valência (citrus sinensis) crescida na sombra ou exposta a 
Iuz do sol, foi examinada com relaça à clorofila e a quantidade de água, densidade e volume de ar no mesófilo. A reflectancia das folhas sombreadas foi afetada apenas pela guantidade de água no comprimento de onda de 0,45 $\mu \mathrm{m}$; enquanto que a das folhas iluminadas, foi afetada pela guantidade de água, elorofila e ar no mesófilo. Concluiu-se que a influência dos dois tipos de folhas deveriam ser consideradas quando se model a reflectancia de coberturas.

CHI AO \& CHENG (1985) explicam que a reflectância de sete espécies de árvores, Taiwania eryptomerioides: Chamaecyparis formosensis; Podocarpus macrophylla cmacrophyllus:; Araucaria excelsa (heterophylla); Cinnamomum camphora; Schefflera octophylla; Calocedrus (Libocedrus) formosana, foram medidas no campo, no outono de 1979 , usando um radiometro de 4 bandas. Curvas de reflectancia espectral foran obtidas para cada árvore. Diferencas significativas entre espécies foran constatadas apenas na região do infravermelho. Numa segunda experiencia con Cryptomerio japonica, diferencas em reflectância espectral foram constatadas entre árvores saudáveis e não saudáveis, novamente na região do infravermel ho.

DALE et alii (1986) explicam que fotografias aéreas infravermelhas coloridas tomadas sobre o sudeste de Queensland na Austrália, num pântano salobro no outono e primavera, foram ampliadas para uma escala 1:1.100. Reflectâncias registradas em amostras locais obtidas a partir de medidas através de filtros neutro, azul, verde e vermel ho de 
um densitometro foram usadas como atributos num procedimento de análise de agrupamento. As classes produzidas foram comparadas em termos de seu componente fixo local, atributos discriminantes e relacão com dados da vegetacão obtidos por amostragem do campo. Embora as reflectancias variassem sazonalmente, os resultados da classificacão foram similares para cada estacão - as características da vegetarão corresponderam bem às classes produzidas. As maiores diferencas sazonais bcorreram na reflectância através dos filtros vermelho e azul representando as faixas espectrais infravermelho e verde. As fotografias tomadas no outono, com alta reflectância no vermelho, forneceram discriminação máxima entre as classes. 
40.

3. MATERT AL E MÉTODOS

3.1. Caracterização da Área de Estudo

A área de estudo localiza-se no municipio de Mogi-Guacu - SP, Região Administrativa de Campinas, entre as

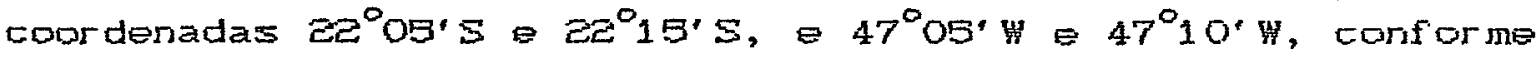
Figura 3 .

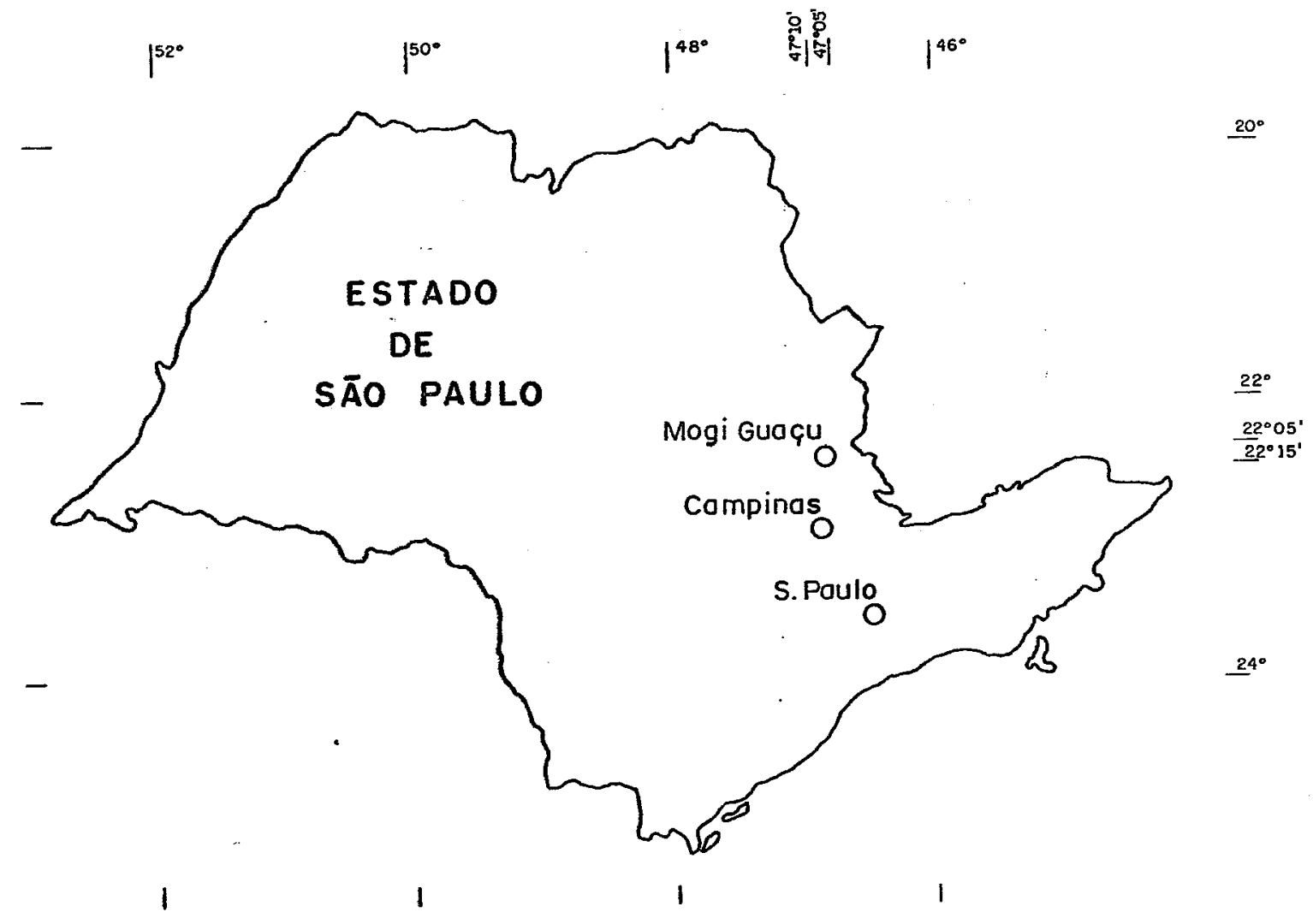

Figura 3 - Mapa de localizacão da área de estudo. 
- trabalho foi desenvolvido no Horto Santa Terezinha, de propriedade da Champion Papel e Celulose S. A. A área total da fazenda é de 3.284 .04 ha; sendo que deste total $2.707,90$ ha são ocupados por Eucalyptus SPP; 85,16 ha por Pinus SpP; 250,76 ha por Bambu $e$ 8,19 ha por Essências Nativas.

Quanto ao tipo de solo, trata-se de Latossolo Vermelho Amarelo CEVA conforme classificação e descricão de OLIVEIRA et alii (1982) - quadricula de Araras. Mais precisamente, a área pertence à unidade Laranja Azeda, que é um LVA álico com A moderado, textura média e relevo suave ondu1 ado.

Essa unidade é a mais extensa da quadricula, cobrindo 58.757, 9 hectares, perfazendo 46,9\% dos latossolos, ocupando extensas áreas representadas por colinas de vertentes longas e suaves, geralmente, com declives inferiores a $5 \%$ topos aplainados. Ainda segundo OLIVEIRA et alii (1982), o material de origem deve estar relacionado com os depósitos rudáceos arenosos do neocenozóico (Figura 4).

Segundo o mapa geológico do Estado de São PaUlo CINSTITUTO GEOGRÁFICO E GEOLÓGICO, 1974 , citado por OLIVEIRA et alii, 1982J, a geologia está representada por rochas relacionadas com o grupo Tubarão do permocarbonifero. com as formaçôs Irati e Cor umbataí do gr upo Passa-Dois, com intrusivas básicas, com arenitos da formação Botucatu - Pirambóia, e com sedimentos cenozóico. 
42.

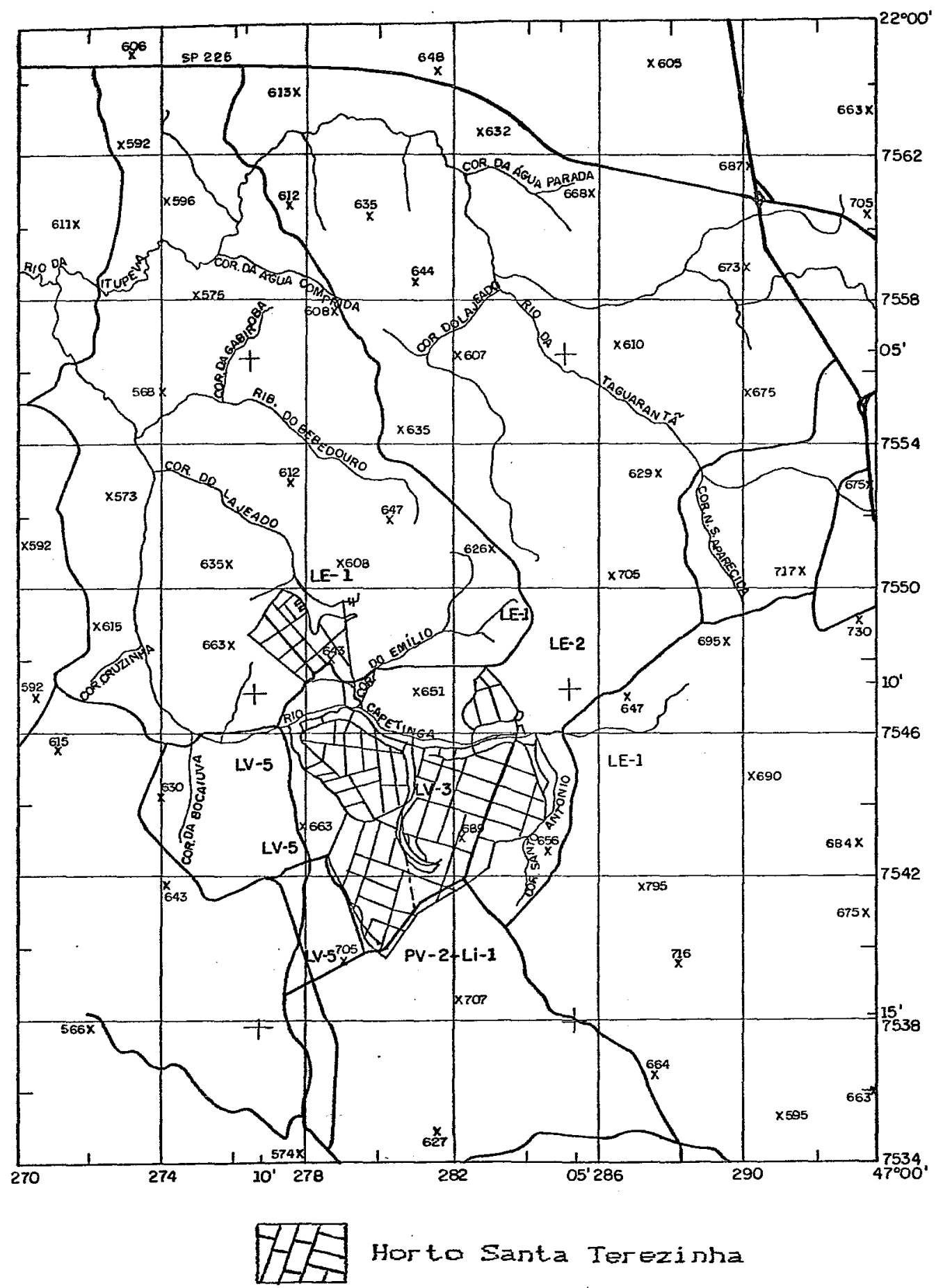

Figura 4 - Levantamento pedológico semidetal hado do Estado de São Paulo - Quadrícula de Araras - Horto Santa Terezinha - Champion Papel e Celulose S. A.

FONTE: OLIVEIRA et alii ( 1981 ). 
A vegetacão original, representada por cerrados e cerradốes ainda cobre expressivas áreas, enguanto no restante, o reflorestamento com Pinus e Eucalyptus e a citricultura, são os principais tipos de cobertura vegetal.

Em relarão ao clima, ainda segundo OLIVEIRA et alii (1982), a distribuicão pluvial segue o regime típico das zonas tropicais de baixa altitude, ou seja, verão chuvoso e inverno seco. A sucessão de periodos chuvosos faz-se elaramente marcando com nitidez duas estaç̃os: uma seca de inverno, que se estende de abril a setembro; e outra chuvosa de verão, que se estende de outubro a marco. o regime térmico acompanha de perto as estacóos do ano, variando, contudo, gradativamente: médias mensais elevadas no verão, ligeiro decréscimo no outono, valores mais baixos no inverno e acréscimo na primavera. As médias do inverno chegam em junho - julho a valores inferiores a $18^{\circ} \mathrm{C}$, superando $22^{\circ} \mathrm{C}$ em janeiro fevereiro.

Segundo o sistema de Köppen, é um clima do tipo Cwa, ou seja, mesotérmico de inverno seco.

\subsection{Espécies Estudadas}

As espécies objeto deste estudo foram: Eucalyptus grandis; Eucalyptus saligna; Eucalyptus urophylla; Eucalyptus alba e Eucalyptus spp, com diferentes idades, rotacão, adubação, espacamento e tratos culturais. 
Essas espécies foram plantadas em talhões com diferentes áreas de ocupação. A distribuicão desses tal hões dentro da área efetiva de plantio pode ser observada através da Figura 5 .

Ao todo foram estudados 32 talhôes, distribuidos da seguinte maneira: Eucalyptus grandis = 17; Eucalyptus saligna $=11 ;$ Eucalyptus urophylla $=4$.

\section{3. Cálculo do Volume de Madeira}

o valume cilindrico de madeira em pé foi obtido por meio de método tradicional.

No caso do Horto Santa Terezinha foi utilizado - método de amostragem, ou seja, dentro de cada talhão foram demarcadas algumas amostras. O número de amost.ras variou de e a: 8 por tal hão.

Demarcada a amostra, foi medido o DAP CDiâmetro a Altura do Peito $-1,30 \mathrm{~m}$ do solol de cada árvore que compöe a amostra, e a altura utilizada foi a altura média das 5 árvores dominantes.

Obtido o DAP, foi calculada a área basal (ab) $\left(\mathrm{m}^{2}\right)$, através da fórmula:

$$
a b=\frac{\pi}{4} \cdot D A P^{2}
$$

Em seguida, foi calculada a Area Basal Total $\left(A B_{t}\right)$, ou seja, $A B . N$; onde $N$ é o número de árvores com a mesma área basal. 
45.

Tendo-se a Área Basal Total, a Área Basal/ha (AB) foi obtida através de $A B_{t}$ multiplicada por $f$ cfator de $\operatorname{corrafão}=253$.

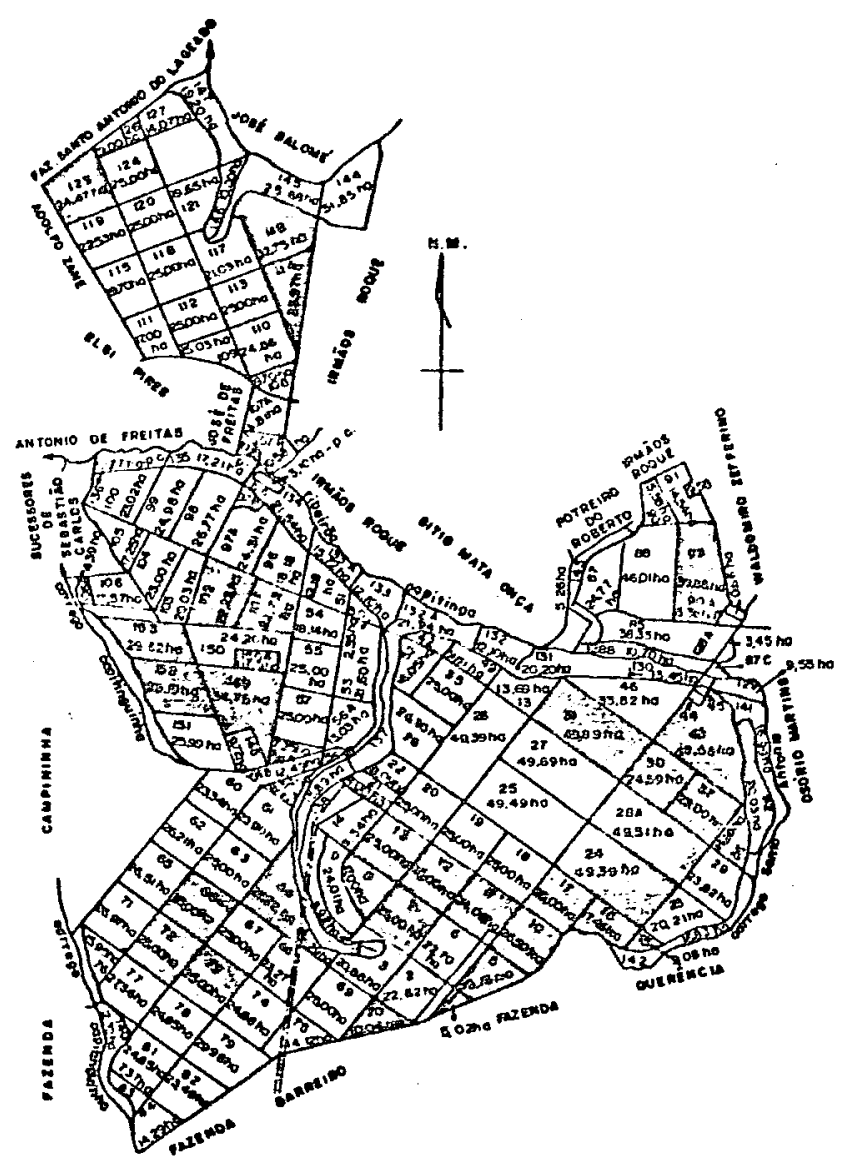

Fal Tãos estudados

Figura 5 - Distribuicão dos talhões de Eucalyptus erandis, Eucalyptus saliena, Eucalyptus urophylla. FONTE: CHAMPI ON PAPEL E CELULOSE S. A. 
Finalmente, foi calculado o Volume Cilindrico

CVOS por bectare:

$$
\mathrm{VC} / \mathrm{ha}=\frac{\pi}{4} \cdot \mathrm{AB} \cdot \mathrm{H}
$$

onde:

$$
\begin{aligned}
& \mathrm{VC}=\text { vol ume cilindrico }\left(\mathrm{m}^{3}\right) ; \\
& \mathrm{AB}=\text { área basal }\left(\mathrm{m}^{2}\right) \\
& H=\text { altura média }(\mathrm{m}) .
\end{aligned}
$$

Todas as medidas e cáloulos foram realizados em formulários padronizados.

\section{4. Fotografias Aéreas}

As fotografias aéreas utilizadas são provenientes de um vôo realizado em julho de 1982, pelo Instituto de Pesguisas Espaciais CINPE, vôo esse denominado "Conchal".

As fotografias utilizadas no estudo se apresentam na forma de transparências positivas infravermelhas coloridas, no formato $230 \mathrm{~mm} \times 230 \mathrm{~mm}$ com uma escala aproxi mada de $1: 10.000$.

- filme utilizado para obtencão das fotografias foi o Aerpchrome Infrared 2443, que apresenta alta estabilidade dimensional para levantamentos florestais conforme Tabela 1, que fornece algumas características de filmes infravermel hos. 
Tabela 1 - Características de alguns filmes Kodak para fotografias aéreas.

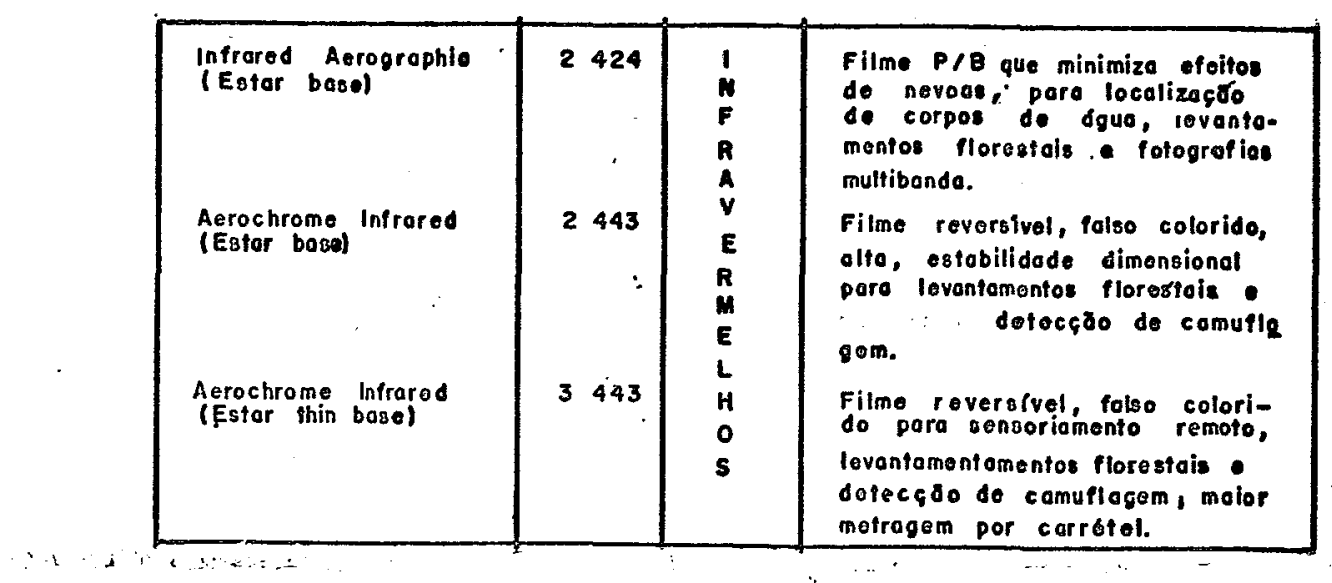

FONTE: GARCIA (1982).

3. 5. Densitômetro

Para efetuar as medidas de densidade óptica em transparências infravermel has coloridas foi utilizado o densitômetro de transmissão Macbeth ID 504 (Figura 6), equipado com filtros Wrattons ge (vermelho), 93 (verde), 94 (azul) e 10B (visual). A Figura 7 mostra a densidade $e$ a faixa de onda em que operam cada um dos filtros do aparelho.

Esse tipo de densitômetro apresenta três opcöes de abertura para passagem de luz, ou seja, abert.uras com diâmetro de $1 \mathrm{~mm}, 已 \mathrm{~mm} e 3 \mathrm{~mm}$.

o sistema de operacão desse aparelho é simples como pode ser visualizado atravós da representacão esquemática mostrada na Figura 8. 


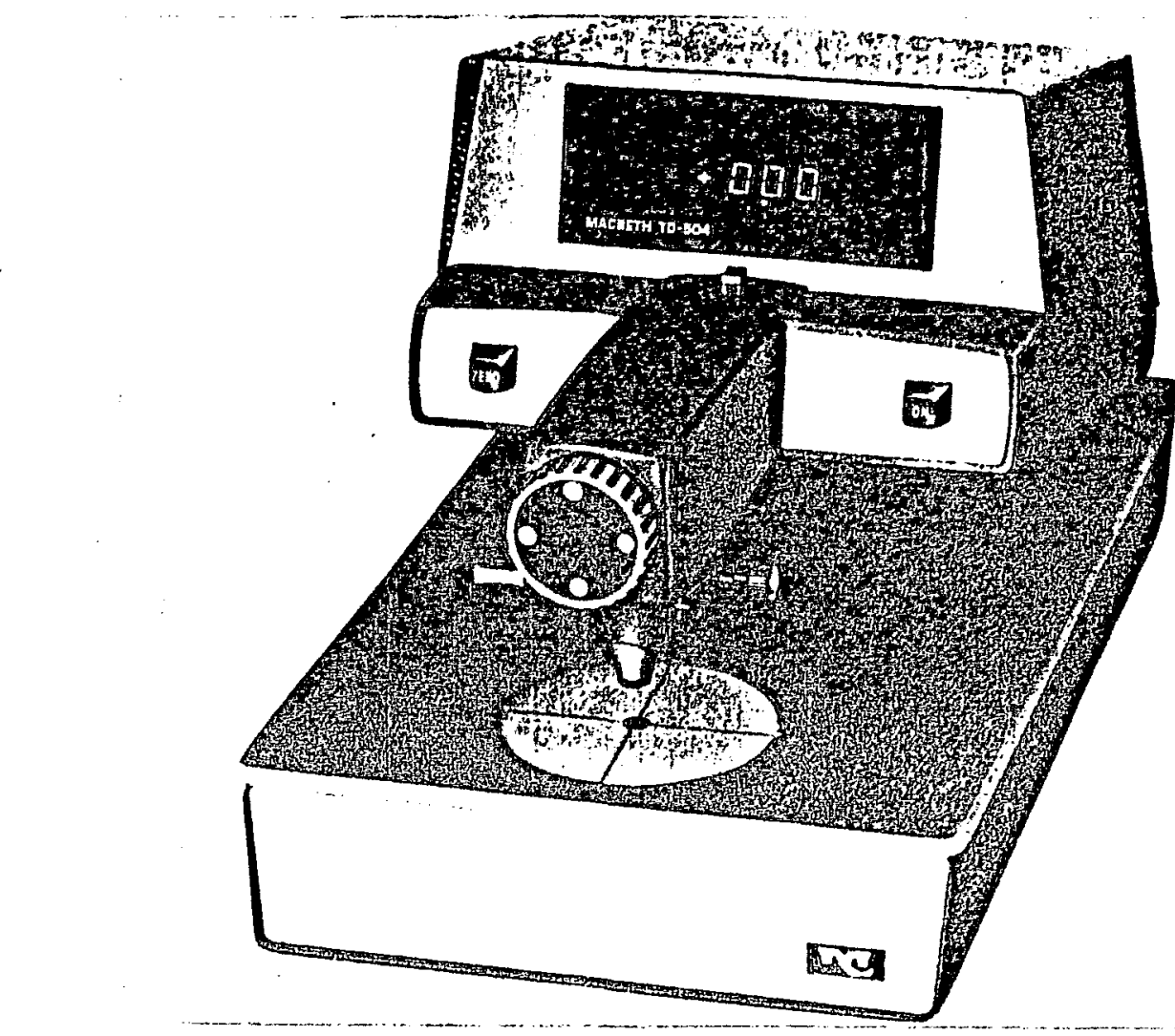

48.

Figura B - Densitômetro de Transmissão TD 504.

FONTE: MACBETH COLOR \& PHOTOMETRY DIVISION (1973).
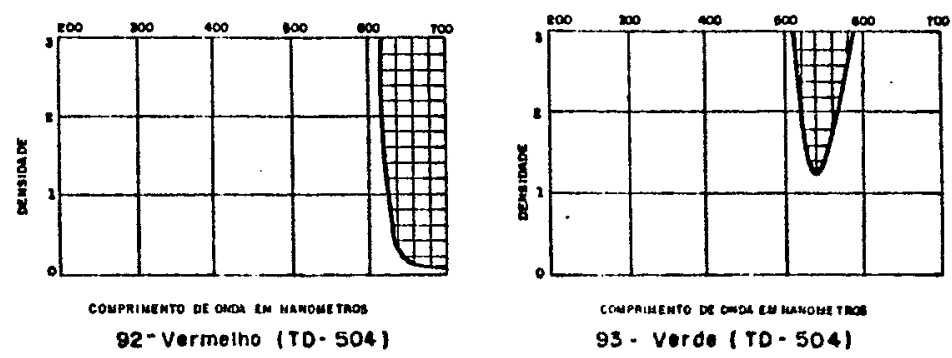

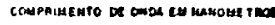

93. Vorde (TO- 504$)$
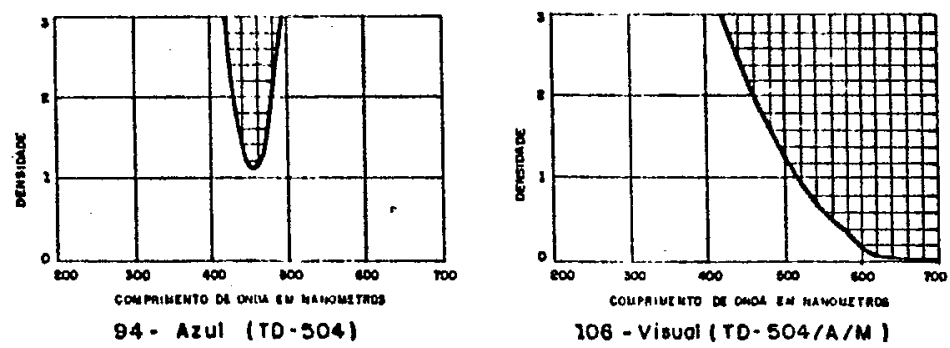

Figura 7 - Características dos filtros TD 504. FONTE: MACBETH COLOR \& PHOTOMETRY DIVISION ( 1973 ). 
49.

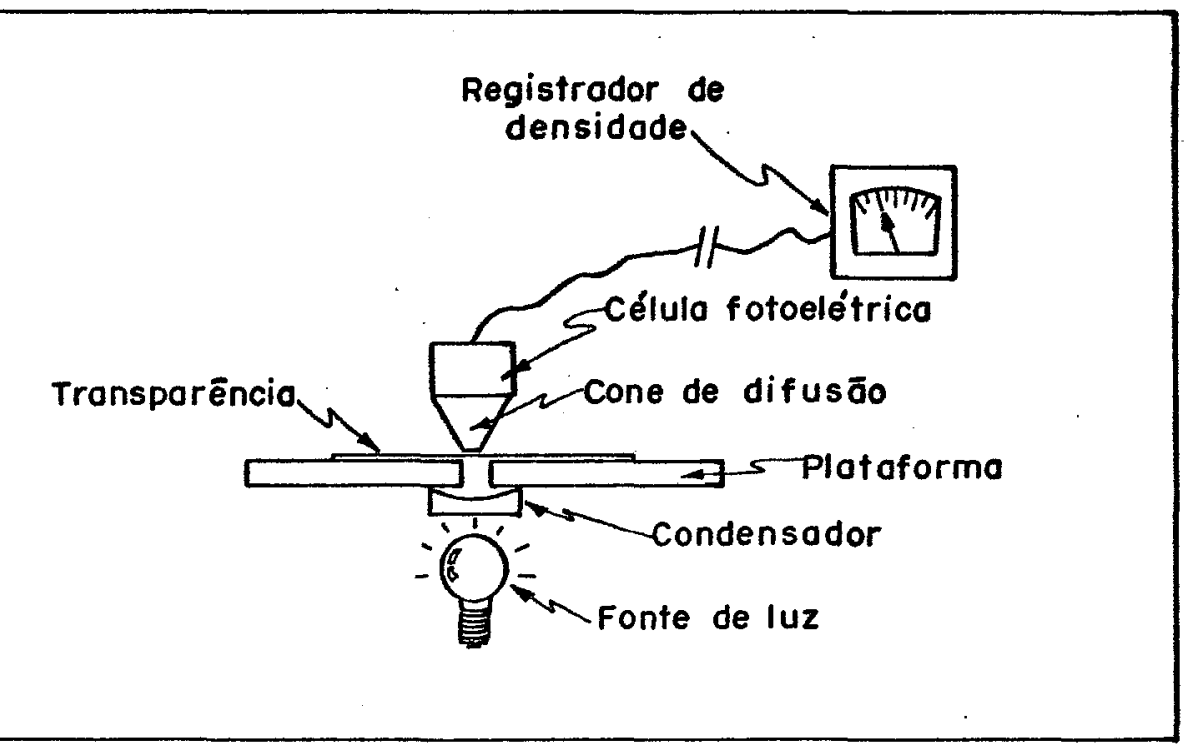

Figura 8 - Representação esquemática de um densitômetro de transmissão, tipo puntual .

FONTE: GARCIA (1982).

\subsection{Análise Densitométrica}

Para a realização das medidas de densidade óptica, tomaram-se as transparências com os respectivos taIhões já identificados e sobre elas foram fixadas fol has de acetato.

A funcão desses acetatos foi para que se pudesse formar uma malha quadriculada sobre cada talhão. As quadriculas foram delimitadas em $2 \mathrm{~mm} \times 2 \mathrm{~mm}$.

Tendo-se a malha quadriculada, procedeu-se às medicôes ponto a ponto. Cada ponto amostrado foi medido quatro vezes, ou seja, foram utilizados os quatro filtros do densitômetro, respectivamente azul, verde, vermelho e visual; e abertura utilizada foi a de diâmetro de $1 \mathrm{~mm}$. 
50.

Para os 32 talhões foram totalizadas cerca de 35. 290 medidas. O talhão de maior área apresentou s29 pontos amostrados o de menor área 196 pontos, para cada filtro.

\subsection{Análise Estatistica}

Para a análise dos dados foi usada a Regressão Linear Simples, uma vez gue a Análise de Regressão dentre outros propósitos, serve para descrever, controlar e predizer valores. Ou seja, a análise de regressão estuda a relação entre duas ou mais variáveis, de tal forma que uma variável pode sor predita por outra ou por outras.

$$
\begin{aligned}
& 0 \text { modelo estatistico } \\
& \qquad y=a+\beta K+\varepsilon
\end{aligned}
$$

onde:

y é o valor da variável resposta

$\alpha$ e $\beta$ são parâmetros desconhecidos

Xé uma constante conbecida (variável independente)

$\varepsilon$ é o erro aleatório $\sim$ NIID $\left(0, \alpha^{2}\right.$

foi utilizado para cada espécie em cada tipo de filtro, sendo definido como variável independente $(X)$ a densidade óptica e como variável dependente $(y)$ o voluméno de leituras - os valores de $\alpha$ e foram estimados através das fórmulas

$$
\begin{aligned}
& \hat{a}=\bar{y}-\hat{\beta} \bar{x} \\
& \hat{\beta}=\frac{\sum\left(x_{i}-\bar{x}\right)\left(y_{i}-\bar{y}\right)}{\sum\left(x_{i}-\bar{x}\right)^{2}}
\end{aligned}
$$


51.

\section{- Coeficiente de Determinacão}

E uma medida descritiva de associacão entro duas variáveis $\mathscr{R} \theta \mathrm{Y}$ denominada $\mathrm{R}^{2}$, tal que a sua variacăo * entre $0 \leq R^{2} \leq 1$. Ou seja, o grau de associacão pode captar informacão do tipo se uma dada relacão de regressão é út.il numa particular aplicacão.

Podemos interpretar $\mathrm{R}^{2}$ crmo uma reducăo proporcional da variacão total, associada ao uso da variável independente 2 . E os 1 imites de $R^{2}$ ocorrem quardo:

a) $R^{2}=1$ : todos os pontos observados coincidem com a reta de regressão.

b) $R^{2}=0$ implica $\hat{\beta}=0$ e acontece quando năo existe re1 ação entre $2 R \odot y$.

Na prática, $R^{2}$ não é exatamente 0 ou 1 e sim valores entre esses 11 mites. 
se.

\section{RESURt ADOS E DI SCUSSĂO}

Os resultados das medicóes de densidade óptica para os talhões de Eucalyptus grandis, Eucalyptus saligna, Eucalyptus urophylla, encontram-se nas Tabelas. 2, 3, e 4, respecti vamente. Nessas tabelas são apresentadas as leituras efetuadas com os quatro filtros - azul, verde, vermelbo e visual; sendo que cada filtro determina a composicão espectral da 1 uz incidente na imagem da qual se deseja avaliar a densidade óptica.

A densidade óptica foi determirada pela composicão e quantificacão da luz transmitida através da imagem. A luz resultante, por exemplo, do filtro vermelho, com composiçăo espectral na faixa do vermelho, ao incidir em uma i magem de matiz também vermelbo, produzirá altos valores de transmitância e, consequentemente, baixos valores de densidade.

Nas referidas tabelas são apresentados, também, o vol ume cilindrico em metros cúbicos, o número de pontos medidos e o volume por quadricula para cada tal hão estudado. As leituras de densidade $D$ apresentadas foram multiplicadas pelo fator 100 , conforme RIE (1968). 
53.

Uma das preocupacỗes deste trabalho foi a de ajustar equações de regressão para obtencão do volume cilindrico, atravós da densitometria, para três espócies de eucalipto e, consequentemente, que se conseguisse rapidez e precisão. Para isso optou-se por trabalhar com fotografias aéreas infravermel has coloridas que, do acordo com ANSON (1968), GARCIA (1975) E STHEPHENS (1976), são as quo fornecem maior número de informacóes, dentro os tipos de fotografias áreas.

As medidas densitométricas em tal hôes homogêneos, ou seja, talhões em que as árvores já atingiram uma altura e um diâmetro suficientes para a não exposicão do so10, mostraram-se com valores menores no filtro vermelho em relacão aos demais filtros. Isto está de acordo com o que BROONER \& SIMONETT (1971) afirmam, ou seja, de que a tonalidade magenta que caracteriza as fotografias do reflorestamento são resultado da alta reflexão no infravermelho.

- mesmo não ocorseu para os talhốes de números: $102,149,152$ e 153 de Eucalyptus grandis o 4 de Eucalyptus saliena onde houve corte raso e as talhões se apresentaram com menor valor de densidade no filtro verde, resultante do predominio dessa tonalidade no matiz, devido à grande contribuicão da cor avermelhada do solo, coberto ainda parcialmente pelo eucal ipto em brotação.

Circunstâncias de época e local, como data de plantio ou de corte anterior, tratos culturais diferenciados, são alguns dos fatores que podem influir na tonalidade 
54.

do eucalipto en fotografias infravermel has coloridas.

Nas Tabelas 5, 6, 7, 8 e encontram-se os valores da razão $1 / D$ para os quatro filtros e 1 f colume no leituras) para o Eucalyptus grandis, Eucalyptus saligna e Eucalyptus urophylla, resperti vamente.

\section{1. Eucalyptus grandis}

No estudo da relacăo entre as variáveis densidade $(X)$ volume (Y) foram obtidas equacóes do regressăes para cada tipo de filtro, encontrando-se as seguintes equaç̃es, o sous respectivos $R^{2}$.

Tipo de filtro

Azul

Verde

Vermel ho

Visual
Equacóses

$$
Y=0,02445+0,00541 X
$$$$
Y=0,07797+0,00483 \mathrm{X}
$$$$
Y=2,59030-0,02518 \mathrm{X}
$$$$
Y=0,19049+0,00476 X
$$

$$
R^{2}
$$

0,0508

0,0608

0,3591

0,0254

As figuras 9, 10, 11 e 12 contêm o valor observado e os valores estimados de densidade óptica (por tipo de filtro). Observa-se gue os coeficientes de determinação encontrados para cada regressão estão próximos de zero o que indica que a relacão de regressão com essas variáveis não é a mais apropriada, o que é ilustrado também pelas figuras.

Com o objetivo de melhorar essa relacão foram feitas transformaçốes nas variáveis $X \quad C=1 / X)$ $Y \quad S=1 / Y)$ obtidas novas equaç̃os de regressões, indicadas a seguir, 
55.

bom como as Figuras 13, 14, 15, $16 \odot 17$.

Tipo de filtro

Equacőes

$R^{2}$

Azul

$1 / Y=0,23453+289,3404(1 / X)$

0,7413

Verde

$1 / Y=0,14345+251,49553(1 / X)$

0,8735

Vermel ho $(\mathrm{Cl} .1)$

$1 / Y=3,21027-158,3998(1 / X)$

0,5942

Vermel ho (C. 2)

$1 / \mathrm{Y}=22,68715-1349,7258(1 / \mathrm{K})$

0,5093

Visual

$1 \gamma=-1,07000+345,2489(1 / X)$

0,8723

Observa-se que, fom as transformacöes nas variáveis, os valores de $R^{2}$ para os filtros: azul, verde $e v i-$ sual ficaram superiores a 0,70 (valor próximo de 1$)$ explicando assim uma relacão inversa entre volume e densidade. No filtro vermelho, optou-se por dividir o conjunto de dados em dois grupos (maiores e menores valores) uma vez que o grupo todo na regressão, apresentava $R^{2}=0,09$, ainda assim, esse filtro foi o único que, mesmo com a transformação, apresentou $R^{2}$ relati vamente baixo.

\section{2. Eucalyptus saliena}

No estudo da relacão entre as variáveis densidade $(X)$ e volume (Y) foram obtidas equacões de regressões entre essas variáveis para cada tipo de filtro, obtendo-se as seguintes equacóos e seus respectivos $R^{2}$ : 
56.

Tipo de filtro

Equacőes

$R^{2}$

Azul

$Y=-0,33495+0,006840 X$

0,3180

Verde

$Y=0,22001+0,003198 \mathrm{X}$

0.3137

Vermelho

$Y=-0,14945+0,01007 \mathrm{X}$

0,1638

Visual

$Y=-0,32779+0,00803 X$

0,3482

$\ominus$ as Figuras 18, 19, 20@21.

Observa-se que os coeficientes de determinacão encontrados para cada regressão são bai xos, a que indica que a relacão de regressăo entre essas variáveis não é a mais apropriada.

Com o objetivo de melhorar essa relacão, buscando uma maior explicacăo e estudando-se a relacão entre a média e a variância dos dados, optou-se por uma transformacão de variáveis $(X) Y)$ do tipo inversa, ou seja $1 / X$ e $1 / Y$. Novamente, agora com os dados transformados, obtiveram-se as equaçöes de regressão indicadas a seguir, bem como as Figuras $22,23,23,25=28$.

Iipo de filtro

Eq̨uações

$R^{2}$

Azul

$1 / Y=-0,4824+341,3013(1 / x)$

0,6915

Verde

$1 / Y=0,2091+249,3252(1 / X)$

0,7581

Vermel ho (C.1)

$1 / Y=-0,9467+172,4991(1 / \%)$

0,7398

Vermel ho (C. 2)

$1 / Y=10,8785-612,0092(1 / x)$

0,7768

Visual

$1 / Y=-0,9516+348,6259(1 / X)$

0,7520

Observa-se que, com as transformacões das variáveis, os valores de $R^{2}$ para os filtros: azul, vorde $e$ visual aumentaram consideravel mente em relacão a primoira aná- 
Iise feita. Quanto ao filtro vermelho, observa-se um aumento substancial de $R^{2}$, quando o conjunto de dados foi dividido em dois, uma vez que para o conjunto total o valor foi de $0,0322$.

\section{3. Eucalyptus urophylla}

No estudo da relacão entre as variáveis densidade $(X)$ e volume (Y) foram obtidas equacóes de regressónes entre essas variáveis para cada tipo de filtro, e encontrou-se as seguintes equacões e suas respectivas Figuras 27, 28, $29=30$

Tipo de filtro

Equaçồ

$\mathrm{R}^{2}$

Azul

$Y=0,14630+0,00477 X$

0,1112

Verde

$Y=-0,3498+0,00667 \mathrm{X}$

0,2433

Ver mel ho

$Y=0,52459+0,00483 \mathrm{X}$

0,0608

Visual

$Y=-0,15076+0,00765 X$

0,1562

Observa-se que o coeficiente de determinacão encontrado para cada regressão é baixo, o que indica que a relação de regressăo entre essas variáveis não é a mais apropriada.

Como nos casos anteriores, optou-se pela transformacão do tipo inversa $(1 / X$ e $1 / Y)$. Feitas as transformaçöes, resultaram as seguintes equaçôes, bem como as Figuras $31,32,33 \odot 34$. 
58.

Tipo de filtro

Equaç̃̃es

$R^{2}$

Azul

$1 / Y=-1,24968+408,4493(1 / X)$

0,4049

Verde

$1 / Y=-1,82327+583,8834(1 / X)$

0,6148

Vermelho

$1 / Y=-0,4423+141,20535(1 / X)$

0,3221

Visual

$1 / Y=-1,7719+424,1275(1 / X)$

0,4873

Observa-se que, com as transformaç̃os das variáveis, os valores de $R^{2}$ apesar de sofrerem um aumento Comparativamento aos casos anteriores?, ainda assim se apresentam baixos, o que talvez possa ser explicado pela guantidade pequena de informậ̃os (4 talhốs).

Os valores de $\mathbb{K}^{2}$ tanto para o $E$. erandis como para o E. saliena, nos filtros - azul, verde, vermelho e visual, com excecão do vermelho para $E$. grandis tiveram valores acima de 0,69 . Estes valores vêm de encontro ads resultados obtidos por MACLEAN \& MARTIN (1985), ou seja, valores para $K^{2}$ de $0, E 7$ - 0,79. E, quando trabalharam com micro-aberturas, para áreas relativamente pequenas, conseguiram valores para $R^{2}$ de $0,8 E-0,88$.

Os valores de $R^{2}$ fara o filtro vermelso no $E$. grandis não responderan da mesma maneira que os demais filtros quando se usou a transformacão, mesmo separando os dados em 2 conjuntos; a não resposta desse filtro pode ser explicada da seguinte maneira:

- observando-so a disposicão dos talhöes dentro do reflorestamento constatou-se que 4 talhões $(102,149,152$ e 1533, como pode ser observado na figura 5, estão próximos uns dos outros, respondendo de maneira semelhante às leitu- 
59.

ras $\theta$, que o tal hão 101 do $E$. saligna também está no mesmo bloco apresentou o mesmo comportamento;

- para o E. saliena a não influência desso valor deve-se, provavelmente, ao fato de ser somente um talhão com esse tipo de resposta dentre os 11 analisados;

- já para o E. grandis são 4 talhões dentre os 17 , com a ressalva de que o tal hão 114, apesar de não pertencer ao mesmo bloco, também apresentou baixos valores de leituras em relacão aos demais;

- as prováveis causas podem ser: problema de solo, tratos culturais, dpencas, estresse hibrico, a posicão em que a fotografia foi tirada ou ainda o processamento da mesma, salientando que estes fatores influenciam na resposta espectral da planta.

Vale ressaltar que se considerou baixos os valores de $R^{2}$ para o filtro vermelho do $E$. grandis $\theta$, também, para os do E. urophylla, sendo que neste foram baixas para todos os filtros, pelo fato de ter-se encontrado valores acima de 0,70 para os demais filtros, tanto para o $E$. Erandis como para o E. saliena.

Cumpre-nos ressaltar que conforme foi destacado na revisão de literatura, não se encontrou nenhum trabaIho especifico sobre densitometria de povoamentos de eucaliptos en fotografias infravermelhas coloridas, com ênfase na relação volume densidade óptica, de modo que não são disponiveis resultados que possam servir de termo de comparacãa para os obtidos no presente trabalho. 
ธิ.

Tabela 2. Donsitometria dos talhões para Eucalyptus grandis.

\begin{tabular}{|c|c|c|c|c|c|c|c|}
\hline \multirow{2}{*}{$\begin{array}{l}\text { NÚMERO } \\
\text { DOS } \\
\text { IALHÖES }\end{array}$} & & FILIROS & $C D \times 100$ & & \multirow{2}{*}{$\begin{array}{l}\text { YOLUME } \\
\text { CILÍN- } \\
\text { DRICO } \\
\left(\mathrm{m}^{3}\right)\end{array}$} & \multirow{2}{*}{$\begin{array}{c}\text { NÚMERO } \\
\text { DE } \\
\text { LEI TURAS }\end{array}$} & \multirow{2}{*}{$\begin{array}{l}\text { VOLUME } \\
\text { NI DE } \\
\text { LEITURAS }\end{array}$} \\
\hline & AZUL & VERDE & VERMELHO & VISUAL & & & \\
\hline
\end{tabular}

\begin{tabular}{|c|c|c|c|c|c|c|c|}
\hline 43 & 167,19 & 107,51 & 98,72 & 138,13 & 330,17 & 480 & 0,68785 \\
\hline $2 B$ & 139,64 & 152,68 & 77,94 & 120,84 & 317,80 & 465 & 0,68301 \\
\hline o7 & 144,17 & 170,11 & 70,71 & 126,16 & 165,16 & 225 & 0,73849 \\
\hline 15 & 134,62 & 140,27 & 63,14 & 108,08 & 307,45 & 72 & 4,27014 \\
\hline 114 & 90,24 & 79,95 & 88,83 & 80,22 & 15,37 & 210 & 0,07319 \\
\hline $89 \mathrm{~B}$ & 150,44 & 149,21 & 120,23 & 137,90 & $1 \mathrm{~B}, 9 \mathrm{~B}$ & 248 & 0,08847 \\
\hline 92 & 167,34 & 182,81 & 84,53 & 138,12 & 141,27 & 162 & 0,87204 \\
\hline $64 \mathrm{~A}$ & 125,44 & 129,01 & 65,74 & 103,30 & 100,16 & 262 & 0,41664 \\
\hline $54 \mathrm{~B}$ & 136,34 & 147,41 & 59,63 & 109,40 & 109,16 & 72 & 1,51611 \\
\hline 102 & 62,57 & 57,19 & 97,03 & 64,23 & 69,82 & 271 & 0,25764 \\
\hline 149 & 68,02 & 55,44 & 76,89 & 59,09 & 78,07 & 376 & $0,207 \mathrm{~B} 3$ \\
\hline 152 & 54,30 & 49,84 & 77,05 & 55,37 & 61,10 & 323 & 0,18916 \\
\hline 153 & 63,15 & 48,66 & 83,44 & 53,65 & 55,23 & 311 & 0,17759 \\
\hline 60 & 137,56 & 143,13 & 76,24 & 115,42 & 134,71 & 256 & 0,52621 \\
\hline 70 & 155,74 & 194,91 & 68,83 & 131,80 & 48,36 & 98 & 0,49347 \\
\hline 72 & 177,00 & 174,91 & 76,36 & 130,50 & 105,14 & 256 & 0,41070 \\
\hline 73 & 156,60 & 154,10 & 58,55 & 115,96 & 92,23 & 256 & 0,36027 \\
\hline
\end{tabular}


61.

Tabela 3. Densitometria dos talhónes para Eucalyptus saligna.

\begin{tabular}{|c|c|c|c|c|c|c|c|}
\hline \multirow{2}{*}{$\begin{array}{l}\text { NÜMERO } \\
\text { DOS } \\
\text { TALHÖES }\end{array}$} & \multirow[b]{2}{*}{ AZUL } & FILIROS & \multicolumn{2}{|l|}{$C D \times 1003$} & \multirow{2}{*}{$\begin{array}{l}\text { VOLUME } \\
\text { CILIN- } \\
\text { DRICO } \\
\left(\mathrm{m}^{3}\right)\end{array}$} & \multirow{2}{*}{$\begin{array}{c}\text { NÚMERO } \\
\text { DE } \\
\text { LEI TURAS }\end{array}$} & \multirow{2}{*}{$\begin{array}{l}\text { VOLUME } \\
\text { NS DE } \\
\text { LEI TURAS }\end{array}$} \\
\hline & & VERDE & VERMELHO & VISUAL & & & \\
\hline 24 & 144,84 & 136,31 & 83,63 & 111,10 & 175,46 & 328 & 0,33231 \\
\hline 30 & 171,61 & 178,59 & 93,19 & 139,88 & 240,23 & 256 & 0,93840 \\
\hline 05 & 145,09 & 173,83 & 73,73 & 132,84 & 121,37 & 238 & 0,50996 \\
\hline 101 & 66,15 & 54,48 & 90,93 & 61,94 & 51,60 & 237 & 0,21772 \\
\hline 42 & 215,74 & 289,91 & 127,73 & 193,60 & 29,52 & 49 & 0,50245 \\
\hline $28 \mathrm{~A}$ & 154,30 & 140,91 & 70,04 & 118,29 & 207,63 & 529 & 0,39250 \\
\hline $28 B$ & 154,84 & 179,21 & 85,95 & 134,20 & 309,58 & 233 & 1,32867 \\
\hline 52 & 201,14 & 260,51 & 111,83 & 175,10 & 249,85 & 140 & 1,78464 \\
\hline 12 & 143,48 & 165,42 & 69,45 & 125,48 & 170,15 & 256 & 0,66465 \\
\hline 16 & 145,84 & 144,11 & 68,58 & 112,40 & 84,63 & 170 & 0,49782 \\
\hline 17 & 163,64 & 190,61 & 81,37 & 137,90 & 182,36 & 253 & 0,72079 \\
\hline
\end{tabular}


62.

Tabela 4. Densitometria dos tal hões para Eucalyptus urophylla.

\begin{tabular}{|c|c|c|c|c|c|c|c|}
\hline \multirow{2}{*}{$\begin{array}{l}\text { NÜMERO } \\
\text { DOS } \\
\text { TALHÖES }\end{array}$} & \multicolumn{4}{|c|}{ FILTROS CD X 1002} & \multirow{2}{*}{$\begin{array}{l}\text { VOLUME } \\
\text { CILIN- } \\
\text { DRICO } \\
\mathrm{cm}^{3} \mathrm{~S}\end{array}$} & \multirow{2}{*}{$\begin{array}{c}\text { NÚMERO } \\
\text { DE } \\
\text { LEI TURAS }\end{array}$} & \multirow{2}{*}{$\begin{array}{l}\text { VOLUME } \\
\text { NQ DE } \\
\text { LEI TURAS }\end{array}$} \\
\hline & AZUL & VERDE & VEKMELHO & VISUAL & & & \\
\hline 31 & 205,24 & 229,11 & 115,53 & 189,30 & 239,39 & 240 & 0,99740 \\
\hline 13 & 159,63 & 191,70 & 79,19 & 138,51 & 307,45 & 72 & 1,42346 \\
\hline 08 & 166,85 & 199,11 & 86,03 & 145,50 & 133,40 & 150 & 0,88933 \\
\hline 11 & 141,00 & 159,53 & 70,03 & 121,20 & 116,27 & 240 & 0,48446 \\
\hline
\end{tabular}

Tabela 5. Inverso da densitometria para talhóes de Eucalyptus Erandis.

\begin{tabular}{|c|c|c|c|c|c|}
\hline \multirow{3}{*}{$\begin{array}{l}\text { NÜMERO } \\
\text { DOS } \\
\text { TALHÖES }\end{array}$} & \multicolumn{4}{|c|}{ FILTROS $(1 / D)$} & \multirow{3}{*}{$\frac{1}{\text { NO LELUME }}$} \\
\hline & AZUR & VERDE & VERMELHO & VI SUAL & \\
\hline & ALUL & VERDE & VENATELSW & & \\
\hline 43 & 0,0059812 & 0,0059598 & 0,0103391 & 0,0072396 & 1,45380 \\
\hline 26 & 0,0071613 & 0,0065496 & 0,0128304 & 0,0082754 & 1,46411 \\
\hline O7 & 0,0089363 & 0,0058785 & 0,0141423 & 0,0079264 & 1,35412 \\
\hline 92 & 0,0059759 & 0,0054702 & 0,0118301 & 0,0072401 & 1,14674 \\
\hline G4A & 0,0079719 & 0,0077513 & 0,0152114 & 0,0096805 & 2,40015 \\
\hline $64 \mathrm{~B}$ & 0,0073346 & 0,0067838 & 0,0167701 & 0,0091408 & 0,65958 \\
\hline 102 & 0,0159821 & 0,0174850 & 0,0103061 & 0,0155690 & 3,88141 \\
\hline 149 & 0,0147016 & 1,0180375 & 0,0130395 & 0,0169233 & 4,81619 \\
\hline 152 & 0,0184162 & 0,0200642 & 0,0129786 & 0,0180003 & 5,28642 \\
\hline 153 & 0,0158353 & 0,0205508 & 0,0119847 & 0,0186359 & 5,63100 \\
\hline 68 & 0,0072698 & 0,0089867 & 0,0131165 & 0,0086640 & 1,90038 \\
\hline 70 & 0,0004210 & 0,0051306 & 0,0145285 & 0,0075873 & 2,02647 \\
\hline 72 & 0,0056478 & 0,0057172 & 0,0130959 & 0,0076628 & 2,43485 \\
\hline 73 & 0.0063857 & 0,0064893 & 0,0170794 & 0,0086237 & 2,77567 \\
\hline
\end{tabular}


63.

Tabela 6. Inverso da densitametria para filtro vermel ho, agrupado em 2 conjuntos, para Eucalyptus erandis.

\begin{tabular}{|c|c|c|c|c|}
\hline \multirow{3}{*}{$\begin{array}{l}\text { NUMEFO } \\
\text { DOS } \\
\text { TALHÖES }\end{array}$} & \multicolumn{2}{|c|}{ CONJUNTO 1} & \multicolumn{2}{|c|}{ CONJUNTO 2} \\
\hline & 1 D YFEMEI HO & VOLUME & $1 \mathrm{D}$ VFEMFLHO & VOLUME' \\
\hline & 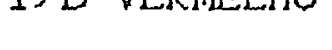 & NQ LEI TURAS & DU D VENDELLTH & NQ LEITURAS \\
\hline 1 & 0,0103391 & 1,45381 & 0,0112575 & 13,6631 \\
\hline 2 & 0,0128304 & 1,46411 & 0,0083174 & 14,5476 \\
\hline 3 & 0,0141423 & 1,35411 & 0,0152114 & 2,4002 \\
\hline 4 & 0,0158378 & 0,23418 & 0,0103061 & 3,8814 \\
\hline 5 & 0,0118301 & 1,14674 & 0,0130395 & 4,8163 \\
\hline 6 & 0,0167701 & 0,65958 & 0,0129786 & 5,2865 \\
\hline 7 & & & 0,0119847 & 5,6309 \\
\hline 8 & & & 0,0131165 & 1,9004 \\
\hline 9 & & & 0,0145285 & 2,0244 \\
\hline 10 & & & 0,0130959 & 2,4349 \\
\hline 11 & & & 0,0170794 & 2,7757 \\
\hline
\end{tabular}


64.

Tabela 7. Inverso da densidade para talhões de Eucalyptus saliena.

\begin{tabular}{|c|c|c|c|c|c|}
\hline \multirow{2}{*}{$\begin{array}{l}\text { NÚMERO } \\
\text { DOS } \\
\text { TALHǑES }\end{array}$} & \multicolumn{4}{|c|}{ FILTROS $(1 / D)$} & 1 \\
\hline & AZUL & VERDE & VERAELHO & VISUAL & $\begin{array}{l}\text { VOLUME } \\
\text { NQ LEITURAS }\end{array}$ \\
\hline 24 & 0,0089042 & 0,0073362 & 0,0119574 & 0,0090009 & 3,00923 \\
\hline 30 & 0,0058272 & 0,0055994 & 0,0107308 & 0,0071490 & 1,06565 \\
\hline OS & 0,0068923 & 0,0057527 & 0,0135630 & 0,0075279 & 1,96095 \\
\hline 101 & 0,0151172 & 0,0183554 & 0,0109975 & 0,0151447 & 4,59302 \\
\hline 42 & 0,0046352 & 0,0034493 & 0,0078290 & 0,0051653 & 1,65989 \\
\hline $28 A$ & 0,0064809 & 0,0070967 & 0,0142776 & 0,0084538 & 2,54780 \\
\hline $28 \mathrm{~B}$ & 0,0064583 & 0,0055800 & 0,0116347 & 0,0074516 & 0,75263 \\
\hline 52 & 0,0049717 & 0,0038372 & 0,0089421 & 0,0057110 & 0,56034 \\
\hline 12 & 0,0069896 & 0,0050089 & 0,0143988 & 0,0079894 & 1,50455 \\
\hline 10 & 0,0068588 & 0,0069391 & 0,0145815 & 0,0088968 & 2,00874 \\
\hline 17 & 0,0081110 & 0,0052463 & 0,0122895 & 0,0072518 & 1,38737 \\
\hline
\end{tabular}


85.

Tabela 8. Inverso da densitometria para filtro vermelho, agrupado em 2 conjuntos, para Eucalyptus saligna.

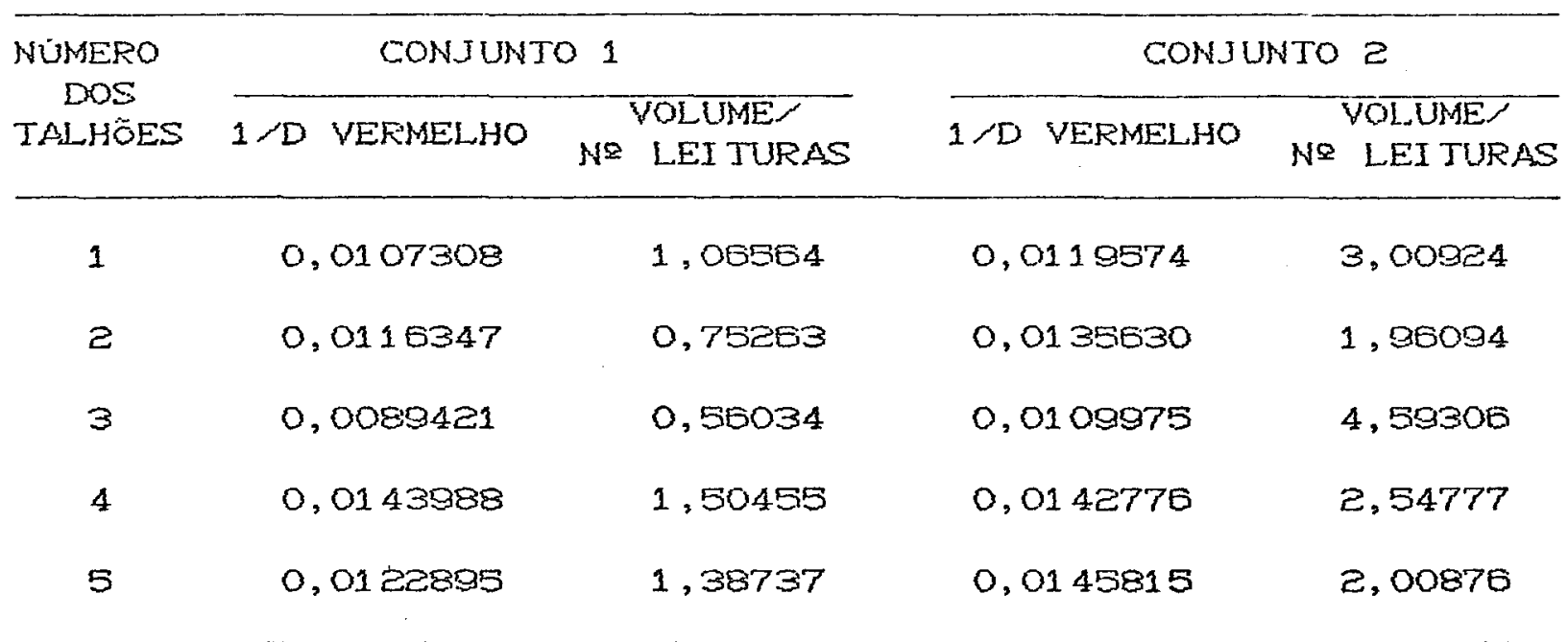

Tabela 9. Inverso da densitometria para talhóes de Eucalyptus urophylla.

\begin{tabular}{|c|c|c|c|c|c|}
\hline \multirow{3}{*}{$\begin{array}{l}\text { NÚMERO } \\
\text { DE } \\
\text { TALHÕES }\end{array}$} & \multicolumn{4}{|c|}{ FILTROS $(1 / D)$} & \multirow{3}{*}{$\frac{1}{\text { NOLUME }}$} \\
\hline & AZUL & VERDE & VERMELHO & VI SUAL & \\
\hline & & & & & \\
\hline $31 \mathrm{~B}$ & 0,0048723 & 0,0043647 & 0,0086558 & 0,0059087 & 1,00255 \\
\hline 13 & 0,0062645 & 0,0052165 & 0,0126279 & 0,0072197 & 0,70251 \\
\hline 08 & 0,0059934 & 0,0050223 & 0,0116239 & 0,0068729 & 1,12444 \\
\hline 11 & 0,0070892 & 0,0052684 & 0,0142796 & 0,0082508 & 2,00415 \\
\hline
\end{tabular}


BB.

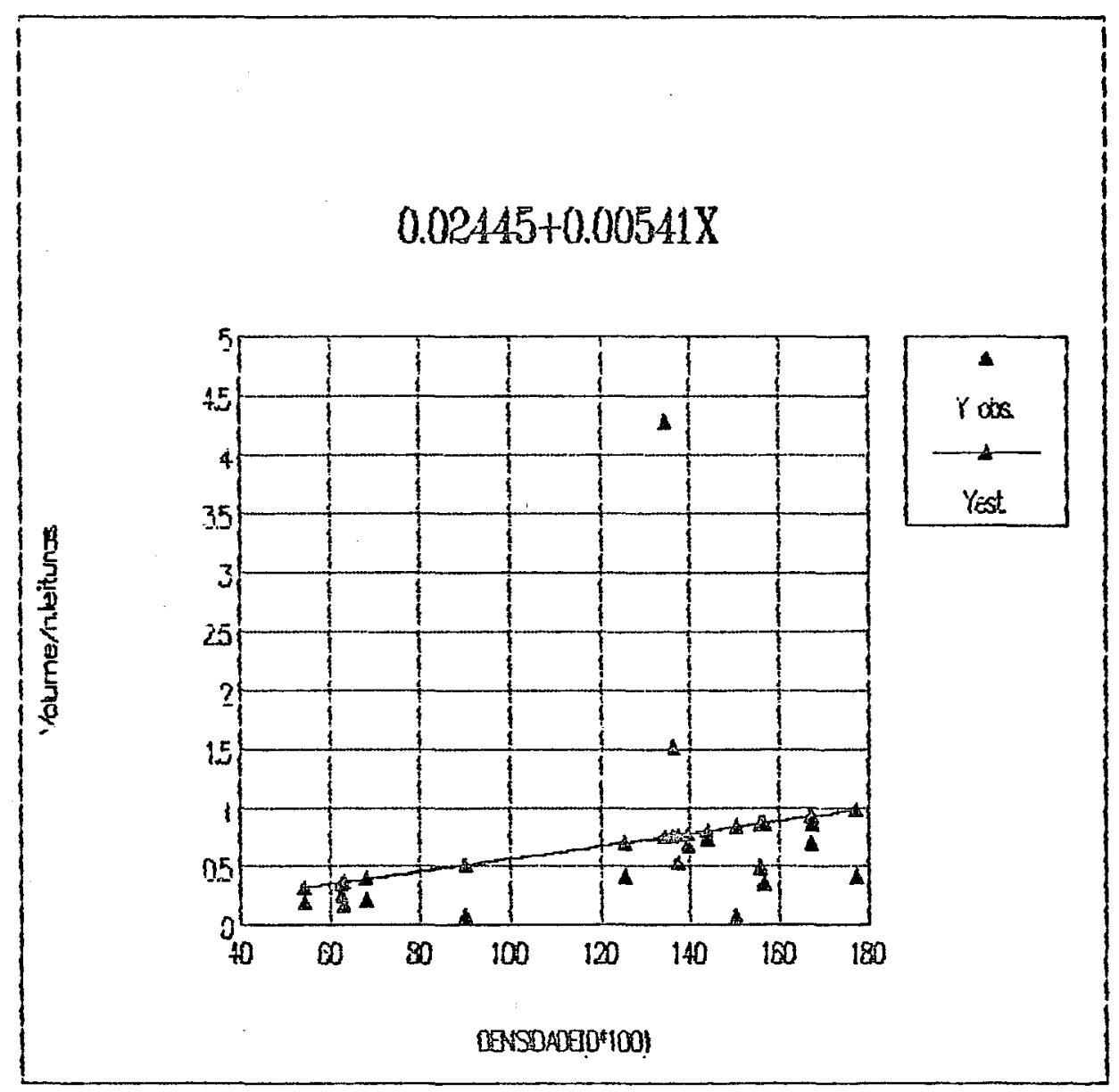

Figura 9. Desempenho do volume/ne leituras para filtro azul em relacão a densidade óptica para Eucolyptus Erandis. 
67.

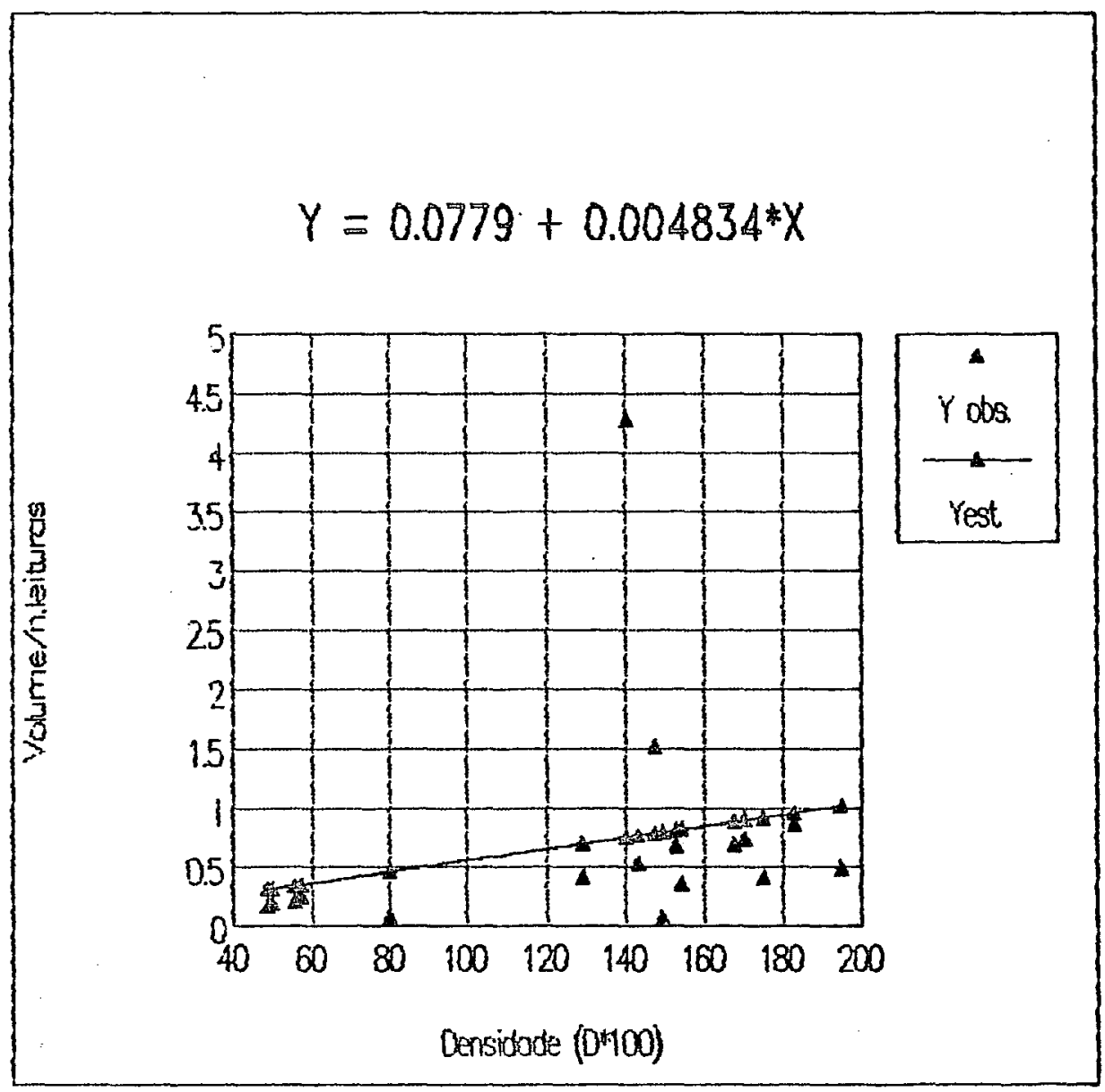

Figura 10. Desempenho do volumerno leituras para filtro verde em relacão a densidade óptica para Euculyptus grandis. 
68.

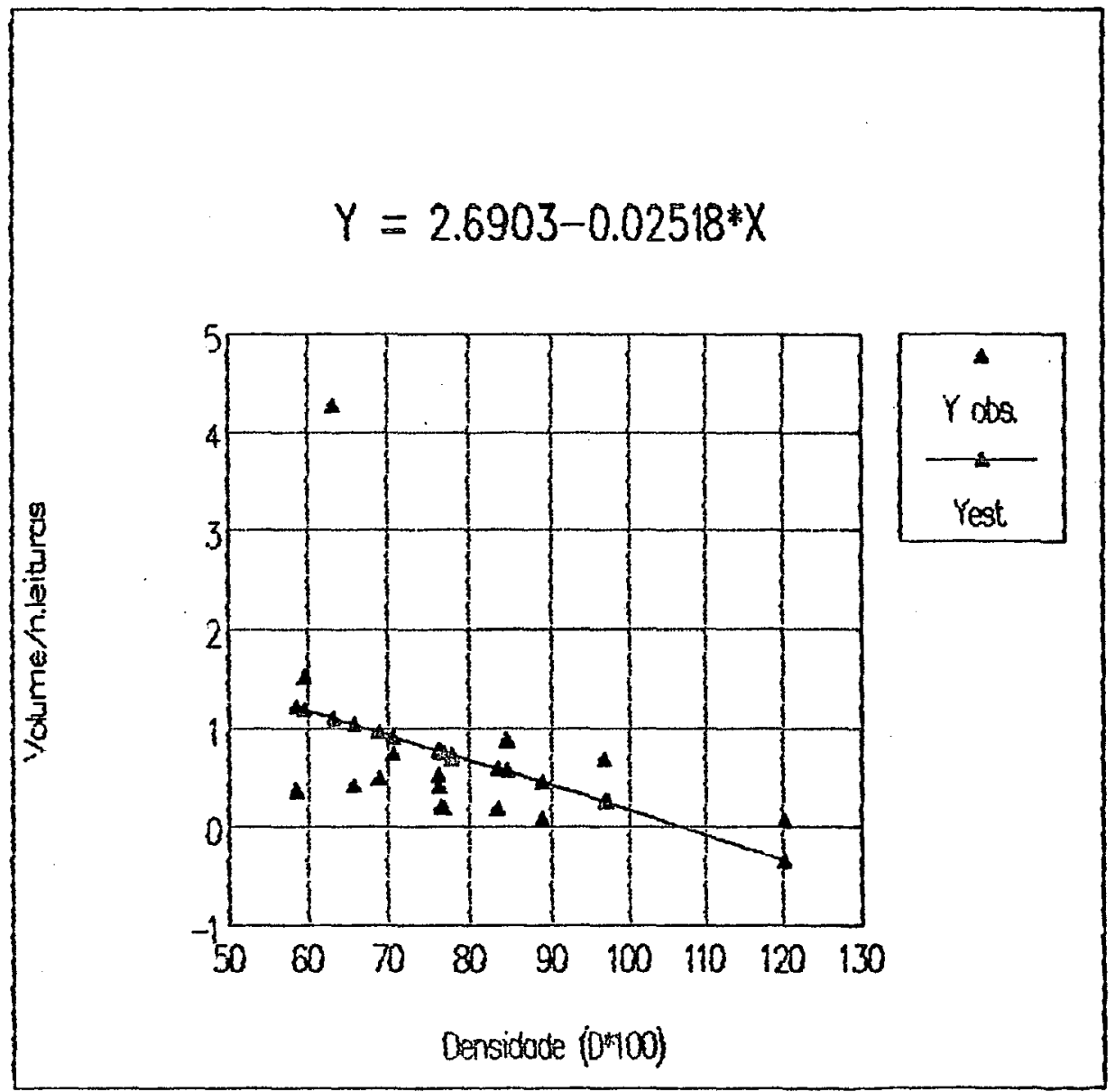

Figura 11. Desempenho do volume/ne leituras para filtro vermelho em relação a densidade óptica para Eucalyptus Erandis. 
69.

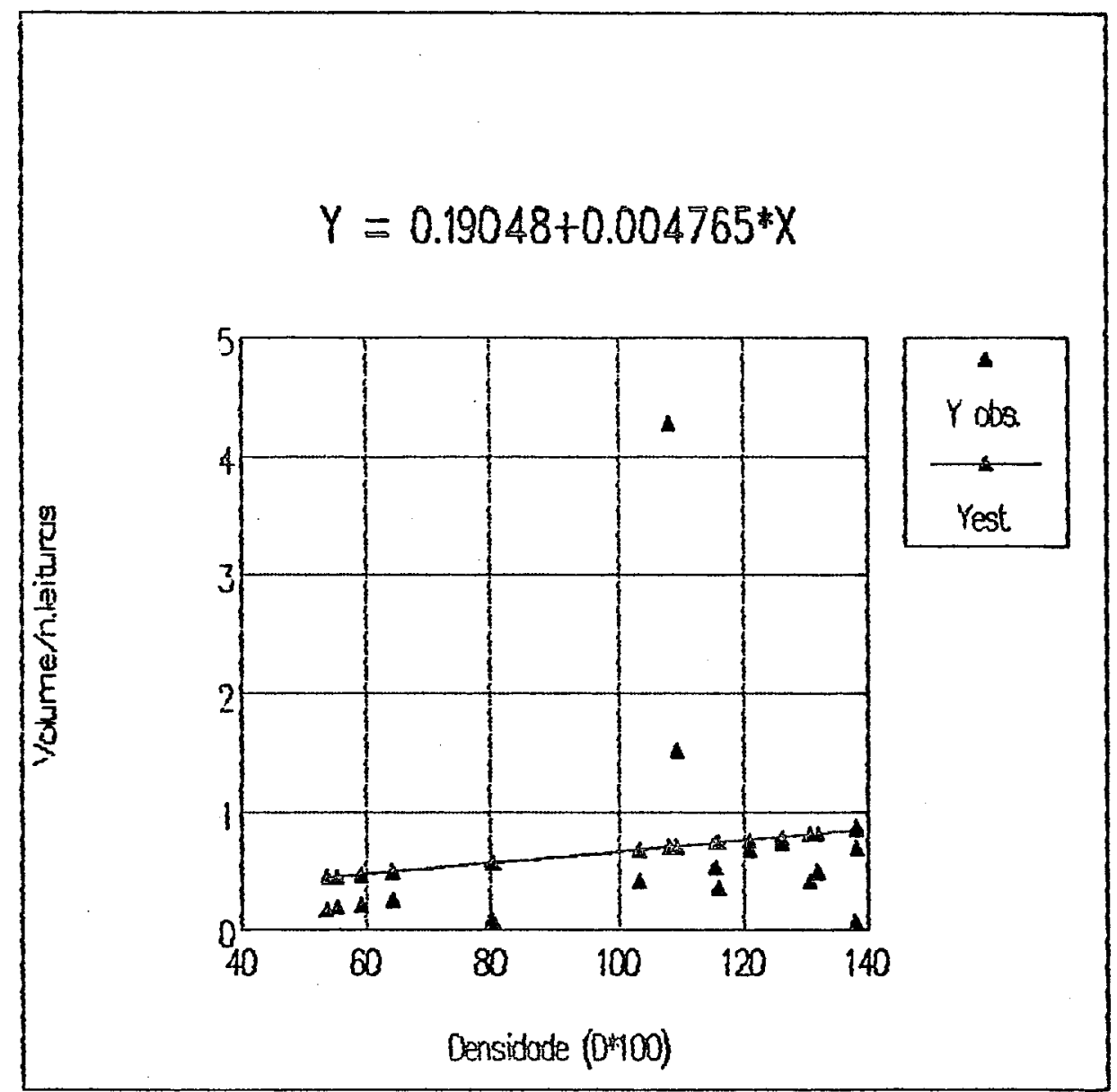

Figura 12. Desempenho do volume/no leituras para filt.ro visual em relacão a densidade óptica para Eucalyptus Erandis. 
70.

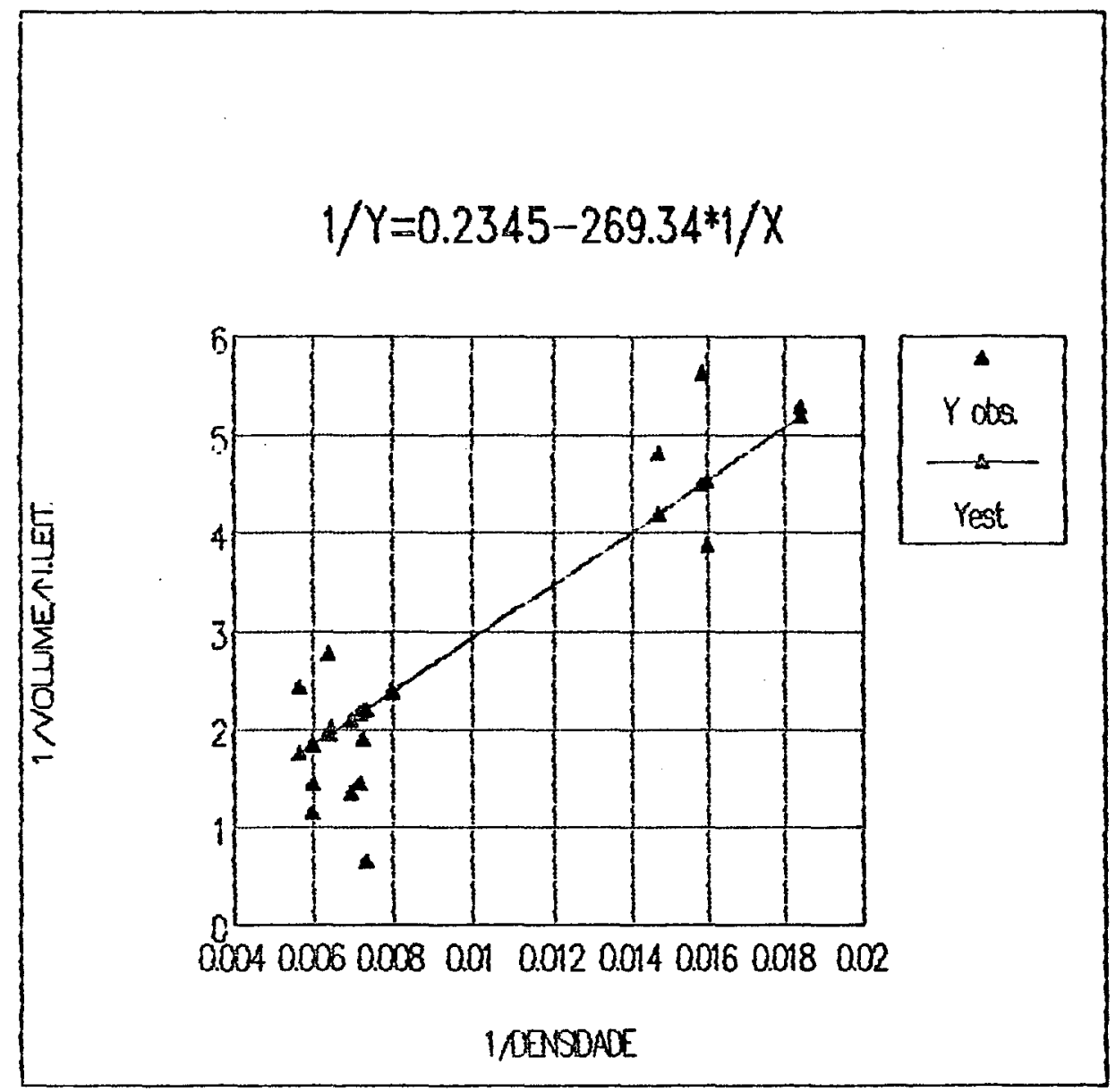

Figura 13 . Desempenho do inverso do volume/ro leituras para filtro azul em relação ao inverso da densidade óptica para Eucalyptus grandis. 
71.

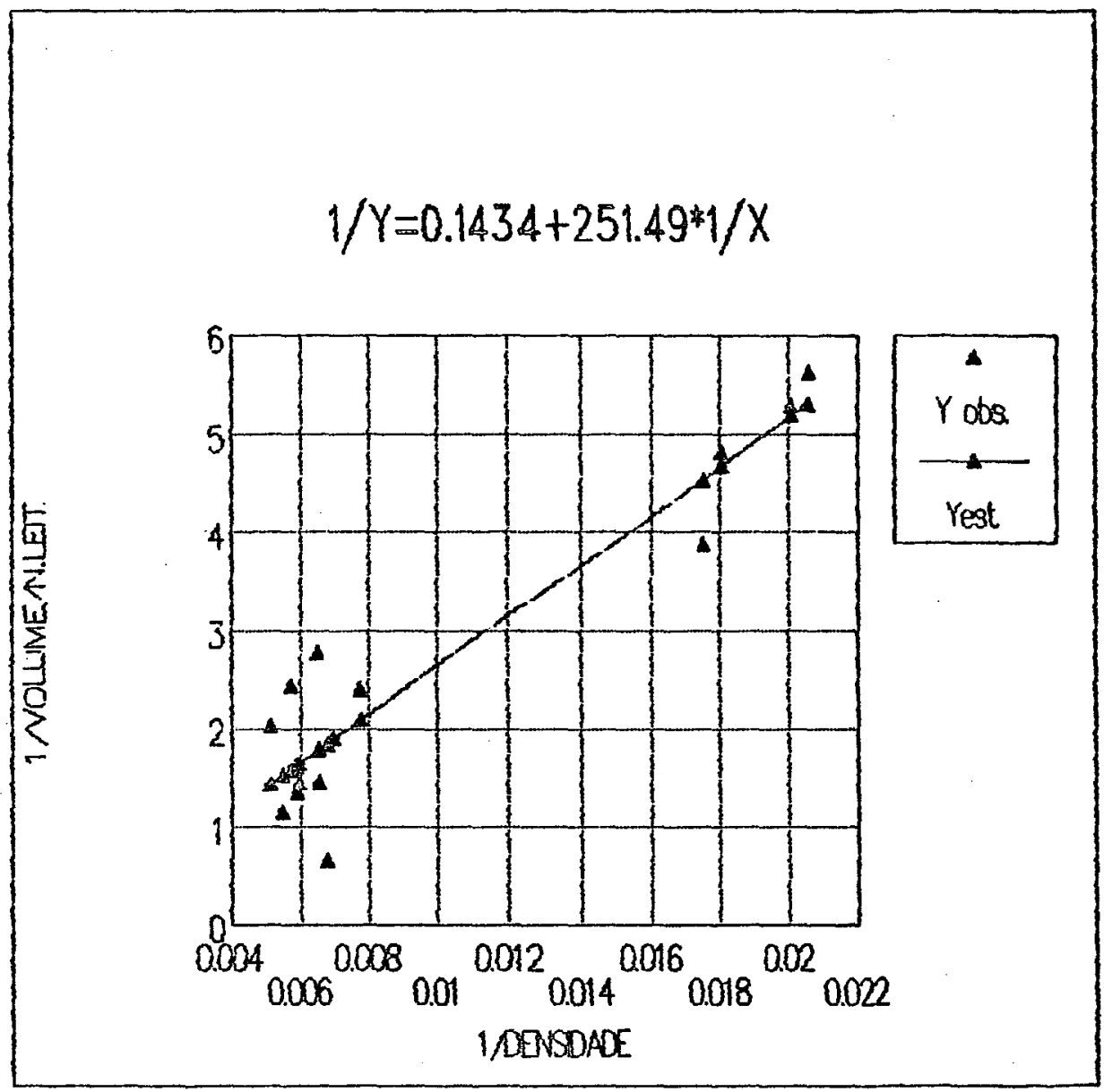

Figura 14. Desempenho do inverso do volumerne leituras para filtro verde em relasão ao invorso da densidade óptica para Eucalyptus grandis. 
72.

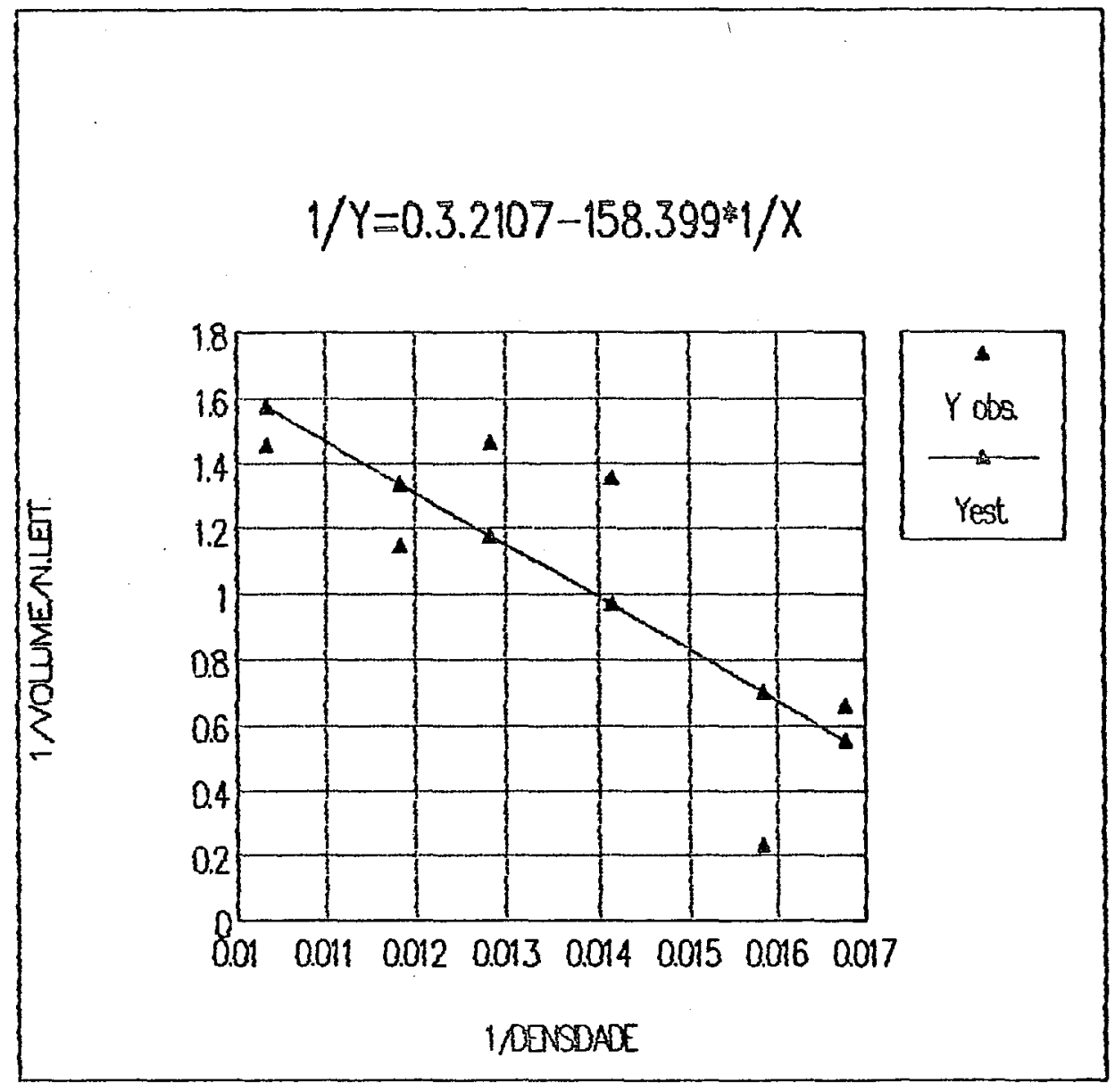

Figura 15. Desempenho do inverso do volume/no leituras para filtro vermelho, conjunto 1 , em relação ao inverso da densidade óptica para Eucolyptus grandis. 
73.

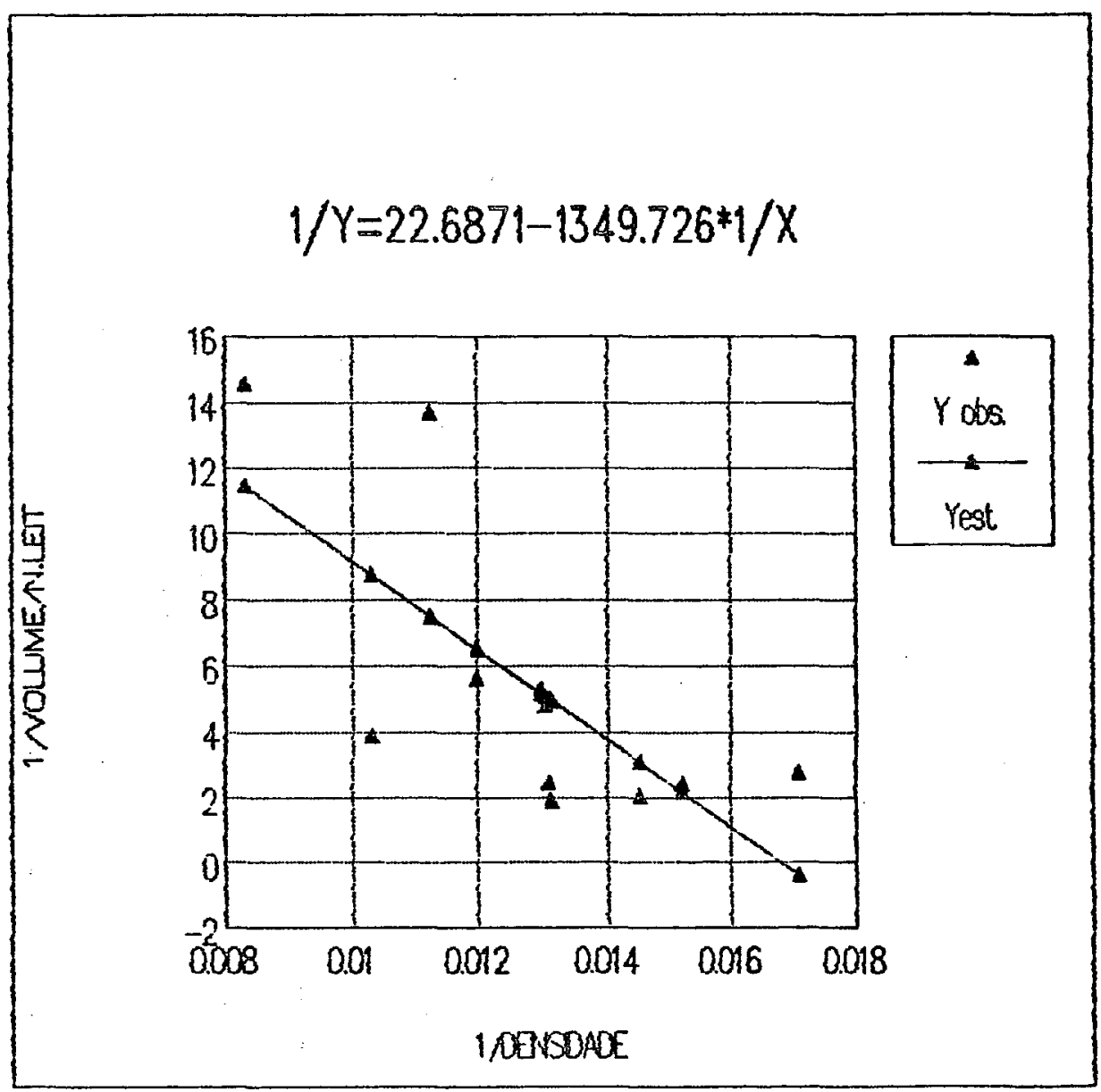

Figura 16. Desempenho do inverso do volume no leituras para filtro vermelho, conjunto 2 , em relação ao inverso da densidade óptica para Eucalyptus erandis. 
74.

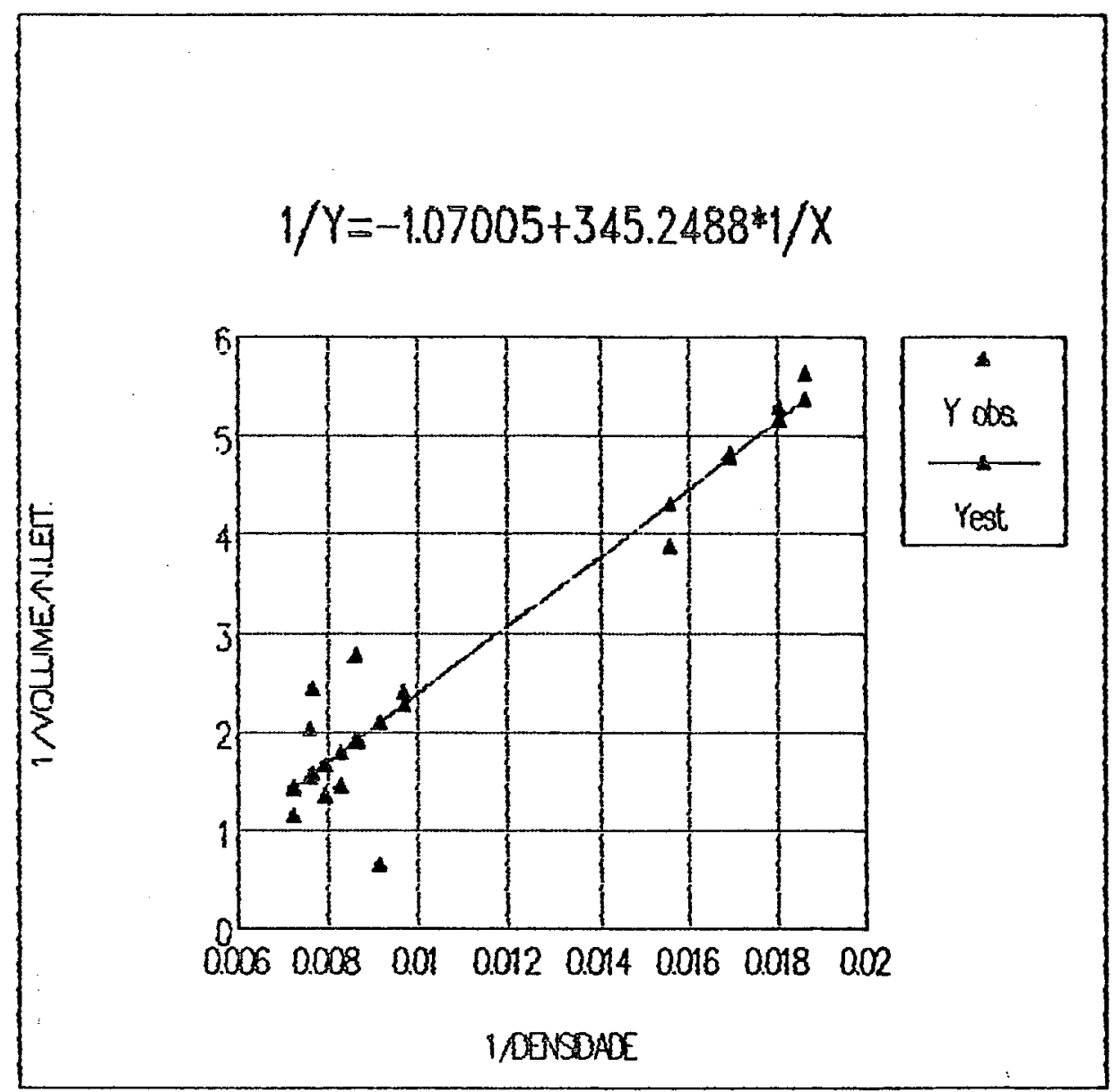

Figura 17. Desempenho do inverso do volumerne leituras para filtro visual em relação ao inverso da densidade óptica para Eucalyptus erandis. 
75.

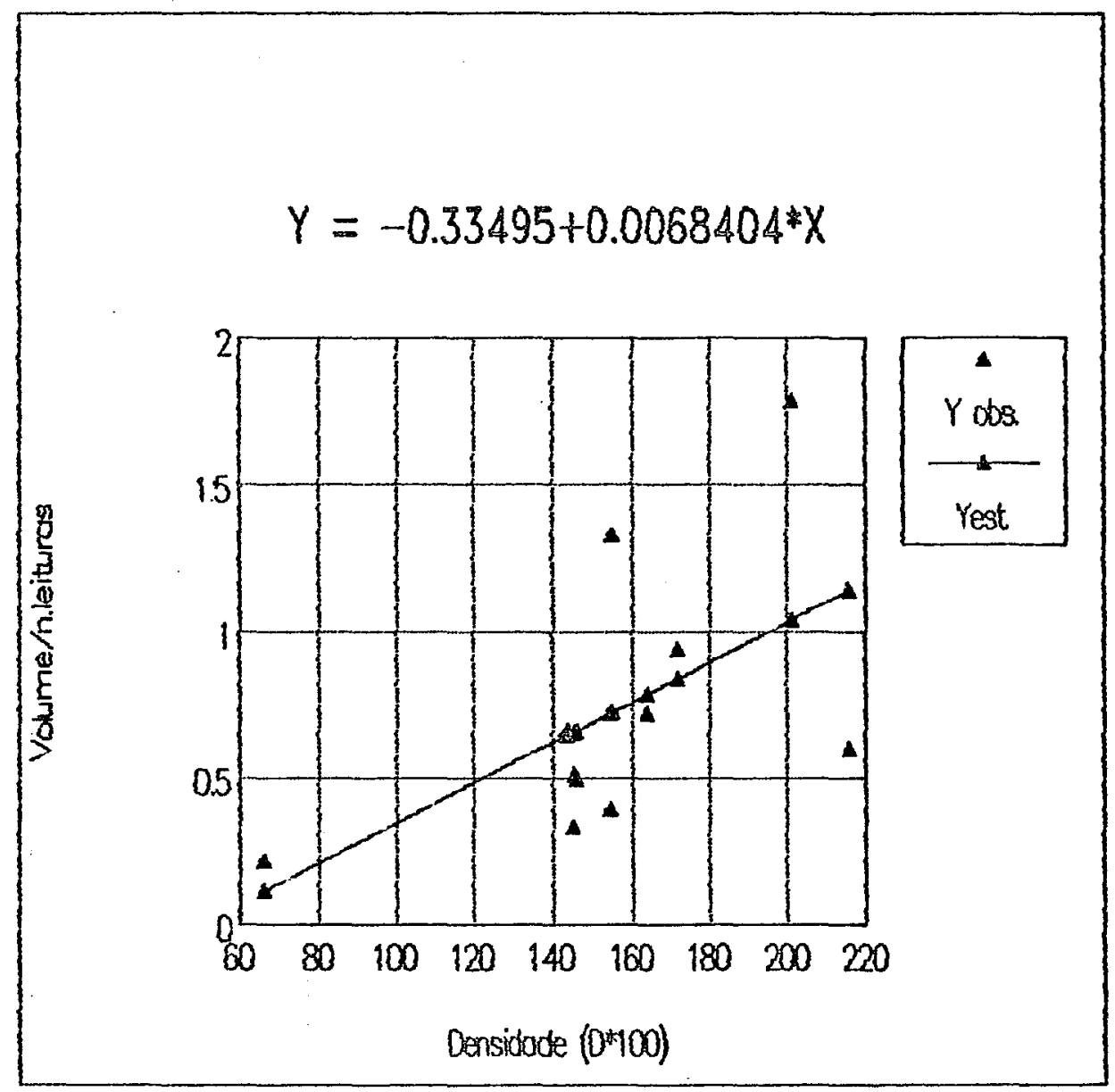

Figura 18. Desempenho do volumerno leituras para filtro azul em relação a densidade óptica para Eucalyptus saliena. 
76.

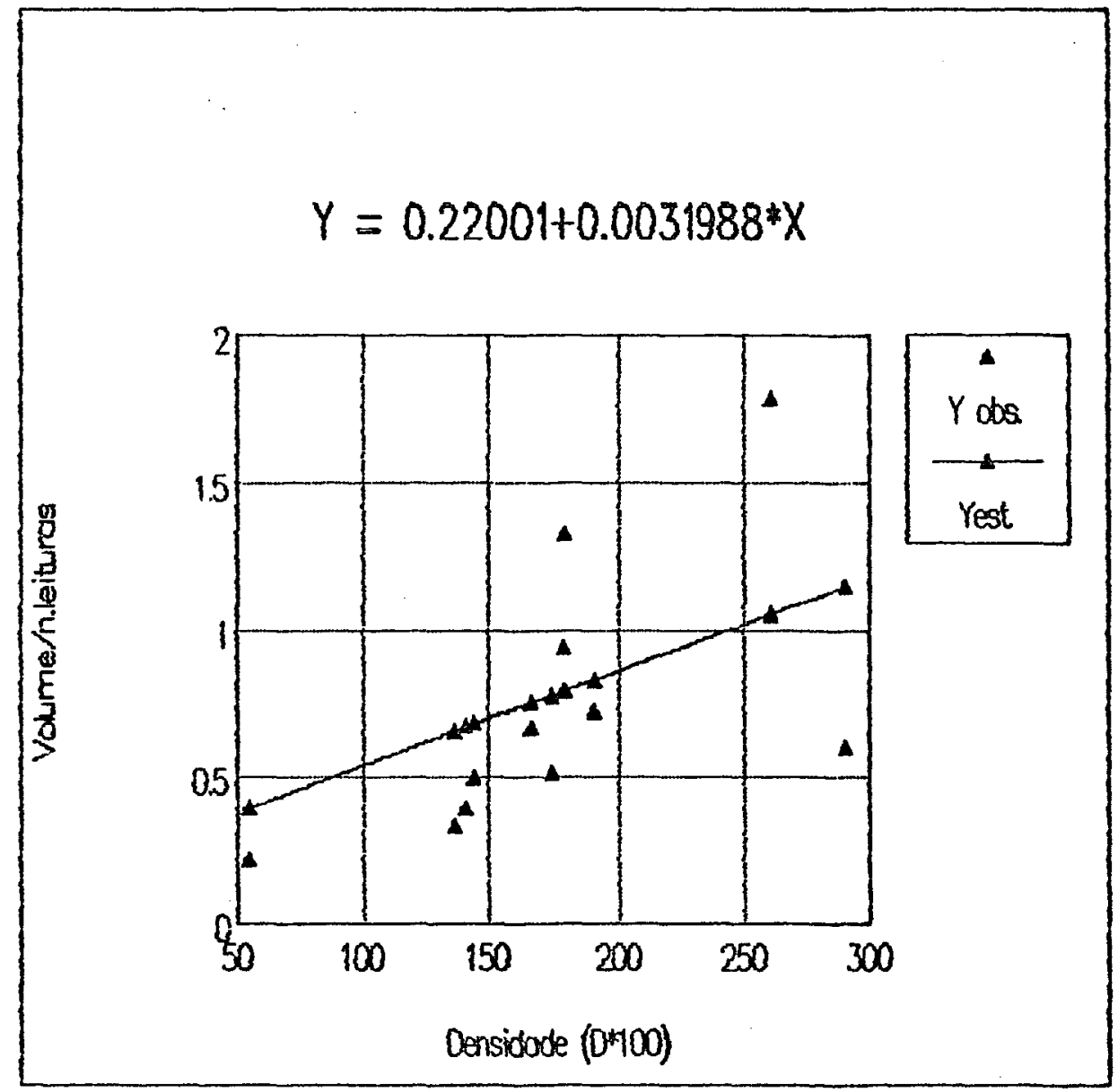

Figura 19. Desempenho do vol une/ne leituras para filtro verde em relaçao a censidade óptica para Eucalyptus saliena. 
77.

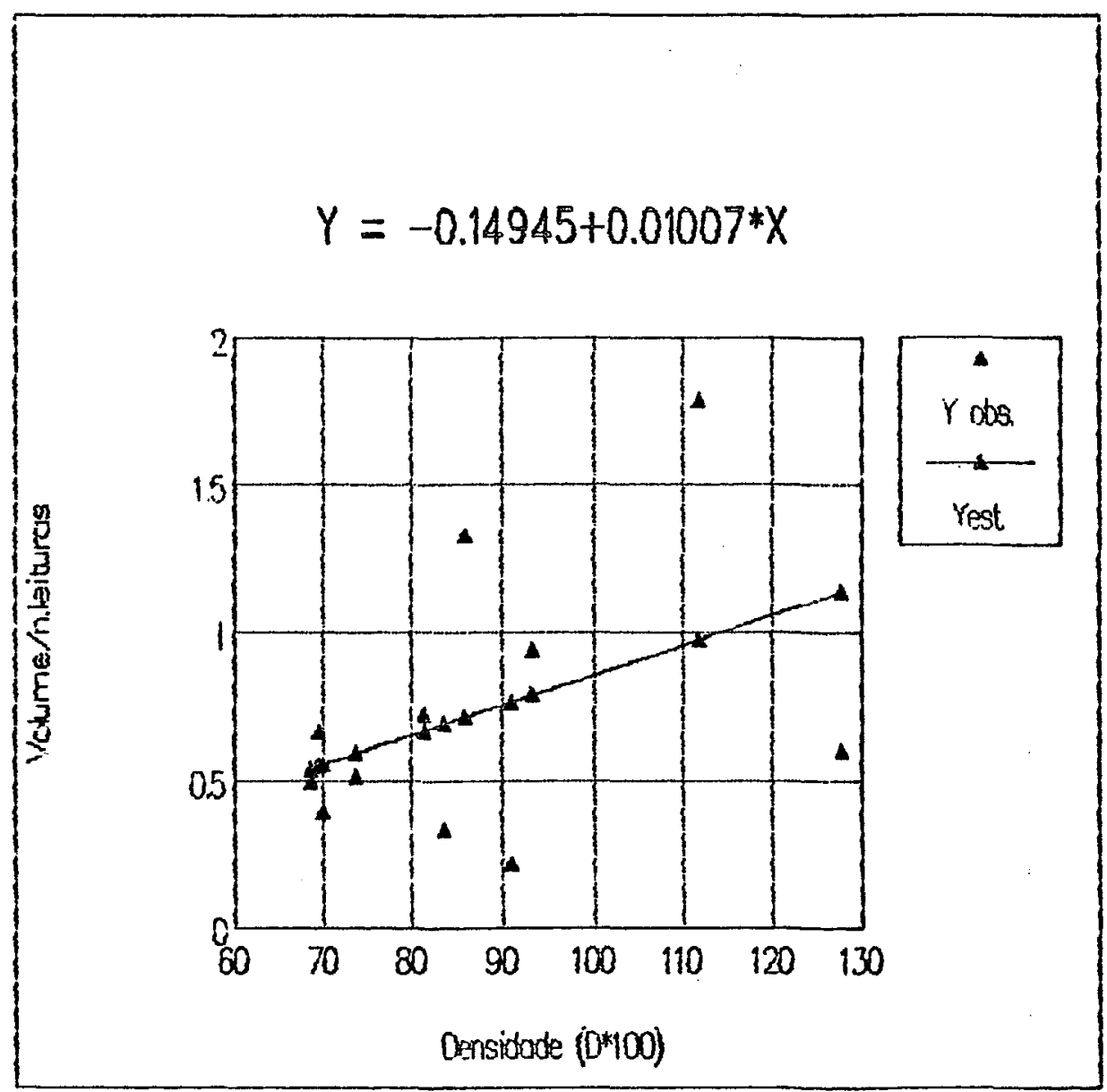

Figura 20. Desempenho do volumerne leituras para flltro vermelho em relação a densidade óptica para Eucalyptus saligna. 
78.

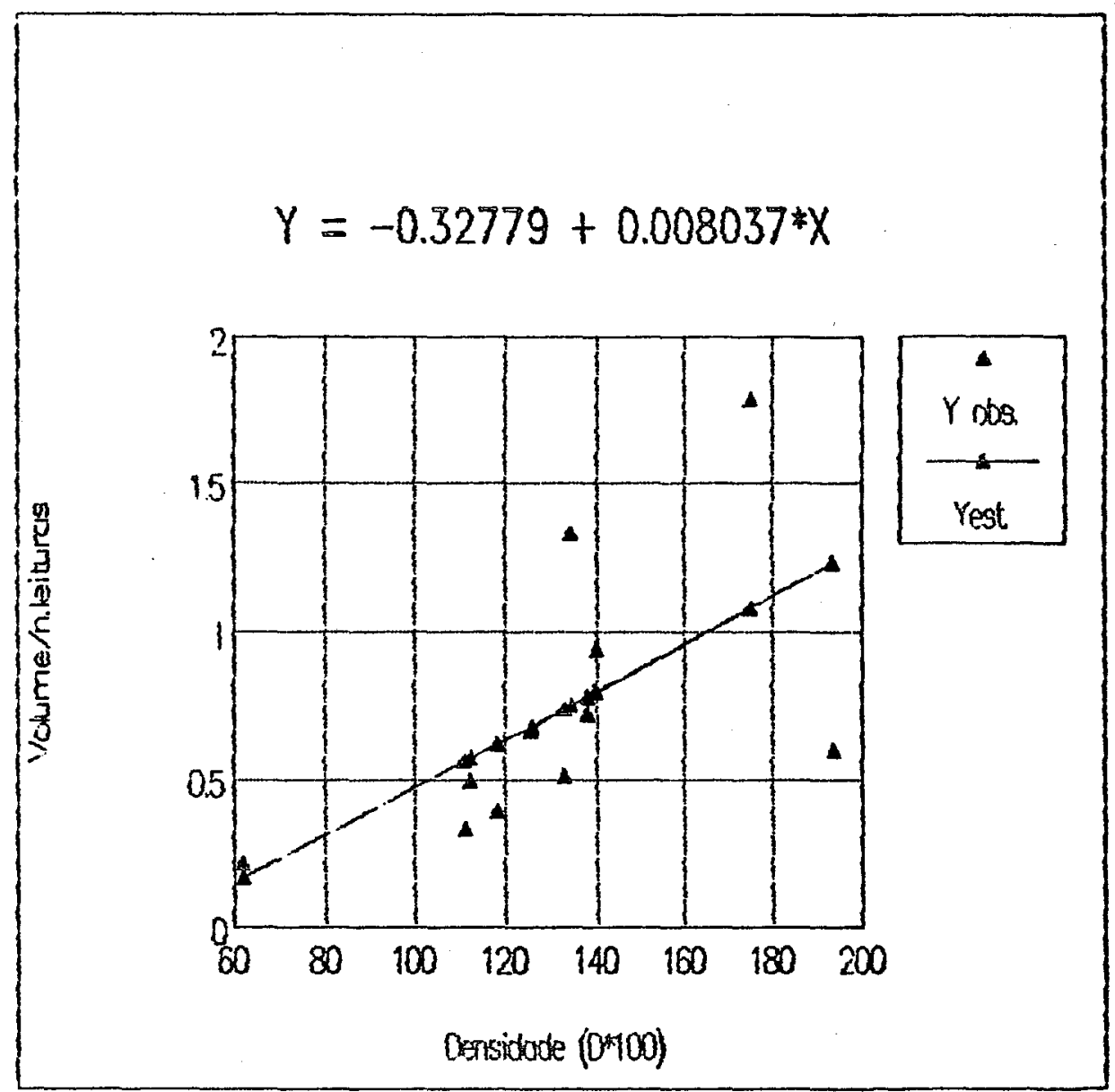

Figura 21. Desempenho do volumerno leituras para filtro visual em relacão a densidade óptica para Eucalyptus saligna. 
79.

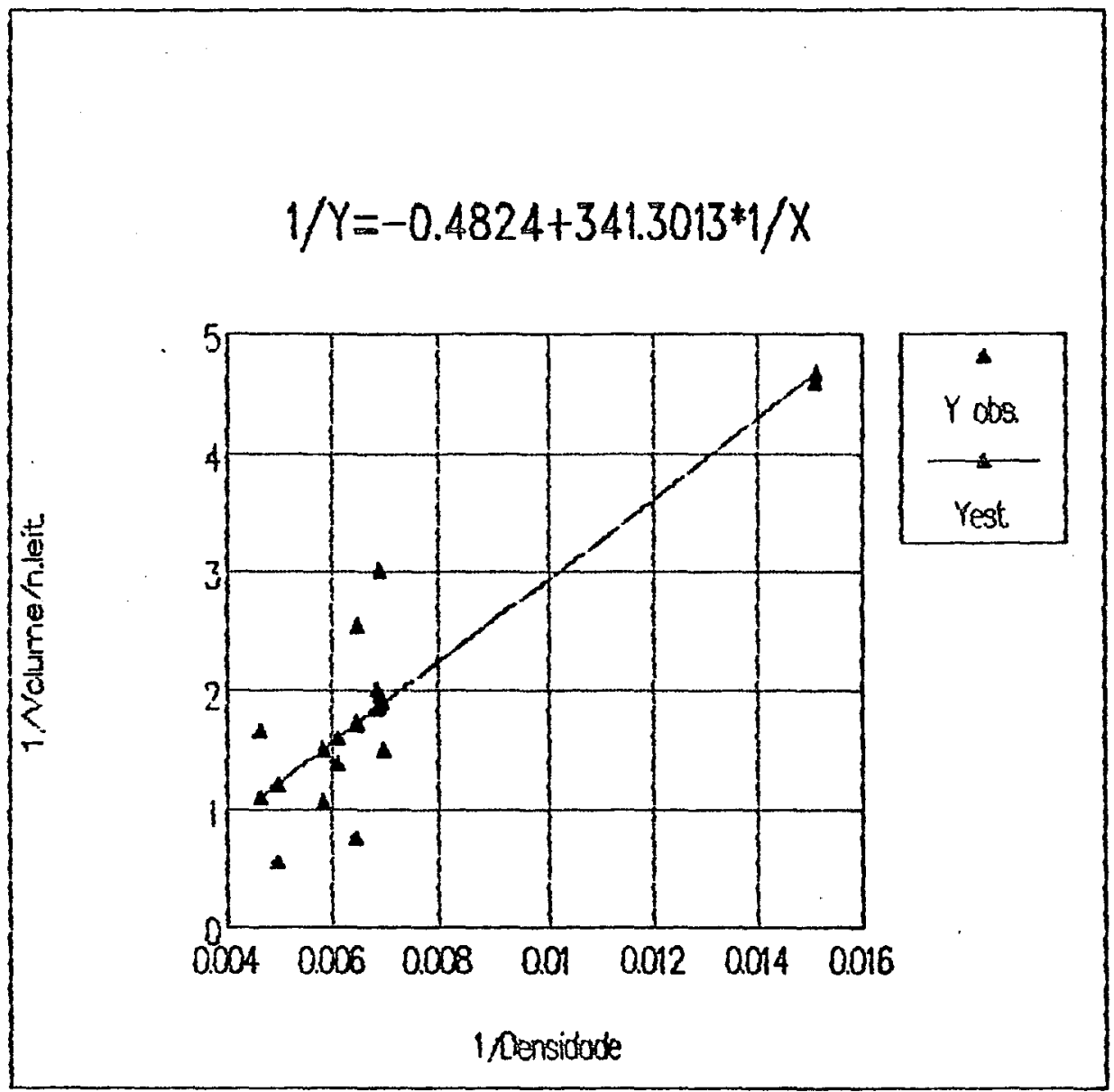

Figura 2e. Desempento do inverso do volume/ne leituras para filtro azul em relação ao luverso da densidade optica para Eucalyptus saliena. 
80.

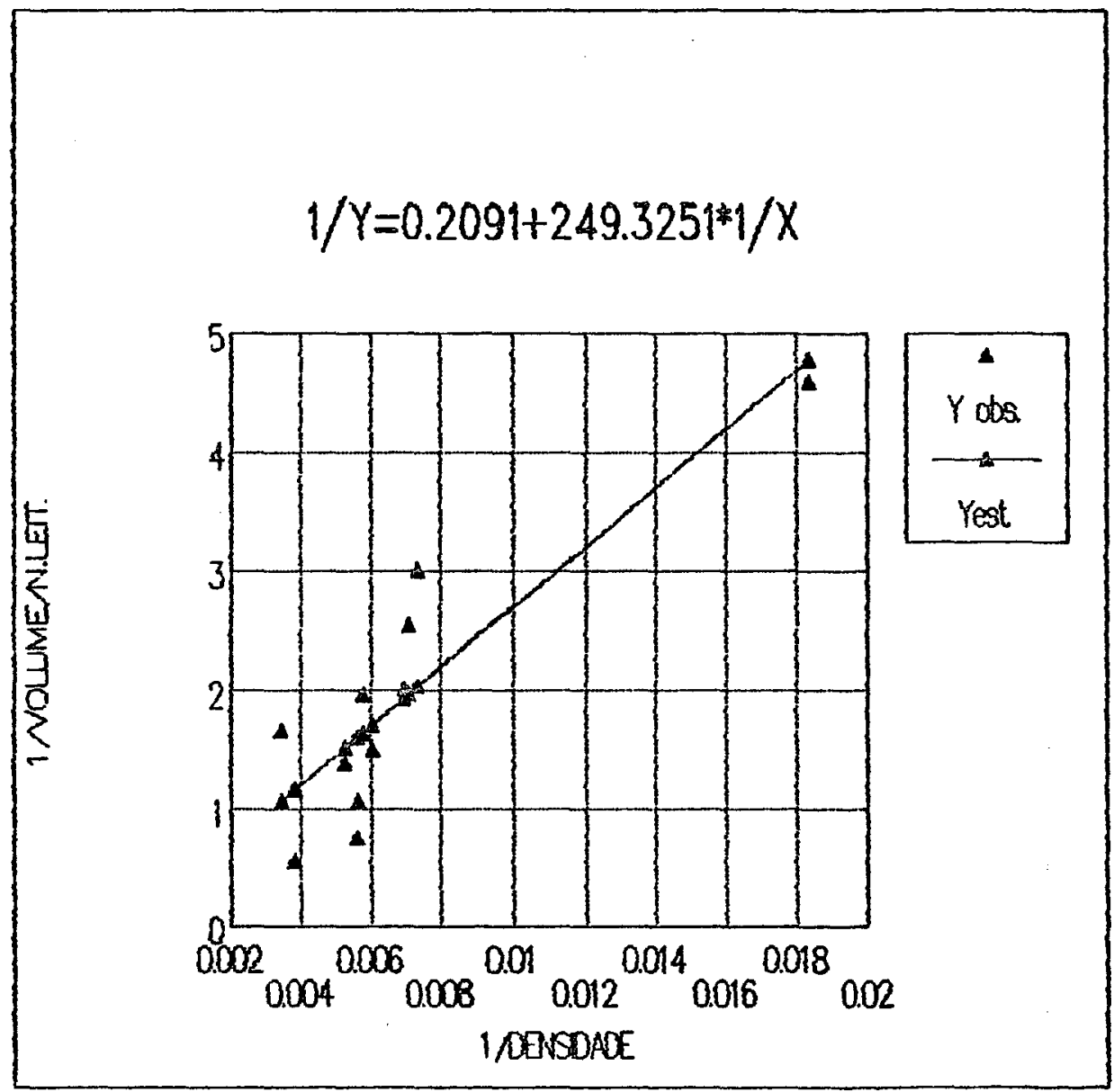

Figura 23. Desempenio do inverso do volumerre leituras para filtro verde em relação ao inverso da densidade óptica para Eucalyptus saligna. 
81.

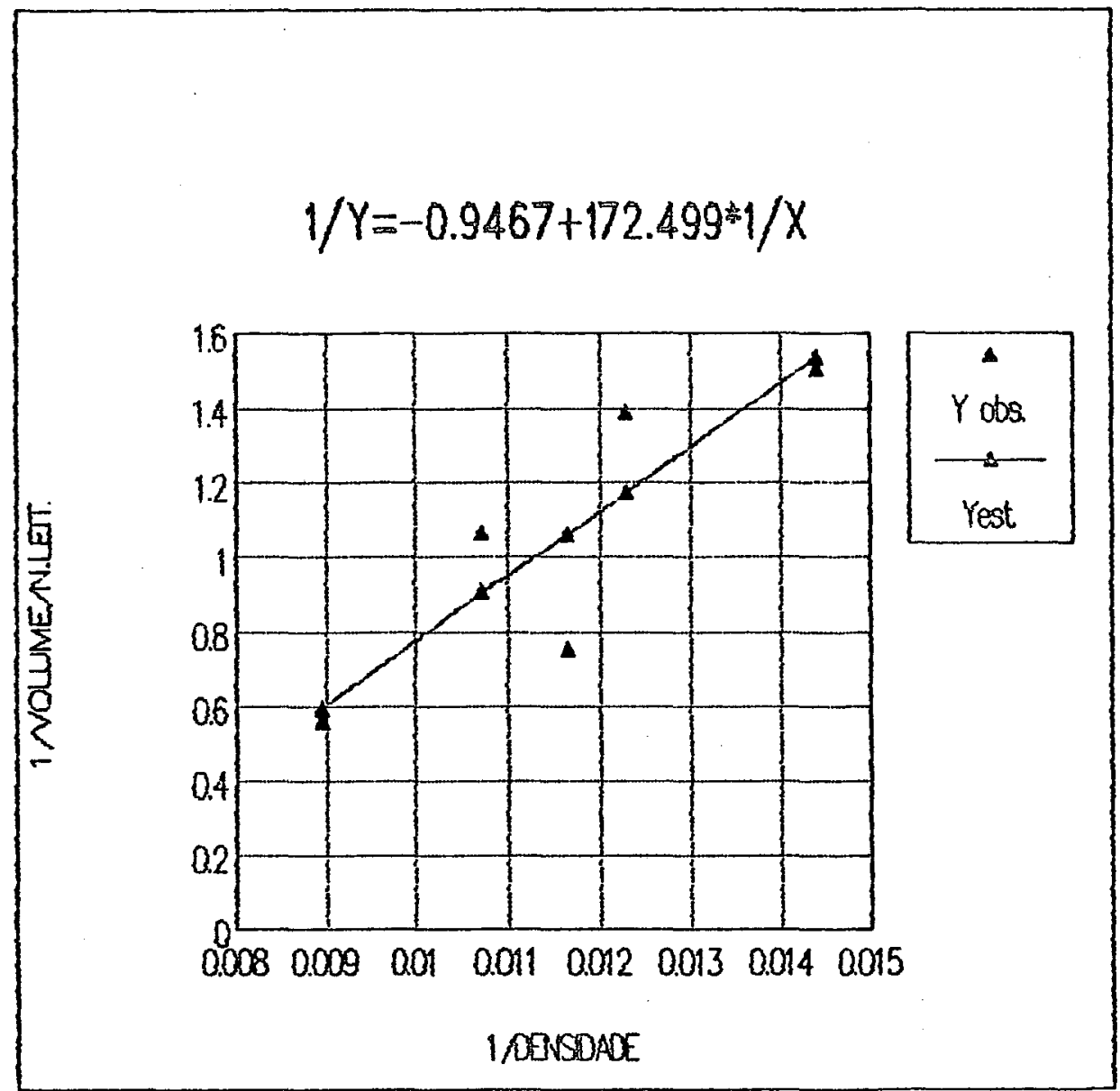

Figura 24. Desempenho do inverso do volume/n? leituras para filtro vermelho, conjunto 1 , en relacão ao inverso da densidade óptica para Euculyptus suliena. 
82.

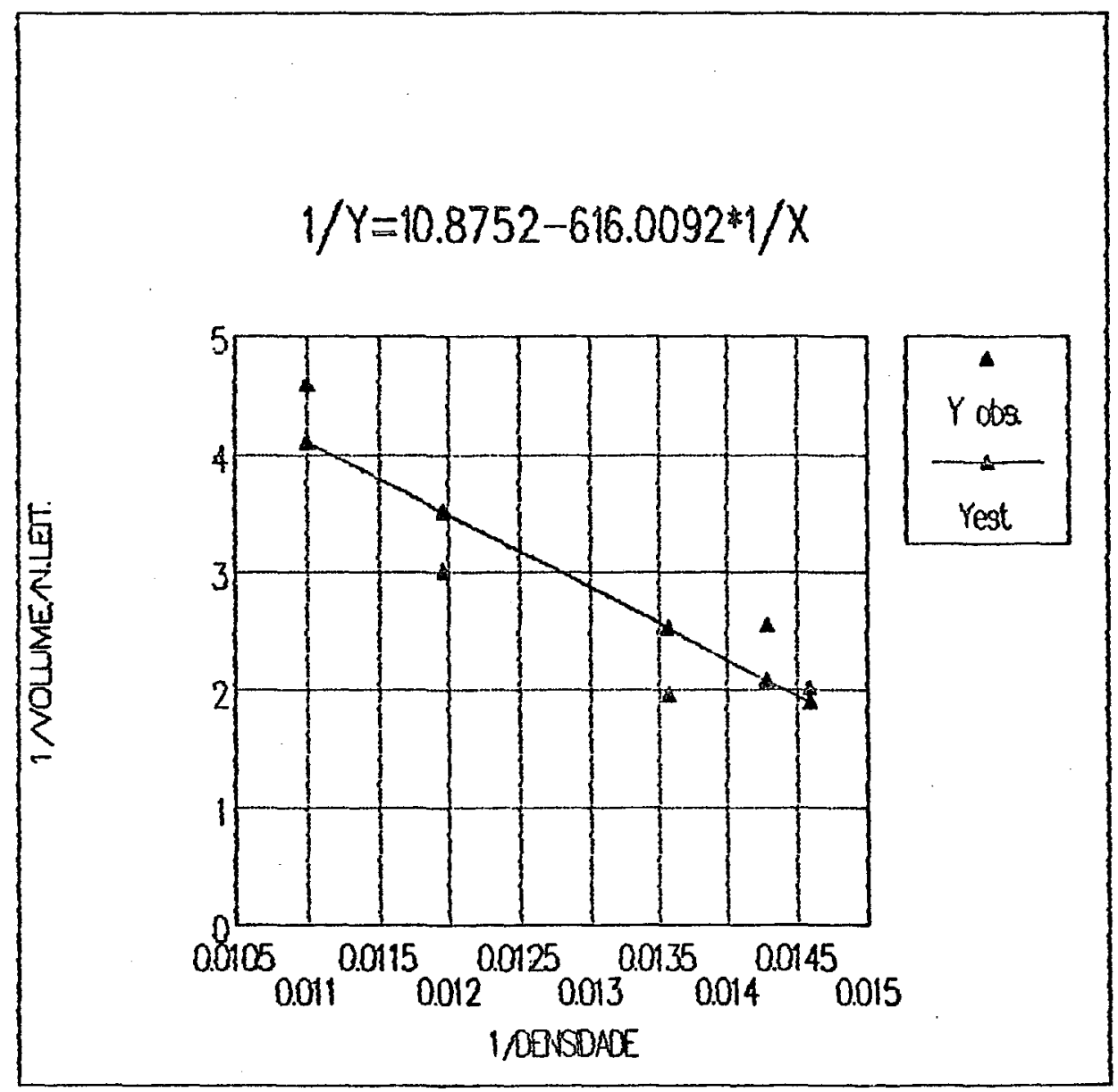

Figura 25. Desempento do inverso do volumerne leituras para filtro vermelho, conjunto 2 , em relação ao inverso da densidade óptica para Euculyptus saliena. 
83.

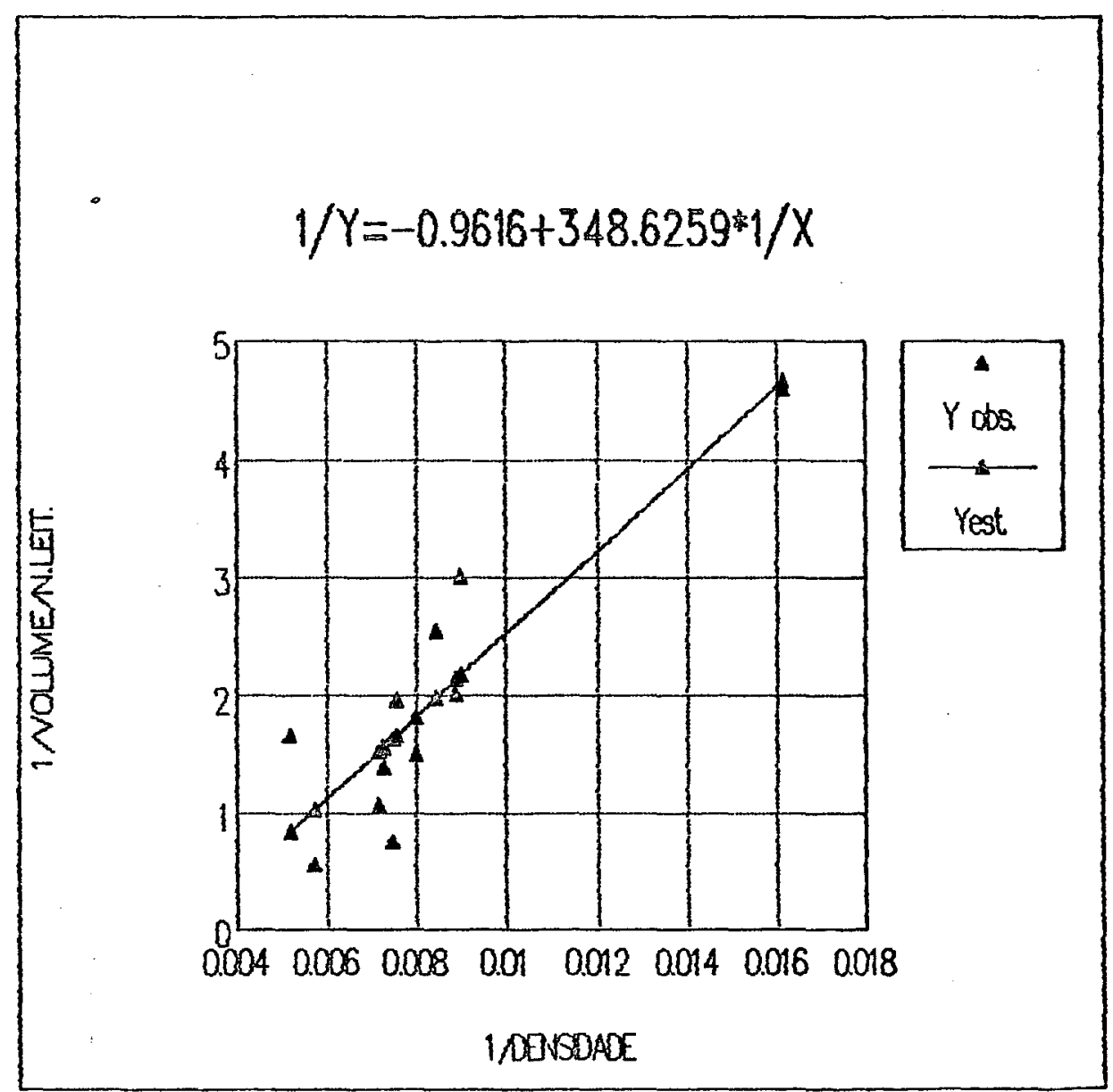

Figura 26. Desempenho do inverso do volumeine leituras para filtro visual em relação ao inverso da densidade óptica para Eucalyptus saligna. 
84.

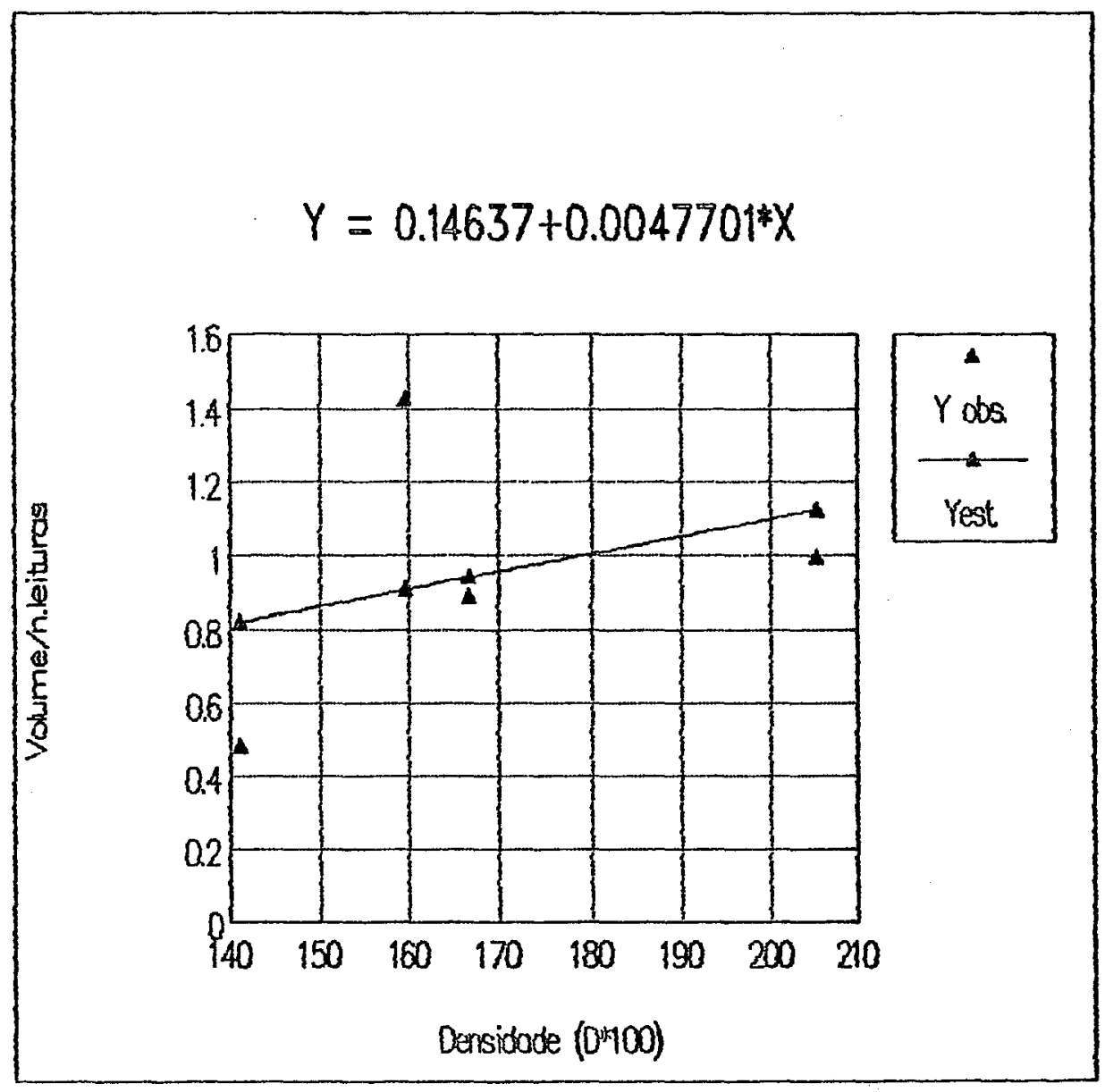

Figura 27. Desempenho do volumerns leituras para filtro azul em relacão a densidade óptica para Eucalyptus urophylla. 
85.

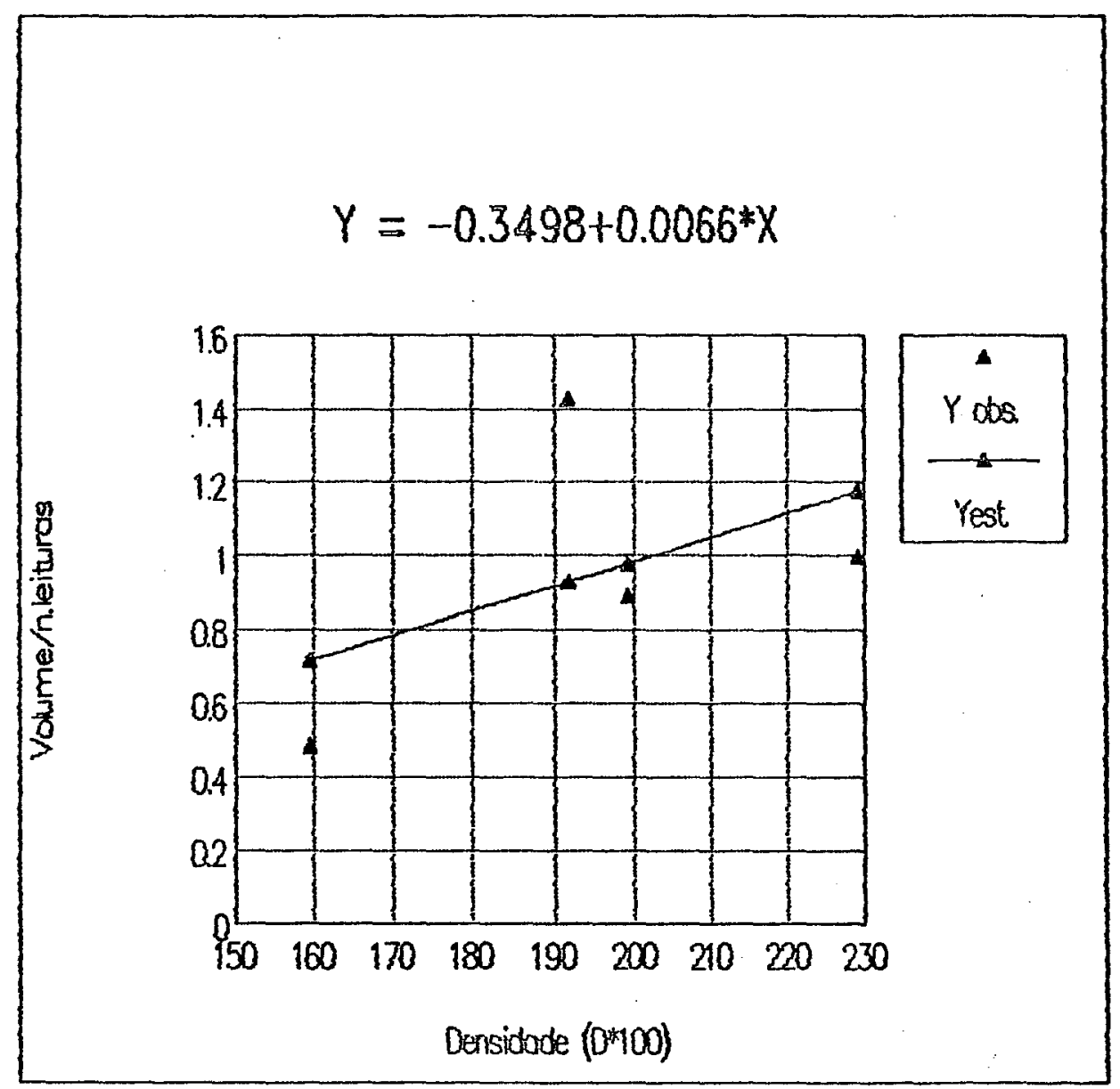

Figura 28. Desempenho do volumerne leituras para filtro verde em relacão a densidade óptica para Eucalyptus urophylla. 
86.

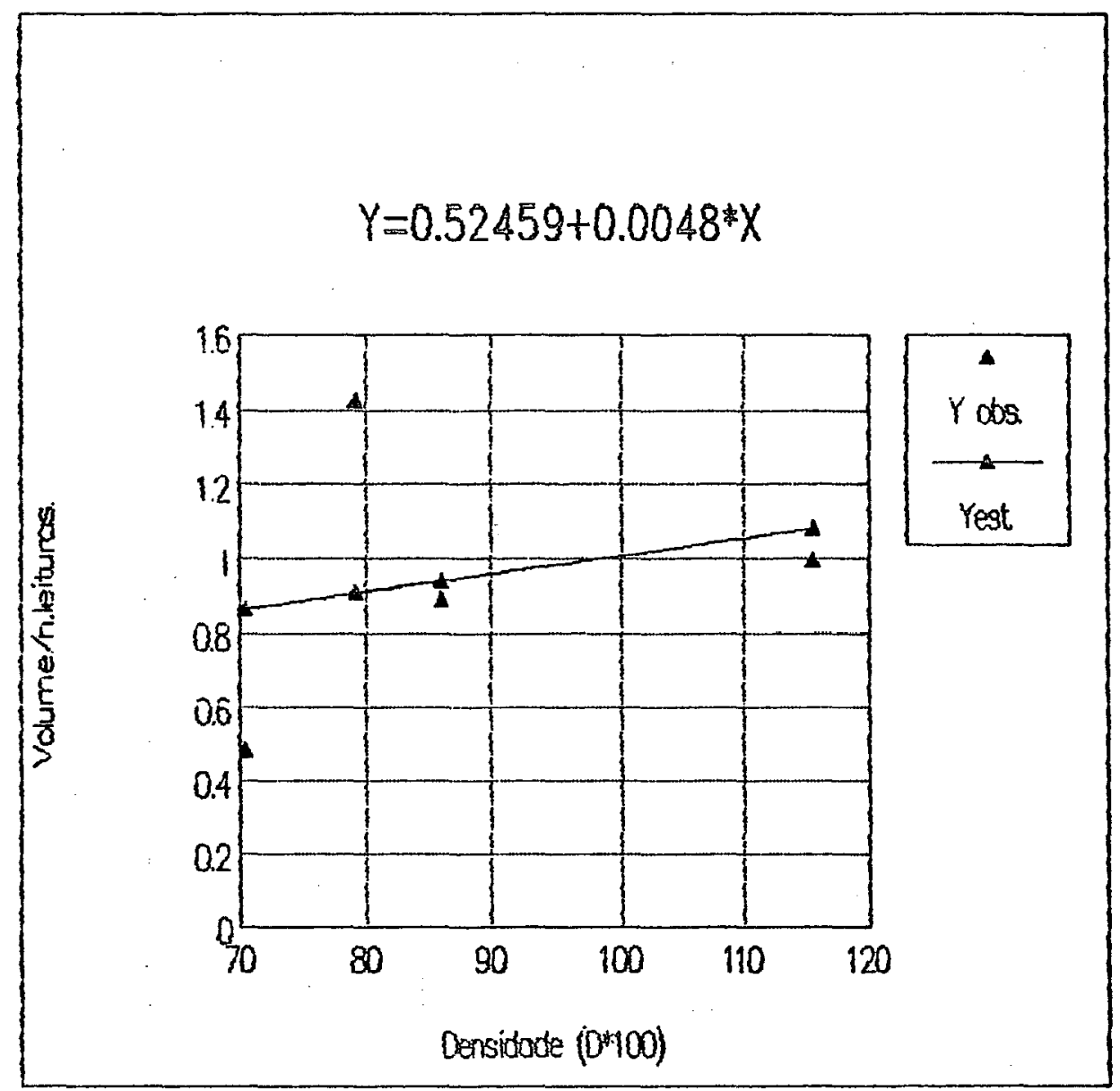

Figura 29. Desempenho do volumerno leituras para filtro vermelho em relacão a densidade óptica para Eucalyptus urophylla. 


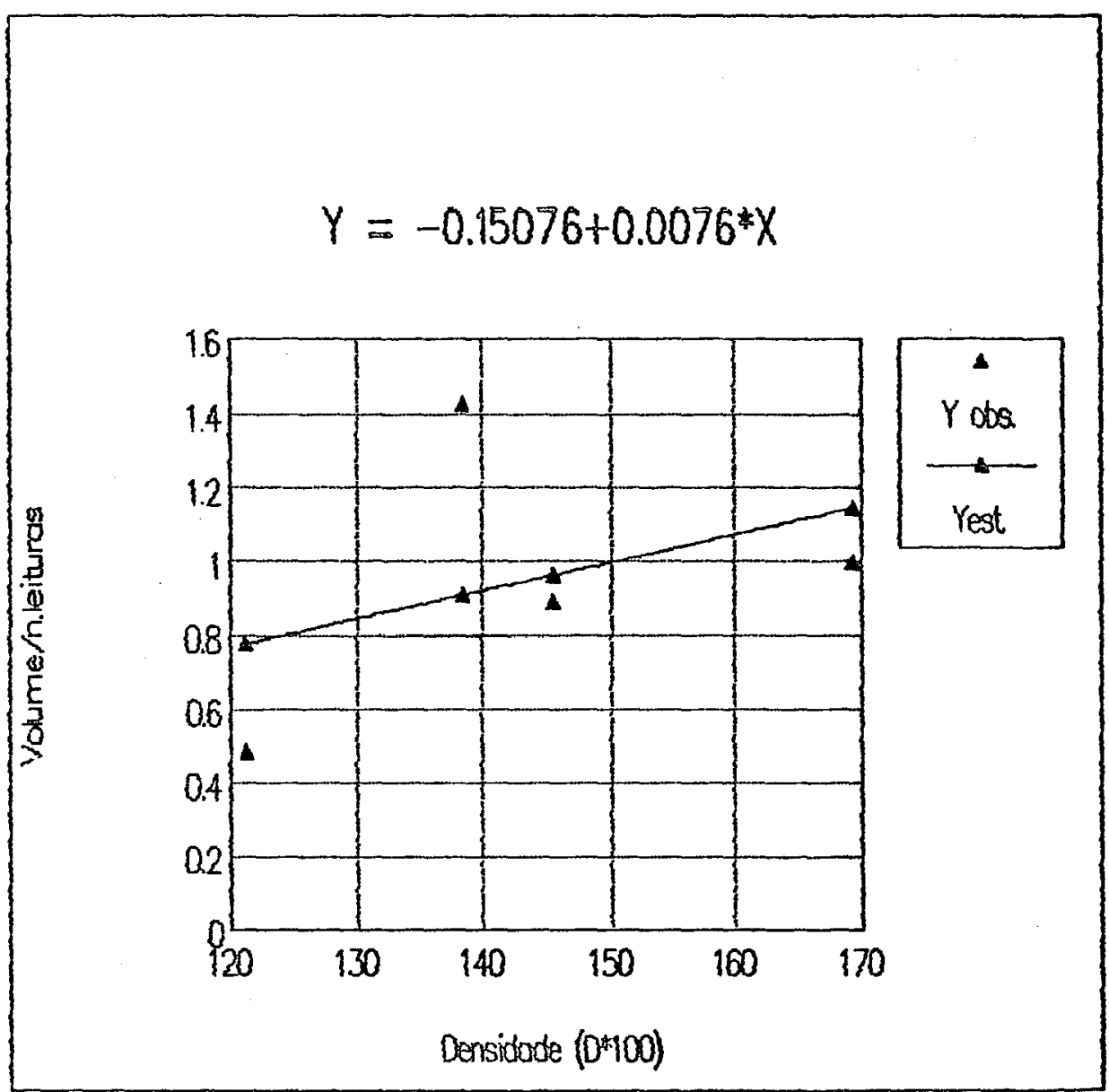

Figura 30. Desempenho do volumerne leituras para filtro visual em relacão a densidade optica para Eucalyptus urophylla. 
88.

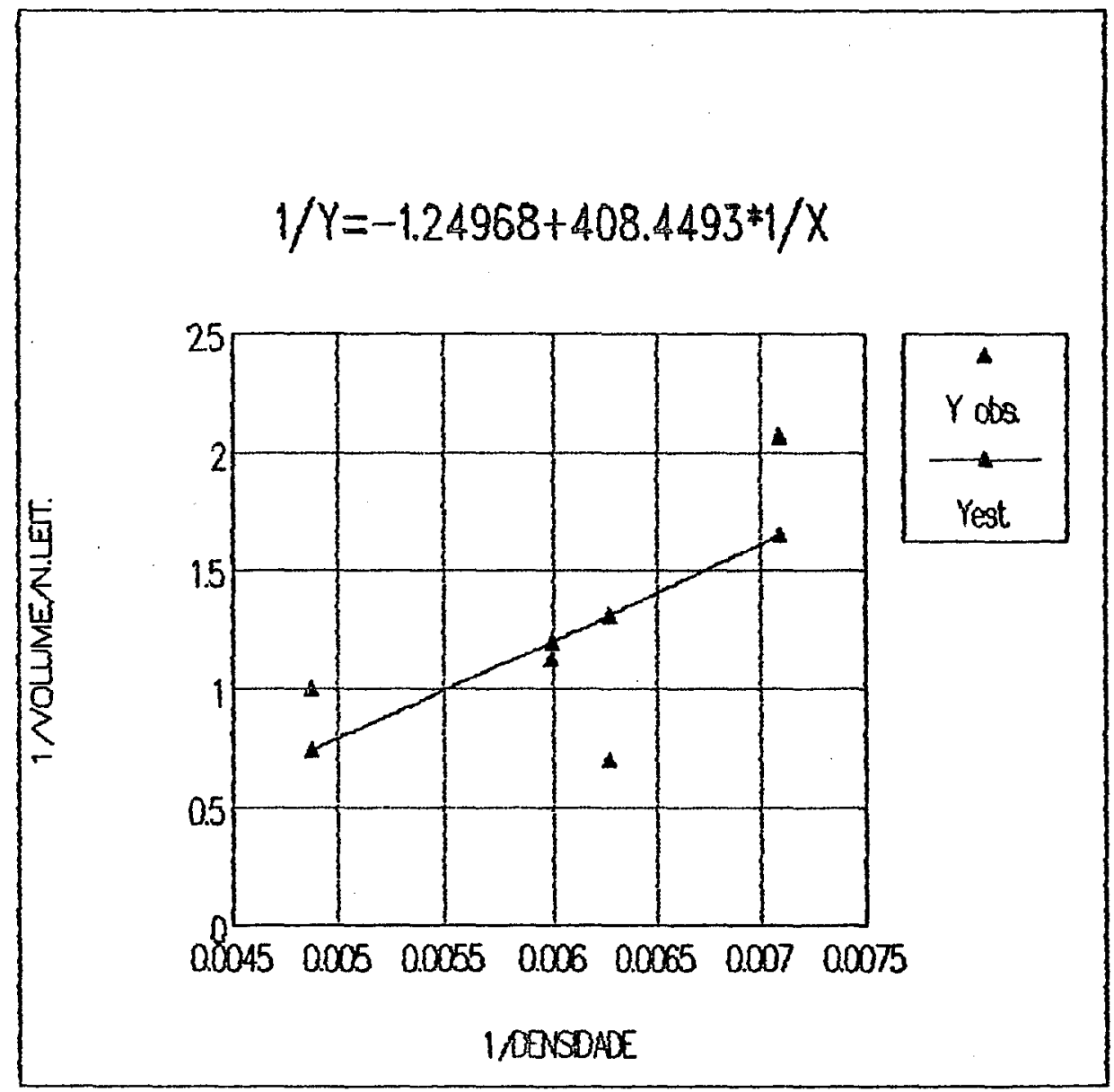

Figura 31. Desempenho do inverso do volume no leituras para filtro azul em relarão ao inverso da densidade optica para Eucalyptus urophylla. 
89.

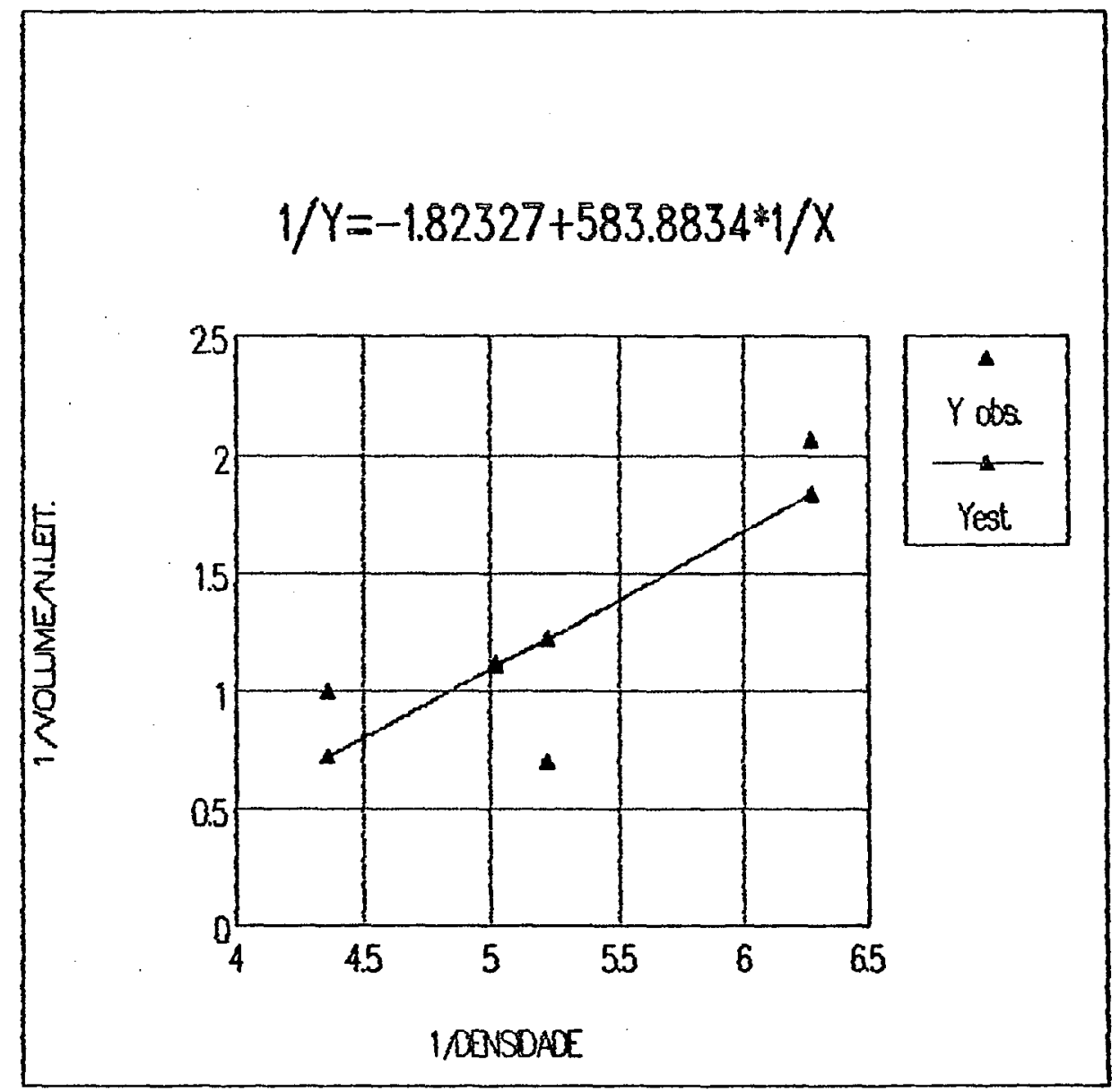

Figura 32. Desemperho do inverso do volume/rs leituras para filtro verde em relação ao inverso da densidade óptica para Eucalyptus urophylla. 
90.

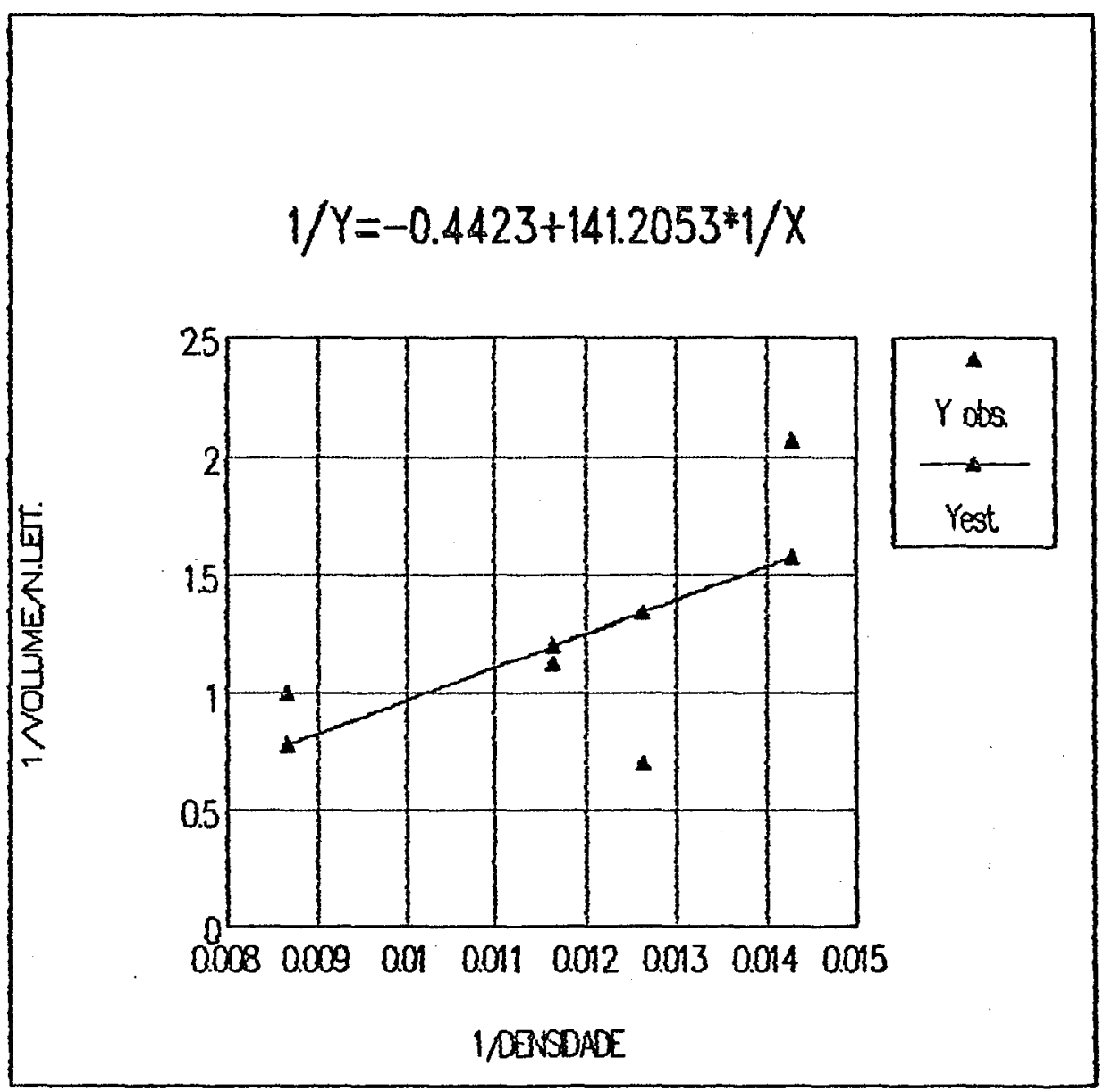

Figura 33. Desempento do inverso do volumerne leituras para filtro vermelho em relacão ao inverso da densidade óptica para Eucalyptus urophylla. 
91.

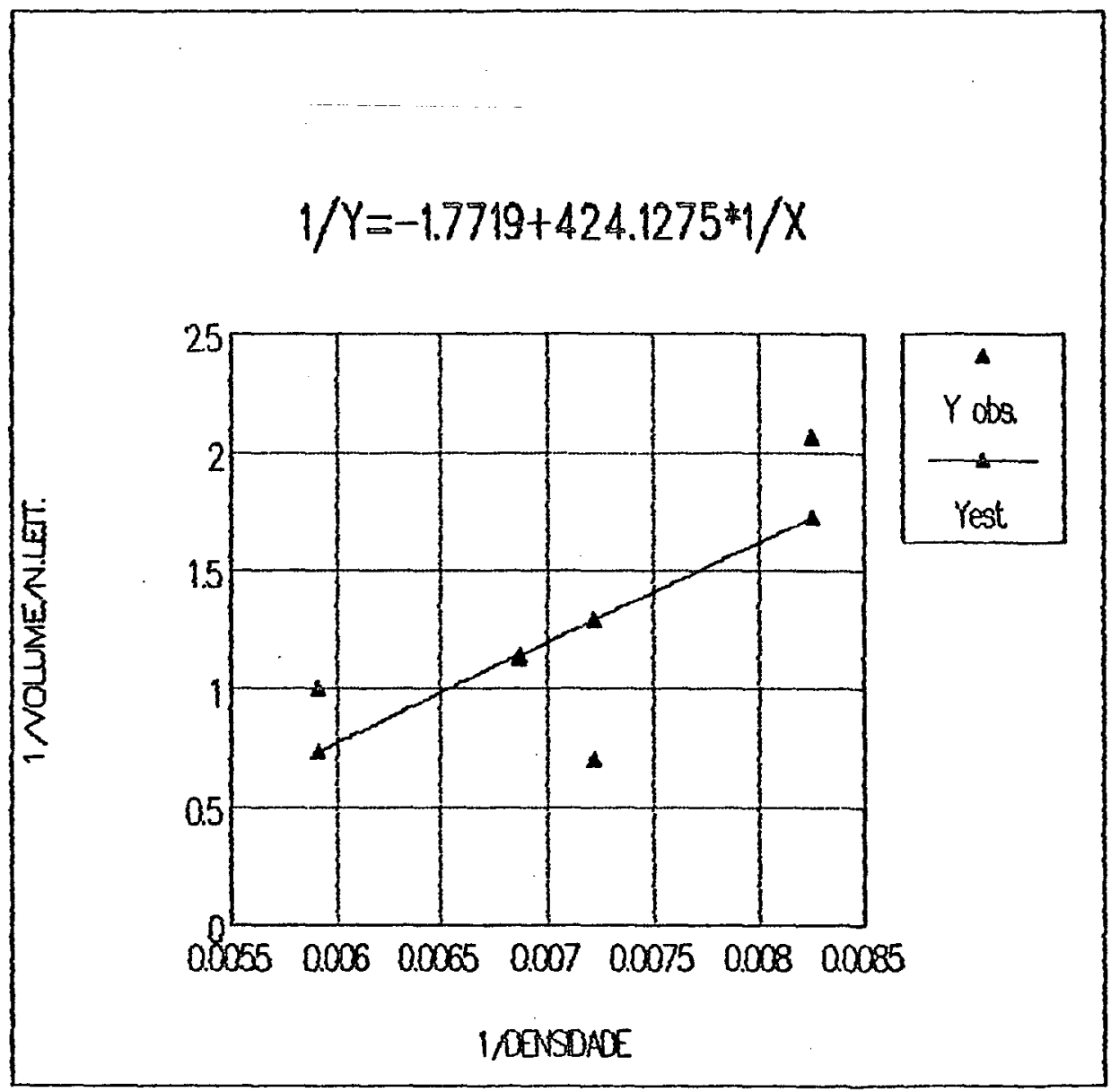

Figura 34. Desemperho do inverso do volumerne leituras para filtro visual em relacão ao invarso da densidade óptica para Eucalyptus urophylla. 
B2.

\section{CONCLUSOEES}

A análise dos resultados obtidos, com o material e mótodos utilizados, permitiu tirar as soguintas conCl usões:

a) A análise espertral realizada atravós da donsidade óptica utilizando transparências infravermol has coloridas evidenciou a sua utilidade para a estimativa volumótrica de reflorestamentos com eucaliptos pelo método semi-automático;

b) O grau de detalhamento espacial e espectral das fotografias aéreas infravermelhas coloridas as tornam adeguadas a este tipo de trabalho, ou seja, a utilizacão da densitometria sobre esse material constitui uma allornativa válida para a realizacão do inventário florestal;

c) O zumero de tal hộ amostrados e un fator altamente relevante, pois contribui para a obtencão de oquarões lineares melhor ajustadas, com altos coeficientes do determinaธão;

d) Tanto para o Eucalyptus grandis como para c Eucolyptus suliena, as equaç̃es pbtidas para os 4 filtros poderäo ser de grande utilidade, pois as mesmas foram itididas através de densidades ópticas de talhōes com difirentes 
93.

graus de homogeneidade.

Sugere-se a continuidade deste trabal ho, a fim de melhorar as equaçóes obtidas, ou seja, trabalhando com dados mais adequados, tais como: maior número de tal hõos com a mesma espécie e espécies diferentes e com a mesma idade ou bem próximas; medidas de DAP e altura na mesma épora; igual número de amostras por talhão; se possivel homogeneidade quanto ao tipo de solo guanto as fotografias aéreas, que estas sejam obtidas no períado seco. 
94.

\section{REFERENCI AS BIBLIOGRÁFICAS}

AASE, J.K.; SIDDOWAY, F.H.; MILLARD, J.P. Spring wheat-leaf phytomass and yield estimates from airbone scanner and hard-held radiometer measurements. International Journal Remote Sensing, 5(5): 771-781, 1984.

ANSON, A. Developments in aerial color photography for terrain analysis. Photogrammetric Engineering, Falls Church, 34(10): 1048-1057, 1958.

ARVANITIS, L.G. \& NEWBURNE, R. Detecting Melaleuca trees and stands in South Florida. Photogrammetric Engineering and Rempte Sensing, Falls Church, 59(1): 95-98, 1984.

BROONER, W. G. \& SIMONETT, D.S. Crop discrimination with color infrared photography: A study in Douglas, Kansas. Remote Sensing of Environment, New York, 2: 21-35, 1971.

GARROLL, D.M. Remote sensing techniques and their application to soil science. Part 1 - The photographic sensors. Soil \& Fertilizers, Harppenden, 36(7): 259-266. 1973.

CHIAO, K. M. \& CHANG, B. Studies in the Spertral Reflectance characteristics of four coniferous seetlings. Forestry Abstracts, 45(5): 258, 1984.

CHIAO, K. M. \& CHENG, C.C. A study on spectral reflectance properties of trees. Forestry Abstracts, 46( 4): 215, 1985. 
95.

COLFELL, R.N. Uses and limitations of multiespectral remote sensing. Proceedings of Symposium on Remote Sensing of Environment, 4th. Ann Arbor, 1: 71-100, 1966.

CURRAN, P.J. Multiespectral photographic remote sensing of green vegetation biomass and produtivity. Photogrammetric Engineering and Remote Sensing, Falls church, 48C2): $243-250,1982$.

GURRAN, P.J. \& MILTON, E.J. The relationships between the chlorophyl concentration, LAI and reflectance of a simple vegetation canopy. International Iournal Remote Sensing, 4(2): $247-255,1983$.

DALE, P.E.R.; HULSMAN, K.; CHANDICA, A.L. Seasonal consistency of Salt-Marsh vegetation ol asses classified from large-scale color infrared aerial photographs. Photogrammetric Engineering and Remote Sensing, Falls Church, 52(2): $243-250,1986$.

DONZELI, P.L. Densitometria en aerofotografias coloridas e infravermelhas relacionada as caracteristicas das cores de três latossolos. Dissertacão de Most.rado, ESALQUSP, Piracicaba, $1979,84 \mathrm{p}$.

DONZELI, P.L. Comportamento espectral de trés latossolos argilosos da região de Limeira - Araras - SP em relacão às suas propriedades físicas e químicas. Tese de Doutoramento, ESALQ, USP, Piracicaba, 1984. 135p.

DOVERSPIKE, G.E.; FLYNN, F.M. ; HELLER, R. R. Microdensitometer applied to land use classification. Photogrammetric Engineering, Falls Church, 31(2): 294-300, 1965.

DRISCOLL, R.S.; FEPPERT, J.N.; HELLER, R. C Microdonsitometry to identify plant communities and components on color 
96.

infrared aerial photos. Forestry Abstracts, 35(9): 525, 1974.

EASTMAN KODAK COMPANY. Practical Densitometry. Rochester, 1972, 15p. CKodak Technical Publication M-283.

EDWARDS, G.J. \& BLAZQUEZ, C.H. Analysis of ACIR transparencies of citrus trees with a projecting spectral densitometer. Photogrammetric Engineering and Remote Sensing, Falls Church, 51(1): 95-98, 1985.

EVERTTI, J.H.; GEREERMANM, A.H.; ALANIZ, M. A.; BOWEN, R.L. Using 70-mm aerial photography to identify rangeland sites. Forestry Abstracts, 42(5): 187, 1981 a.

EVERITI, J.H.; GEREERMANN, A.H.; ALANIZ, M. A. Mierodensitometer to identify saline rangelands on $70-\mathrm{mm}$ color infrared aerial film. Photogrammetric Engineoring and Remote Sensing, Falis Church, 47(9): 1357-1362, $1981 \mathrm{~b}$.

EVERTTI, J.H.; RICHARDSON, A. J. ; GERBERMANN, A.H. I dentification of rangeland sites on small scale (1:120.000) color - infrared aerial photos. Photogrammetric Engineering and Remote Sensing, Falls Church, 51(1): 89-93, 1985.

FULLER, S.P. \& ROUSE, W.R. Spectral refllectance charges accompanyng a post fire recovery sequence in a subartic sreucelichen woodl and. Forestry Abstracts, 40(11): 389, 1979.

GARCIA, G.J. Fotointerpretacão comparativa de fotografias pancromátricas, coloridas $\theta$ infravermelhas coloridas (falsa-cor). Tese de Doutoramento, ESALQ USP, Piracicaba, $1975,111 \mathrm{p}$. 
GARCIA, G.J. Sensoriamento remoto: principios e interpretação de imagens. Nobel, São Paulo, $1982,357 p$.

GARCIA, G.J. \& MARCHETII, D. A.B. Fotointerpretação da vegetação através da densitometria. Anais da ESALQ, PiracicaLa, 34: $275-279,1977$.

GARCIA, G.J. \& MINTZER, o. Utilizarão da razão espoctral na interpretaçäo de imagens de satélite. Cientificas UNESP, gris: $33-36, \quad 1981$

GAUSMAN, H.W. Evaluation of factors causing reflectance differences between sun and shade leaves. Forestry Abstracts, 45(7): 436, 1984.

GAUSMANN, H.W.; ALLEN, W.A.; CARDENAS, R. Reflectance of cotton leaves and their structure. Remote Sensing of Environment, 1: 19-22, 1969a.

GAUSMANN, H.W.; ALLEN, W.A.; MYERS, V.I.; CARDENAS, R.; LEAMER, R.W. Reflectance of single leaves and field plots of Gycocel-treated cotton CGossypium hirsutum L. 3 in relation to leaf structure. Remote Sensing of Environment, 1: $103-107,1909 \mathrm{~b}$.

GAUSMAN, H. W.; CARDENAS, R.; GEREERMANN, A.H. Plant size, etc., and aerial films. Photogrammetric Engineering, Falls Church, 40(1): $51-67,1974$.

GEREERMANM, H.H.; CUELLAR, J.A. ; GAUSMANN, H. H. Relationship of Sorehum canopy variables to reflected infrared radiation for two wavelengths and two wavebands. Photogrammetric Engineering and Remote Sensing, Falls Church, soces: $209-213,1984$. 
98.

HELLER, R.C. Remote sensors for airbone and spacebone imagery. Forestry Abstracts, 39(7): 285, 1978 a.

HELLER, R.C. Caso applications of remote sensing regetation damage assessment. Photogrammetric Engineering and Remote Sensing, Fal1s Church, 44C90: 1159-1168, 1978b.

HOLEEN, B.N.; TUCKER, C.J.; FAN, C.J. Spoctral assessment of soybean leaf area and leaf biomass. Photogrammetric Engineering and Remote Sensing, Falls Church, 46(5): $651-656, \quad 1980$.

JACKSON, R.D.; SLATER, P.N.; PINTER JR, P.J. Discrimination of growth and water stress in wheat by various vegetation indices through clear and turbid atmospheres. Remote Sensing of Environment, 13: 187 - 208, 1983.

JORDAN, D.C.; GRAVES, D.H.; HAMMETER, M.C. Use of manual densiometry in land cover classification. Photogrammetric Engineering and Remote Sensing, Falls Church, 44(8): $1053-1059,1978$.

KADRO, A. Spectral reflectance propertips of various vegetations types. Forestry Abstracts, 45( 4): $192,1984$.

KNIPLING, E. B. Physical and physiological basis for the reflectance of visible and near-infrared radiation from vegetation. Remote Sensing of Environment, 1: 155-159, 1970.

KOFFLER, N.F. Identificarão da cultura da cana-de-açúcar (Saccharum spp) através de fotografias ab́reas infsavermeihas coloridas e dados multiespectrais do satélite Landsat. Tese de Doutoramento, ESALQ USP, Piracicaba, 1982 , $234 p$. 
99.

LEE, Y.J. \& MCKELVEY, R.W. Digitized small format aerial photography as a tool for measuring food consumption by trumpeter swans. Photogrammetric Engineering and Remote Sensing, Falls Church, 50(2): 215-219, 1984.

MACBETH COLOR \& PHOTOMETRY DIVISION. OpErator's manual for transmission densitometer, model TD-504. Kollmorgen Corporation, New York, 1973, 19p.

MACLEAN, G.A. \& MARTIN, G.L. Merchantable timber vol ume estimation using cross-sectional photogrammetric and densitometric methods. Forestry Abstracts, 46(6): 365, 1985.

MARCHETII, D.A.B. \& GARCIA, G.J. Principios de fotogrametria e fotointerpretaçăo. Nobel, São Paulo, 1978, 257p.

MURTHA, F.A. \& HAMILTON, L.S. Detection of simulated damage on conifers using near infrared film. Forestry Abstracts, $31(3): 598,1970$.

MURTHA, P.A. \& KIPPEN, F.W. Fomes annosus infections centers are revealed, on false-color aerial photographs. Forestry Ahstracts, 31(1): 139, 1970 .

Novo, E.M.L. de M. Sensoriamento remoto: principios e aplicaç̃es. Edgard Blücher, São Paulo, $1989,308 p$.

OLIVEIRA, J.B.; MENK, J.R.F.; BARBIERI, J.L.; ROTTA, C.L.; TEEMOCOLDI, $W$ Levantamento pedológico semidetal hado do Estado de São Paulo: quadrícula de Araras. Bol. Téc. Inst. Agronômico 71, Campinas, 1982, $180 p$.

PIECH, K.R.; GAUCHER, D.W.; SCHOTT, J.R.; SMITH, P.G. Terrain classification using color imagery. Forestry Abstracts, $40(4): 113,1979$. 
100.

RIB, H.T. Color measurements. In: Manual of eolor aerial photography. American Society of Photogrammetry, 1: $12-$ $-24,1968$.

SCARPACE, F.L. Densitometry of multi-emulsion imagery. Photogrammetric Engineering and Remote Sensing, Falls Church, A4(10): 1279-1292, 1378.

SIEGAL, B.S. \& GOETZ, A.F. Effect of vegetation on rock and soil type discrimination. Protogrammetric Engineering and Remote Sensing, Falls Church, 436): 191-196, 1977.

SMITH, D.V. Timber volume estimate using Kelsh plotter and densitometry. Forestry Abstracts, 31(1): $138,1970$.

SMITH, D. V. Estimating timber volumes on aerial photos with dessitometer readings. Forestry Abstracts, 32(1): 167, 1971 .

SPURR, S.H. Photogrammetry and photointerpretation. Ronald Press, New York, 1960, 472p.

STEPHENS, P.R. Comparison of color, color infrared, and panchromatic aerial photography. Photogrammetric Engineering and Remote Sensing, Falls Church, 42610): 1273$-1277,1976$.

STORY, R. \& YAPP, G.A. Variation in infra-red reflectance of Eucalyptus radiata DC. Forestry Abstracts, 3364): 781 , 1872.

STRONG, L. L.; DANA, R.W.; CARPENTER, L.H. Estimating phytomass of sage brush habitat types from microdensitometer data. Photogrammetric Engineering and Remote Sensing, Fal1s Chunch, $51(4): 467-474,1985$. 
101

TALERICO, R.L.; WALKER, J.E.; SKRATI, T.A. Quantifying gypsy moth defolation. Forestry Abstracts, $41(1): 27,1980$.

THOMPSON, D. R. \& WEHMANEN, O. A. Using Landsat digital data to detect moisture stress. Photogrammetric Engineering and Remote Sensing, Falls Church, 45(2): 201-207, 1979.

THOMPSON, D.R. \& WEHMANEN, O.A. Using Landsat digital date to detect moisture stress in corn-soybean growing regions. Photogrammetric Engineering and Remote Sensing, Fal1s Church, 46(8): $1087-1093,1980$.

YOU-CHING, F. Aerial photo and Landsat image use in forest inventory in China. Photogrammetric Engineering and Remote Sensing, Falls Church, 46(11): 1421-1424, 1980.

ZEL, D.W. van der. Present and future applications of satelite remote sensing in the forestry sector. Forestry Abstracts, 46C10): 694, 1985. 